Andrews University

Digital Commons @ Andrews University

\title{
Adventist Healthcare: A Qualitative Study of 19th Century Founding Governing Principles in 21st Century Adventist Hospitals
}

Cesiah Yareth Pimentel Melendez

Andrews University, cesiah@andrews.edu

Follow this and additional works at: https://digitalcommons.andrews.edu/dissertations

Part of the Health and Medical Administration Commons, and the Health Services Administration Commons

\section{Recommended Citation}

Pimentel Melendez, Cesiah Yareth, "Adventist Healthcare: A Qualitative Study of 19th Century Founding Governing Principles in 21st Century Adventist Hospitals" (2019). Dissertations. 1733.

https://digitalcommons.andrews.edu/dissertations/1733

https://dx.doi.org/10.32597/dissertations/1733

This Dissertation is brought to you for free and open access by the Graduate Research at Digital Commons @ Andrews University. It has been accepted for inclusion in Dissertations by an authorized administrator of Digital Commons@ Andrews University. For more information, please contact repository@andrews.edu. 


\begin{abstract}
ADVENTIST HEALTHCARE: A QUALITATIVE STUDY OF 19TH CENTURY FOUNDING GOVERNING PRINCIPLES IN 21ST CENTURY ADVENTIST HOSPITALS
\end{abstract}

by

Cesiah Yareth Pimentel Meléndez

Chair: Duane Covrig, Ph. D. 


\title{
ABSTRACT OF GRADUATE STUDENT RESEARCH
}

\author{
Dissertation
}

\author{
Andrews University \\ School of Education
}

\section{Title: ADVENTIST HEALTHCARE: A QUALITATIVE STUDY OF $19^{\mathrm{TH}}$-CENTURY GOVERNING PRINCIPLES IN $21^{\mathrm{ST}}$-CENTURY ADVENTIST HOSPITALS}

Name of researcher: Cesiah Y. Pimentel Meléndez

Name and degree of faculty chair: Duane Covrig, $\mathrm{PhD}$

Date completed: November 2019

\section{Problem and Purpose}

Founding values and principles can help organizations stay focused on fulfilling their mission. This is especially true in faith-based organizations that seek to continue their founding principles as a governing commitment to their core identity. This study identified Adventist healthcare founding principles in Ellen G. White's early health visions and explored how Adventist healthcare leaders perceived these principles as governing principles applied to current Adventist healthcare practices. 


\section{Conceptual Framework and Research Design}

Two metaphors and three areas of literature review guided my approach of this qualitative study of Adventist healthcare founding principles. My first metaphor of DNA helped me think about Adventist healthcare as having an original DNA that could guide its growth and identity as it interacted with the environment across time. The second metaphor I chose was metamorphosis, a biological process where the phenotype of an organism can change dramatically but the organism's identity and DNA stay the same. This metaphor applied to organizations would suggest that noticeable change could take place that makes the organization almost unrecognizable from its earlier original form. But even here, there could be evidence of original identity. Both these metaphors framed my study.

Three areas of scholarship guided my conceptual framework. The first was sociology of organizations and how they are formed and change over time. I focused on organizational identity. The second area was social science scholarship on the nature and practice of faith-based organizations, especially healthcare institutions. The final area reviewed literature on SDA healthcare identity.

My method included document analysis and focus groups. I distilled 12 principles from Ellen White's early visions on health and then secured feedback on my document analysis from Adventist historians. Second, I did focus group interviews with Adventist healthcare leaders and asked them what they thought of these 12 founding governing principles and if and how they applied to Adventist healthcare. Finally, I had two physicians and a Ph.D. scholar check or "triangulate" my process and findings. 
I distilled 12 principles from Ellen White's early visions on health: (a) health education and preventive medicine, (b) healthcare for Seventh-day Adventist (SDA) members, (c) indirect witnessing to non-believers patients, (d) sustain financial and administration model despite attention to all social classes, (e) unwavering biblical principles, (f) wholistic perspective, (f) physical activity as part of treatment, (g) preparing people to be whole before God, (h) prayer combined with treatment and obedience to the laws of health, (i) God-fearing personnel, (j) therapeutic nature interaction, and $(\mathrm{k})$ altruistic and trusting institutional model. I labeled these as Adventist healthcare funding governing principles. I then used three experts' suggestions to make changes.

I then asked four focus groups to comment on these 12 principles and explore their application to current Adventist healthcare. Several principles were seen as now universally shared by most healthcare institutions. Those were: (f) wholistic perspective, (a) health education and preventive medicine, and a general respect for the place of spiritual \& religious integration in medical practice. Other principles were seen as challenging to apply to modern Adventist healthcare. This included (b) Adventist Healthcare for SDA members, (d) sustaining financial and administration model despite attention to all social classes, (f) Physical activity as part of treatment, (h) prayer combined with treatment and obedience to the laws of health, (i) God-fearing personnel, (j) therapeutic nature interaction and (k) altruistic and trusting institutional model. Finally, a few principles seemed to have limited or different application to modern practices. For example, it was hard to envision how (j) Physical activity as part of 
treatment would be appropriate as most hospitals have such acute care patients and (g) preparing people to be whole before God.

Discussion, Conclusions, and Recommendations

I drew five main conclusions. First, I found widespread support for these founding principles present among Adventist healthcare leaders. Second, many of the founding principles of Adventist healthcare were seen by these Adventist leaders as now widely accepted and practiced in many healthcare systems today. Third, there were some principles that Adventist healthcare struggle to apply, even as they believe in the essence of those principles. For example, employing God-fearing personnel. There were some differences and even resistance to a few of these principles as applied to modern Adventist healthcare systems because of the nature of acute care, insurance companies, local regulations, or other factors. For example, getting patients to work in a garden or other labor seemed unlikely given the acute care nature of the modern hospital patient. I recommended to Adventist healthcare leaders on ways to help institutions identify, celebrate, and promote founding governing principles, including ways to adapt to the international and intercultural difference in applying these principles. I also made recommendations for how further research on governing principles could use existing records from founders such as Ellen G. White to expand the analysis of governing principles through other stages in history. 
Andrews University

School of Education

\title{
ADVENTIST HEALTHCARE: A QUALITATIVE STUDY OF 19TH CENTURY FOUNDING GOVERNING PRINCIPLES IN 21ST CENTURY ADVENTIST HOSPITALS
}

\author{
A Dissertation \\ Presented in Partial Fulfillment \\ of the Requirements for the Degree \\ Doctor of Philosophy
}

By

Cesiah Yareth Pimentel Melendez

November 2019 
(C) Copyright by Cesiah Yareth Pimentel Melendez 2019

All Rights Reserved 


\title{
ADVENTIST HEALTHCARE: A QUALITATIVE STUDY OF 19TH CENTURY FOUNDING GOVERNING PRINCIPLES \\ IN 21ST CENTURY ADVENTIST HOSPITALS
}

\author{
A dissertation \\ presented in partial fulfillment \\ of the requirements for the degree \\ Doctor of Philosophy
}

by

Cesiah Yareth Pimentel Meléndez

APPROVAL BY THE COMMITTEE:

Chair: Duane Covrig

Member: Tevni Grajales

Member: Liz Muhlenbeck

External: Ernest Buck
Dean, College of Education:

Alayne Thorpe 
To my husband,

Dr. Eustace A. Penniecook Sawyers, and my sons,

Eustace Arnoldo \& Gabriel Jared, whose encouragement, companionship, and prayers supported me to thrive to find better ways to serve God, resulting in this inquiry process. Their desire to unconditionally serve God inspires me to continue. 


\section{TABLE OF CONTENTS}

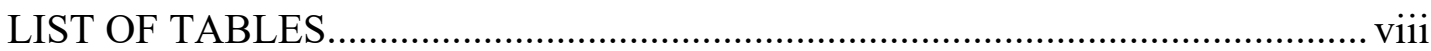

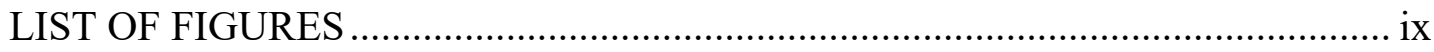

LIST OF ABBREVIATIONS …...................................................................

ACKNOWLEDGEMENTS........................................................................

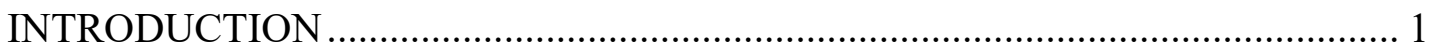

The Problem ........................................................................................... 3

Purpose of the Study ..................................................................... 4

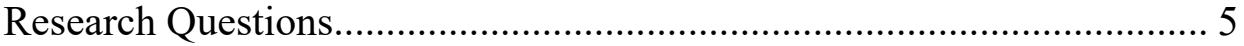

Conceptual Framework....................................................................... 5

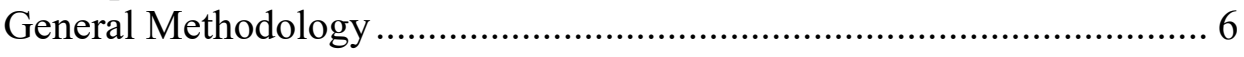

Role of the Researcher................................................................. 7

Significance of the Study ................................................................. 10

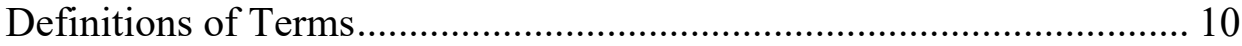

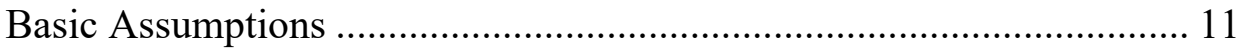

Delimitations of the Study ............................................................. 11

Organization of the Study ............................................................. 12

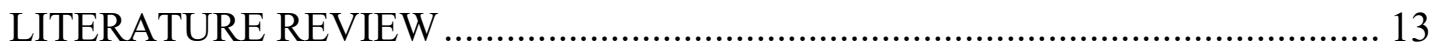

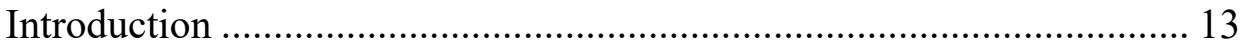

Organizational Theories and Frameworks......................................... 13

Organizational Identity ................................................................ 15

Managing, Leading and Changing an Organization's

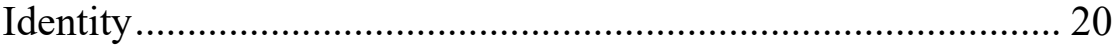

OI and Selznick's institutional character and old institutionalism .................................................................. 22

Founding Governing Principles ..................................................... 26

"Principles" Terminology ........................................................ 26

Understanding and Studying Founding Governing Principles ............... 30

Dynamics of Governing Principles: Birth, Change, and Death.............. 30

Leaders Role in Governing Principles .......................................... 32

Relation Between Governing Principles and Organizational

Identity ................................................................................. 33

Research on Governing Principles and OI in Specific

Organizations ...................................................................... 34

Faith-Based Healthcare Research .................................................... 37 


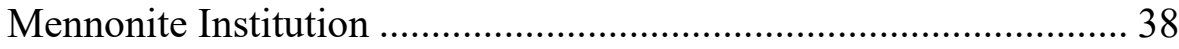

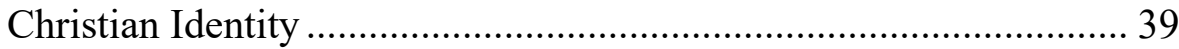

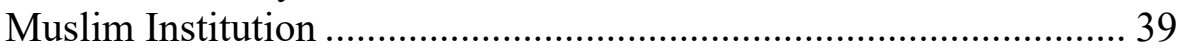

Jewish Institution......................................................................... 40

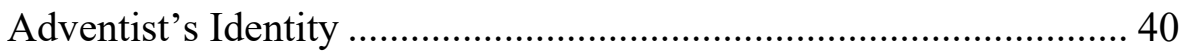

Identity Crisis: Denominational Institution Existence................... 41

Identity Crisis: Mission Diluted ................................................. 42

Current Adventist Healthcare Institutions ......................................... 43

Loma Linda Hospital's Case ...................................................... 44

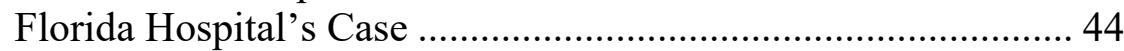

Summary and Conclusions ................................................................... 46

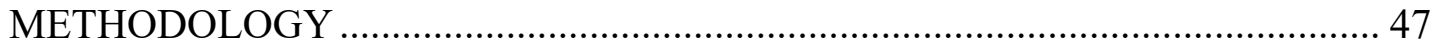

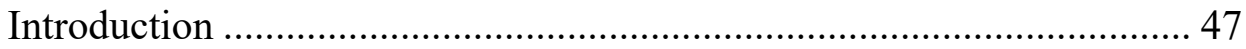

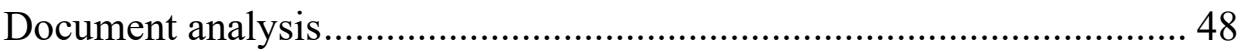

Methodology and Research Design ................................................... 48

Sample and Collection ...................................................................... 49

Document Data Analysis ................................................................ 50

Document Analysis Validation......................................................... 50

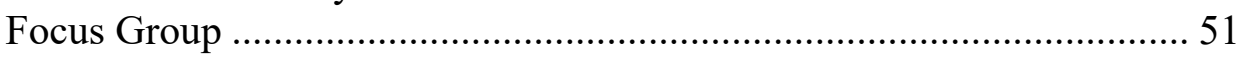

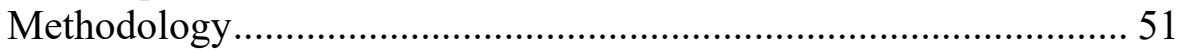

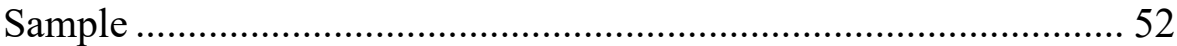

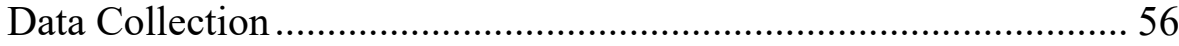

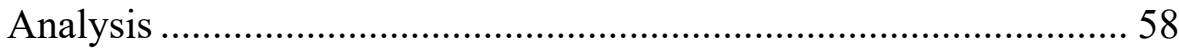

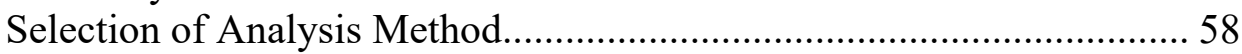

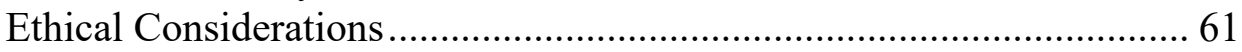

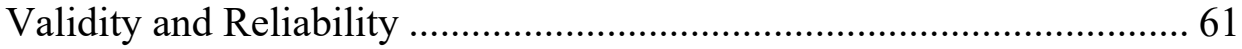

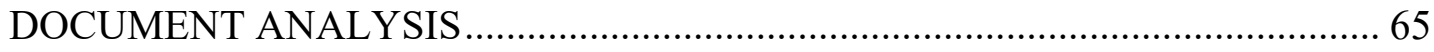

Purpose of Adventist Healthcare Institutions ..............................................65

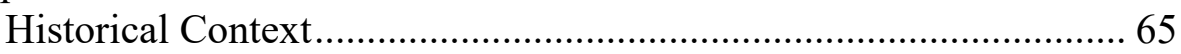

Ellen G. White's Visions Regarding Healthcare Institutions .................... 65

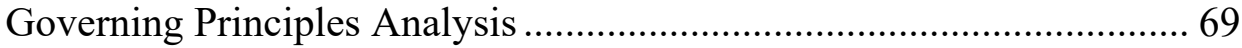

Adventist Governing Principles Description............................................ 72

Health Education and Preventive Medicine .............................. 72

Healthcare for SDA Members ..................................................... 73

Silent Witnessing to Non-Believing Patients ............................... 74

Sustainable Financial and Administration Model

Despite Attention to all Social Classes.................................. 75

Unwavering Biblical Principles.................................................. 76

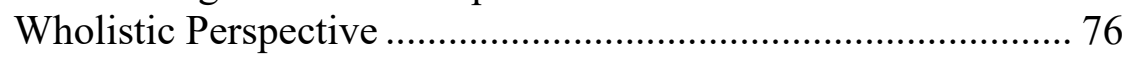

Exercise as Part of Treatment...................................................... 77

Preparing People to be Perfect Before God................................. 77

Prayer Combined with Treatment and Obedience to the

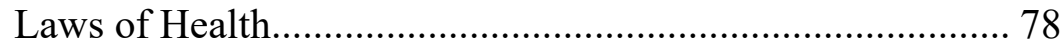


God-Fearing Personnel ............................................................. 79

Therapeutic Interaction with Nature ............................................ 79

Altruistic and Trusting Institutional Model ................................. 80

Why are the Adventist Governing Principles Relevant Today?.............. 80

Participants ..................................................................................... 81

Principles Adjustment After Historian's Input .............................. 88

RESULTS FROM FOCUS GROUPS ................................................................. 90

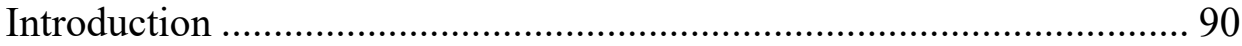

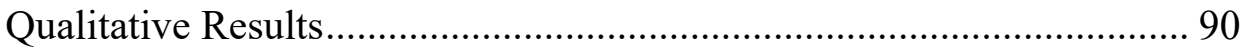

What Makes Adventist Hospitals Adventist? ............................................ 91

Perceptions That Were Indirectly Linked to $19^{\text {th }}$ -

Century Ellen White's Principles ............................................ 91

Perceptions Not Linked to a $19^{\text {th }}$-Century Ellen White

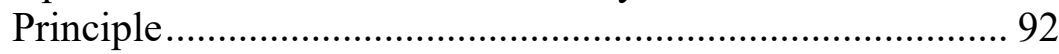

Do the Principles Presented Still Apply in a $21^{\text {st }}$

Century SDA Hospital? ......................................................... 92

1. Health education and preventive medicine.......................... 94

2. Healthcare for SDA members........................................... 94

3. Indirect witnessing to non-believer patients ........................ 97

4. Sustainable financial and administration model despite attention to all social classes ................................ 98

5. Unwavering biblical principles.......................................... 99

6. Wholistic (body, mind, and soul) perspective ................. 100

1. Exercise as part of treatment ......................................... 100

8. Preparing people to be holy before God........................... 101

9. Prayer combined with treatment and obedience to

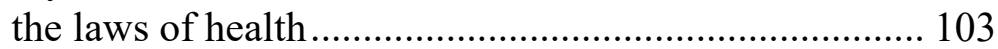

10. God-fearing personnel .................................................... 104

11. Therapeutic interaction with nature................................ 107

12. Altruistic and trusting institutional model ..................... 108

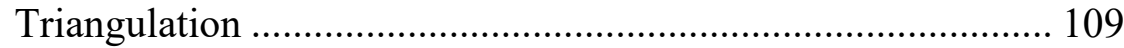

Summary and Conclusion.................................................................. 110

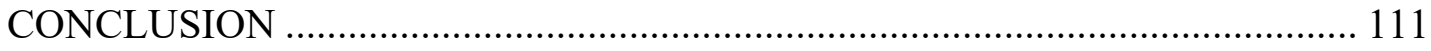

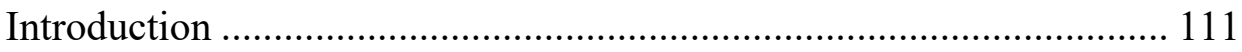

Research Questions and Design ........................................................... 111

Summary of Findings .................................................................. 114

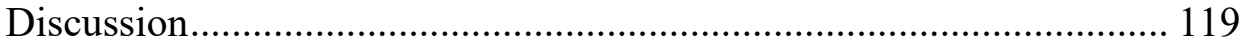

Strong Consensus .................................................................... 119

Exercise as Part of Treatment/ Therapeutic Nature................... 120

Preparing People to be Holy Before God ................................. 122

God-Fearing Personnel .......................................................... 125

Prayer Combined with Treatment and Obedience to the Laws of Health... 
Sustain Financial Model with Attention to all / Service for SDA /Altruistic Model.................................................. 127

Organizational Dimensions: Leadership, Drift and

Institutionalizing Values................................................... 129

Universality ...................................................................... 130

Uniqueness of Adventist..................................................... 130

Diversity in Applicability of Governing Principles and Organizational Drift................................................ 131

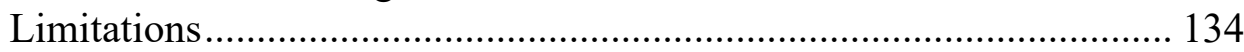

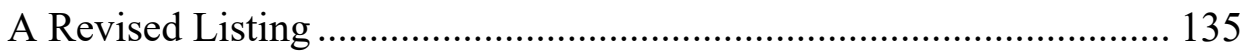

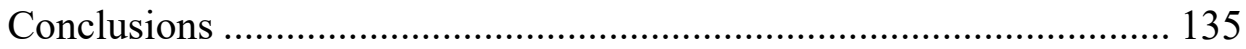

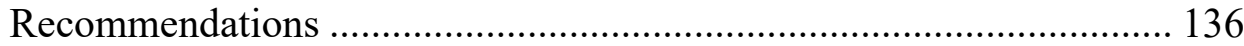

Recommendations for Adventist Hospital Leaders .................... 136

Recommendations for Regional and Global Adventist

Healthcare Leaders: .......................................................... 137

Recommendations for Further Research ................................. 137

Final Thoughts ......................................................................... 138

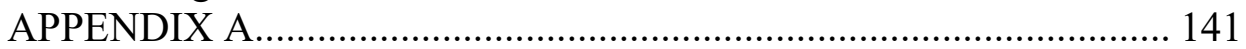

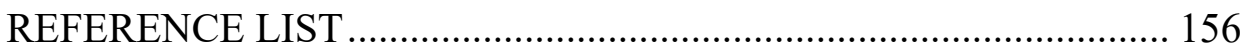

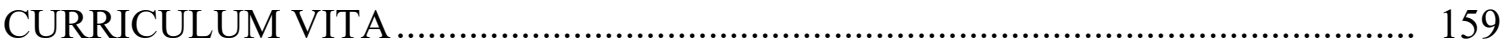




\section{LIST OF TABLES}

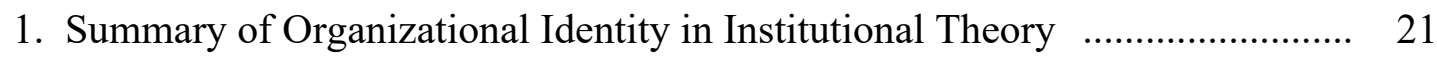

2. Definition of Terms ……………...................................................... 24

3. Objectives and Their Actions ………………………............................... 54

4. Ellen G. White's Visions on Health …………………............................... 58

5. Ellen G. White's Visions Document Analysis …………………………….... 63

6. Participant 1 Comments and My Responses ................................................... 73

7. Participant 2 Comments and My Responses .................................................. 76

8. Participant 3 Comments and My Responses ……………............................. 78

9. Participant's Responses and Their Link to Principles ……………................. 89

10. Summary of Focus Groups Responses ………............................................ 92

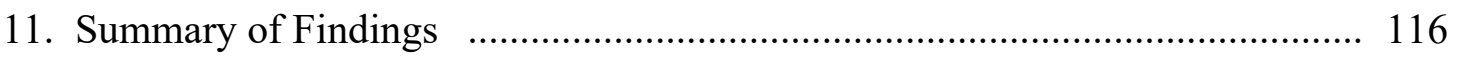




\section{LIST OF FIGURES}

1. Sinek's Golden Circle ....................................................................... $\quad 30$

2. Flow Chart of Research Design ................................................................. 45 


\section{LIST OF ABBREVIATIONS}

EAI Early Adventist Identity

EGW Ellen G. White

NIV New International Version

SDA Seventh-day Adventist 


\section{ACKNOWLEDGEMENTS}

I praise God for His guidance and the manner He opened doors for this dissertation to take place. I am amazed by how He led me throughout this journey. He allowed many people in my way for this project to be a blessing. Glory to Him!

First of all, I want to appreciate the unconditional support I received from my husband and friend, Eustace Arnoldo, as he witnessed every stage of the process and was a partner in this dissertation, ranging from brainstorming, identifying potential participants and reading drafts. To my sons, Eustace Arnoldo and Gabriel Jared for their love, understanding, and support. I want to acknowledge the role of my family, particularly my parents, Ptr. Arnulfo Pimentel and Marielena Meléndez de Pimentel. Besides their leadership example, they were always there for me, encouraged me and prayed for me. To my siblings, both leaders in their own field, Laura and Samuel as well as the rest of my family for their support and prayers. To my parent's in-law, Dr. Eustacio A. Penniecook and Dr. Myrtle Sawyers de Penniecook for their advice and constant prayers. Additionally, I would like to acknowledge exceptional leaders who supported me in this journey: Prof. Ismael Castillo and Dr. Christon Arthur.

To Dr. Gustavo Gregorutti, my program advisor as he assisted me to put my first ideas in variable terminology. He also connected me to my dissertation chair. Special thanks to my dissertation committee chair, Dr. Duane Covrig, whose passion for Adventist values was vital in this study. His research experience in the topic and his patient guidance made a vital difference in the dissertation's outcome. To my other 
dissertation committee members Dr. Liz Muhlenbeck and Dr. Tevni Grajales and their time and valuable contribution. To my external committee member, Dr. Ernest Buck, who took the time to put aside his busy schedule to be part of my dissertation defense.

I appreciate my Leadership Learning Group, Quantum Leap, with its different members throughout the years, starting by my cohort classmate, Seth Bardu; to others such as, William Colwell, Cary Valentine, Edwin Romero, Barna Magyarosi and those that have joined recently. Dr. Barry Tryon, whom despite having concluded the LEAD program couple of years ago, continued supporting those coming behind.

Finally, I want to recognize all those participants in the different stages of this study. The Adventist history's experts that provided their valuable feedback; Dr. Peter Landless and his team, the organizers of the Global Healthcare Conference, thank you for the opportunity and the accommodations made in order the focus group sessions to take place. I want to acknowledge all healthcare leaders that participated and joined me in a sincere search for what makes an Adventist Hospital Adventist those in the focus groups and those transcripts validation's sessions. Their contribution was pivotal in connecting the study to today's challenges.

Thank you everyone! 


\section{CHAPTER 1}

\section{INTRODUCTION}

Leadership in the $21^{\text {st }}$ century is often about managing or even creating change (Anderson, 2010). This is especially true in healthcare. Change and healthcare are almost synonymous, with healthcare continually being impacted by new technologies, techniques, research, and innovation, as well as economic, political, and regulatory change. While these changes are whirling from the outside, leaders in faith-based institutions face an additional challenge of keeping their institutions faithful to core "moral and spiritual commitments" and "integrity" (Iltis, 2003). Hence, healthcare leadership in faith-based institutions face an existential challenge. How can change be made to maximize core commitments?

Seventh-day Adventist healthcare is one such faith-based system facing this challenge. Its intensive involvement in healthcare (Branson, 2015) has to lead the church to have 1,006 medical institutions, about 184 of which are hospitals and sanitariums (Adventists, 2019). While working in one of these Adventist healthcare hospitals, I started wondering what do we, as Seventh-day Adventist Healthcare leaders supposed to hold on to? What makes us Adventist? Are mission hospitals still valid in today's contemporary world? These existential questions were derived from my observations on faith-based and non-faith-based systems and their missions. Apparently, we all had a similar purpose to help the suffering. However, I was longing for a guidance for 
Adventist healthcare leaders on a worldwide system. I had difficulty accepting that every Adventist system has no core guiding principles that unites them into a worldwide healthcare identity.

Adventist healthcare work has its roots in philosophy and practice dating back to the $19^{\text {th }}$ century in what some Adventists call "the health message." From this early commitment to healthcare, the Adventists have developed not only a focus on prevention, health education, and lifestyle, but also expanded their work to include cutting-edge, acute medical services (Covrig, 2003; Ellen G. White, 1909). Adventist healthcare institutions have become significant players in many regional and national healthcare systems, even as many Adventists still consider this work a significant Christian ministry, or what they often refer to as the "right arm" of the gospel (Ellen G. White, 1963).

After more than 150 years of healthcare change in which hospitals have had to undergo rapid adaptation to shifting environments, Adventist healthcare looks a lot different than it did in the late 1800s (Cummings \& Worley, 2008). These massive changes - in the size of populations served, governmental and local policies and regulations, technology, professional training, pharmaceutical and scientific discoveries, etc.-lead to some deep questions. Is it possible for Adventist health in the $21^{\text {st }}$ century to share any resemblance to what it was in the late $19^{\text {th }}$ century? Are there any shared characteristics with its founding values, governing principles, and current practices? What are the lasting, core identity or strong, anchoring beliefs, values, and practices of Adventist healthcare? In a changing environment, to what has, or should the institution hold? 


\section{The Problem}

On April 23, 2018, Modern Medicine announced that Adventist Health and St. Joseph Health were uniting in Northern California to form a regional, joint operating company (Kacik, 2018). Such news is common as healthcare systems try to survive a competitive industry. Indeed, such actions responded to a collective, strategic leadership decision. A regional president announced to the press that "patients will benefit from more access points, better health outcomes, and controlled costs by coordinating their care across the spectrum of their health needs." (Kacik, 2018).

However, the response within the Adventist community was mixed. One Adventist (Mayer, 2018) raised concerns about a lack of commitment of the new partner to the governing principles that are basic to Adventist healthcare. One reader posted a comment:

Be ye not unequally yoked together with unbelievers: for what fellowship hath righteousness with unrighteousness? and what communion hath light with darkness?" 2 Cor 6:14

For a Bible-believing institution to enter into a partnership with a Bible, unbeliever is a disaster. The opposing principles and morals, and business decisions made daily will reflect the worldview of one partner or the other. For the relationship to work, one or the other must abandon his moral standard and move toward that of the other. More often than not, it is the believer who finds himself pressured to leave his Christian principles behind for the sake of profit and the growth of the business. (Post by ELao Sunday, May 6th, 2018 at 10:56 PM)

While this was not the first Adventist institution to create such an agreement, the adverse reactions it produced raised the issue about what Adventist healthcare institutions should hold on to, but on the other hand, what they could do as organizations to survive. 
Indeed, Adventist healthcare leaders and institutions are facing enormous pressure due to modern demands and competition in healthcare (Branson, 2015; Covrig, 2003). They face constant pressure to change, adapt, innovate, move, downsize, upsize, diversify, repurpose, and even compromise. While responding to these changes, the question arises, when do changes alter the adherence to Adventist governing principles (founding DNA) and the mission of the organization? As new medical technologies and community health needs change, government regulations or instability disrupt or support Adventist practices, and economic shifts erode resources or enrich Adventist workers, these changes enhance or diminish original Adventist practices. As each new generation of Adventist healthcare leaders brings various backgrounds into their leadership roles, how is it possible to identify the timeless, founding governing principles of Adventist healthcare institutions?

\section{Purpose of the Study}

This research project has several purposes. First, it seeks to define, contextualize, enumerate, and explain the founding governing principles distilled from the original guiding testimonies of Ellen G. White on healthcare ministry. This research project uses a literature review approach with some document research methodology. The second purpose of this study is to clarify this interpretation of Adventist healthcare governing principles among Adventist health experts. They helped interpret the founding, governing principles, and values of Adventist health. The third purpose is to identify the core, timeless beliefs, values, and practices that are believed to persist as a way to identify the "Adventist" nature of its healthcare. In other words, what makes Adventist healthcare unique? 


\section{Research Questions}

Question One: What were the 19th-century, governing principles of Adventist healthcare?

Question Two: How do Adventist historians and experts understand and interpret these Adventist healthcare core commitments?

Question Three: How do Adventist healthcare leaders and experts believe these governing principles work to define the unique identity in Adventist healthcare?

\section{Conceptual Framework}

Two metaphors and three areas of literature conceptually guided this study. The first metaphor is a biological one. Individuals have studied DNA over time, and conclusions state that DNA manifests in interaction with the environment. Similarly, healthcare institutions have a founding DNA that influences their interaction with the environment across time. While this founding DNA does not dictate a person's development and life outcome, it influences much of that development and outcome. An adult will resemble some identifying features of his or her earlier, younger days, but change will be evident. Researchers have named this process Epigenetics (Dupont, 2009), where changes in the genes can occur without really modifying the DNA itself, due to an array of factors such as the environment.

The goal of the study was to identify Adventist healthcare's DNA. We attempt to identify Adventism's original healthcare ideals as its founding governing principles and practices, and how experts in the system understand those founding governing principles today. If the Adventist hospital provides the same type of services as any other (e. g. surgeries, labs, x-rays, etc.), then, what makes a hospital “Adventist"? 
A second metaphor, also from the biological field, guided this study. Metamorphosis is the process of "abrupt developmental change in the form or structure of an animal" (Merriam Webster, 2018) in which it turns into a complete and almost unrecognizable being. However, the animal is the same being; even though it evolves, it keeps its core. In the same manner, SDA's healthcare institutions could know what the core or governing principles are before "evolving" in the process of its being.

To analyze the topic of Adventist healthcare's ( $19^{\text {th }}$ century) governing principles and potential legacy for current healthcare delivery, I reviewed several topics and created a conceptual platform to understand governing principles and their impact on organizational practice better. First of all, I reviewed the sociological understanding of organizational governing principles. I reviewed the literature related to the uniqueness of organizations and how their governing principles establish and may even evolve.

Second, I reviewed the social science scholarship and researched the nature and practice of faith-based organizations. Several authors have intended to explain their processes and the religious and non-religious characteristics of these institutions. I focus on organizational, sociological research of healthcare institutions. Finally, I mainly reviewed a variety of studies on SDA institutions, especially hospitals.

\section{General Methodology}

The methodology used to attend to the research questions presented above was a qualitative study with a combination of document analysis and focus-group assessment. Initially, the proposed research contemplated three phases of data collection and analysis. The first phase utilized historical literature to summarize Adventist, $19^{\text {th }}$-century healthcare principles. I reviewed the literature to identify and articulate these principles. 
In the second phase, I solicited expert feedback on my analysis of the $19^{\text {th }}$ century from Adventist healthcare principles. I identified experts as well-known Adventist academicians within the SDA denomination. During the third phase, focus group participants were asked to comment on these principles. They were comprised of SDA healthcare leaders from different geographical areas of the world- North America, South America, Africa, and Asia. All of the participants belonged to an institution in which governance is within the denominational system and was listed in a yearly publication called yearbook.

After analyzing the transcripts, I restated one of the governing principles of Adventist healthcare in order to be more explicit. Then my last step was to triangulate in two ways: (a) a Ph.D. researcher that analyzed the transcripts, my conclusions and then (b) another small group with two experienced medical doctors, and Adventist hospital leaders together with me, reviewed the transcripts to remove any evident bias from my conclusions. After concluding the data collection, I reported these stages as two: (a) the document analysis and a validations step with the Adventist historians, and (b) the focus group, also with its validation stage.

\section{Role of the Researcher}

I followed the qualitative methodology recognizing my natural bias derived from my experiences related to healthcare systems. I have worked in three different healthcare institutions that belong to the Seventh-day Adventist church system: Lusaka Eye Hospital, in Zambia, Africa; Maluti Vision Center, which is part of the Maluti Adventist Hospital in Lesotho, Africa; and in Hospital La Carlota in Mexico. Additionally, I have also visited other Adventist healthcare institutions in Kenya, Malawi, Botswana, South 
Africa, Dominican Republic, and eSwatini. In the United States, I visited Loma Linda healthcare system in California, Kettering Health Network in Ohio and AdventHealth System in Florida. Besides the Adventist healthcare systems, I have been in nonAdventist healthcare institutions in Tanzania, Zambia, Lesotho, South Africa, Mexico, Costa Rica, Rwanda and the United States,

My experience includes a wide spectrum of healthcare institutions: government hospitals, mission hospitals, not-for-profit hospitals and other hospitals that openly operate as for profit-making. Some hospitals are shockingly challenged by the critical conditions in which they operate. For instance, in at least two countries I saw patients on the floor sleeping on mattresses or multiple patients sleeping on each bed due to the lack of space. A heartbreaking experience I cannot forget, while visiting an acquittance after she suffered a car accident, I tried to calm her using my headphones while she was being sutured without anesthesia, due to the lack of medical supplies in the hospital. On the other end, I marbled fancy-looking first-class hospitals in South Africa with services including heliport, electric cars (golf cart type) shuttles to the parking lot, hospital's cafeteria with electronic buttons to call waiters or managers and, of course, the latest medical technology.

I do not consider that I have seen it all, since the countries I have experienced only represent two continents. However, these encounters have resonated in me the philosophical dilemma of what makes the Adventist hospitals Adventist and the need for a worldwide purpose-driven Adventist healthcare system. While working in Adventist hospitals, I started to inquire within me: What do we suppose to hold on to as healthcare 
institutions? What makes us Adventist? Are mission hospitals still valid in today's contemporary world?

When I started this research project, I did not have the answers to any of these questions. I had the notion that somewhere existed a list of core governing principles that Adventist organizations should abide by. I decided to start this quest with Ellen G. White's visions. Despite being Adventist from birth, and being Adventist from second generation, I had not read the Testimonies of the Church volumes 1 and 3 related to health and healthcare institutions before to this study. I was glad at what I found. My next question was on the validity of such findings. My impression was that they were still valid. During the focus groups, I sensed that most people agreed on the validity, however, the implementation had some challenges in modern setting hospitals for some participants.

Regarding this study, and in the best of my ability, I tried to prepare an objective manner of presenting and designing the procedures, interpretations, and reporting of findings. I perceived an existing prejudgment while referring to the founders of the church since some trends tend to see those revising the origins of the founding core as fundamentalist or idealist. I perceived that some Adventist's non-mission hospitals employees perceived that their system has evolved from the traditional mission hospital, hence their system is not part of such founding core principles. I believe if participants could have the time to revise all the material that I saw, they would agree that even though it may seem challenging to implement some aspects, these principles should be considered in every Adventist hospital. I'm convinced that further studies on the field will expand the understanding of such principles. 


\section{Significance of the Study}

This study intends to contribute to several groups:

- Provide another portrait of Adventist healthcare institutional governing principles.

- Provide SDA healthcare leaders at all levels (General Conference, division, union, and conference level) a nuanced itemization of founding governing principles applicable to healthcare institutions.

- This enumeration can be useful in guiding strategic decision-making practices.

\section{Definitions of Terms}

The following terms and concepts are used in the present document:

Governing principle $(G P)$ : Foundational rule that guides the way an organization should operate.

Identity: Qualities of an organization that makes it unique.

Founding values: Principles that are the base of an organization.

GP for Adventist healthcare institutions: Original purpose provided by Ellen G. White's testimonies.

Institutional direction: The course or route along which an organization is moving, based on the philosophical foundation of the organization.

Ellen G. White's testimonies: Instruction given to the Adventist church, believed to be divinely inspired.

SDA healthcare institution: An Adventist institution, with its governing board, reports to the head of a denominational organization or that is listed in the Adventist Yearbook where all worldwide denominational organizations are listed. 
Wholistic: Different from the eastern holistic term (that has philosophical and religious implication), the term wholistic in this document refers to the whole person concept in which a person has three components or dimensions: physical, mental and spiritual.

\section{Basic Assumptions}

An assumption that I considered in the preparation of the present study is that Ellen G. White was a prophetess that received divine visions. Visions are understood as "something seen in a dream or as a result of a religious experience" (Vision, 2018a). Visions can include "trance or ecstasy" and are related to "a supernatural appearance that conveys a revelation" (Vision, 2018b). Through the years, polarized groups have argued whether Mrs. White received messages from God or her "visions" came as side effects of her fragile health condition (Numbers, 2008). Regardless of my personal belief, the fact is that she influenced the way Adventist healthcare institutions began and evolved. Hence, the study will not address the discussion of whether or not her visions were legitimate.

\section{Delimitations of the Study}

I delimited this study to the first visions reported by Ellen G. White, before any Adventist hospital came into existence, I also restricted the focus groups to Adventist Healthcare institutional leaders who are native English speakers or understand the English language. Indeed, Adventist Healthcare institutions can vary from dispensaries, nursing homes, lifestyle centers, clinics, and hospitals. This study only considers hospital leaders. 


\section{Organization of the Study}

The study is organized into six chapters. In Chapter 1, I present the background of the problem and how it is stated. Furthermore, the reader can understand the rationale of the problem, as well as its background, assumptions, definitions, and delimitations.

In Chapter 2, the conceptual framework is expanded into a literature review of the organizations and their governing principles. Also, the scope is reduced to the healthcare sphere and further to the Adventist healthcare literature. In Chapter 3, the methodology is explained in detail, while describing, step by step, the process of the development of the qualitative study and the different levels of data gathering. In Chapter 4, the results are presented for the historical part. Further, the results from the Adventist experts' input is presented in a way to confirm or discard the governing principles that were identified. In Chapter 5, the data presentation describes the question of the ways the governing principles are either valid or even present in modern Adventist hospitals.

In Chapter 6, the problem is once again restated, as is the literature review, in order to discuss the results in the light of previous research and the goals of the study. Finally, the implications and recommendations are presented. 


\section{CHAPTER 2}

\section{LITERATURE REVIEW}

\section{Introduction}

This study explored the founding healthcare principles of the Seventh-day Adventist Church (SDA) and healthcare leaders' beliefs about the applicability of these principles in current Adventist healthcare practices. This chapter reviews the scholarship used to guide my research.

First, I review the scholarship on organizational theories (OT) to better understand various approaches to studying organizations. I then review organizational identity (OI) and ways to explain OI. I also review components of OI, especially related to leadership. I then settle around Selznick's idea of organizational character as a way to think about OI. I then introduce my conceptual understanding of looking at the role of founding principles as a starting point for understanding and tracking OI. The last part of this chapter reviews research on faith-based organizations, especially as it relates to the role of faith identity in healthcare. I also review some specific research on my main study group: Adventist healthcare. Finally, I end by summarizing how this literature was used to guide my study.

\section{Organizational Theories and Frameworks}

To study governing principles in faith-based healthcare institutions, I needed to understand organizations and the nature of their development. Organizational theories 
(OT) provide a scholarly approach to studying organizations as a unit of analysis (Miles, 2012).

While organizations existed for more than 4,000 years; the formal study of organizations as a scholarly and theory-driven social science is about 100 years old (Shafritz, Ott, \& Jang, 2016). About sixty years ago, Herbert Simon did much to promote the study of the organization and the emergence of a social scientific field of OT (Starbuck, 2003). By the late 1950s, he conceived it as a wide area of study ranging from management studies, human resources, industrial engineering, social psychology, and strategy. By 1960s academicians were already distinguishing organizational behavior from OT and differentiating it from other studies on management. By the 1970s, organizations were evolving as a result of "education, occupation, and technological changes" (p. 144), and the study of these topics also diversified and became more specialized.

OT is a field of study which includes "(a) single organizations as integrated systems, (b) many organizations that resemble each other, or (c) interactions among groups of organizations" (p. 144). Miles (2012) stated that an organization could be referred to as "deliberate arrangements and conscious coordination of people to achieve a common goal or set of goals" and a "managed system designed and operated to achieve a mission, vision, strategies, and goals" (p. 7). Hence the key concepts are a group of people and the mission or goal. OT has also been defined as a "collection of general propositions about organizations" (Starbuck, 2003, p. 143) and how they function. The aim of OT is to "generate reflective dialogue" (Idem) to produce explanations of the 
institutional problems, not necessarily at mainly universal levels but in ways that help to interpret local processes and entities (Tsoukas \& Knudsen, 2003).

OT is not one particular theory but an array of theories that attempt to provide both complementary and competing explanations and predictions of how organizations form and develop by attention to "structures, culture, and circumstances" (Shafritz et al., 2016, p. 1). It has become a very dynamic field of study which includes several disciplines. Organizations emerge and change based on many factors, and their complexity has generated many theories.

Given the diversity of the field and peculiar circumstances of organizations, OT has generated hundreds of theories and areas of focus among scholars (Shafritz et al., 2016). Given such diversity, it is difficult to attempt to group theories into categories. However, OT scholars Shafritz et al., have classified OT into (a) classical OT, (b) neoclassical OT, (c) human resource theory, (d) modern structure OT, (e) organizational economics theory, (f) power and politics OT, (g) theories of organizational culture and change, (h) theories of organizations and environments, and (i) theories of organizations $\&$ society. Each area often tries to explain aspects of the organization or the nature of their interaction with the environment. Since our focus is more on understanding the unique aspects of an organization, we will focus on one area known as organizational identity.

\section{Organizational Identity}

Organizational identity (OI) is an emerging field of study within OT made popular by Albert and Whetten in 1985 (Pratt, Schultz, Ashforth, \& Ravasi, 2016). Whetten's OI definition is “the central and enduring attributes of an organization that 
distinguish[es] it from other organizations" (Whetten, 2006). Other authors define OI, as "the way core values, purpose, brand, and reputation are integrated" in an organization (Cummings \& Worley, 2008, p. 171). While some authors considered identity as a static or still picture, other perceive it as an evolving in motion concept such as a movie, in other words, an ongoing process (Gioia \& Hamilton, 2016). I believe the key three factors in OI "are the three qualities of "central" and "enduring" and "distinctive" (Whetten, 2006).

From 1985 this concept of OI as dealing with "central" and "enduring" and "distinctive" qualities has led to many different ways of understanding OI. It has also led OI researchers to look at various areas within the organization for OI to be manifest. First, I review three paradigmatic approaches within OI and then discuss dimensions of organizations, on which OI research typically focus. Even though other perspectives of classifications exist, such as He \& Brown's (2013) four categories, I use Gioia and Hamilton's research classification to identify three main paradigms to OI: The social actor, the social construction and the institutional perspective (Gioia \& Hamilton, 2016).

The social actor perspective states that OI is a "property of an organization" and that the identity was given "legal rights and powers similar to those enjoyed by individuals" (p. 23). In this perspective, the organization is seen as a social person with identity and rights. Gioia \& Hamilton, citing Albert and Whetten's 1985 work, stated that the organization "define who they are by creating or invoking a classification scheme and locating themselves within it" (p. 23). In this perspective, the organization becomes alive and is "self-determined, self-defined and self-proclaimed" (p. 23). The members of the organization adhered themselves to this organizational identity. Consequently, identity is 
more stable through time. Finally, the members perceive, label, and commit to an organization's identity by observing the "formal commitments, actions and official claims" of the organization (p. 23).

The second approach, the social construction perspective, differs from the social actor perspective by arguing that members within an organization play an important role in shaping identity (p. 24). Every member "alters," the way an organization explains itself to others and "members imbue old labels with new meanings or interpretations" (p. 25). This keeps "a sense of continuity with the past while enabling new strategic directions" (p. 25). In other words, this perspective considers OI as more dynamic. Each new group of members works to recreate that identity. Even though OI provides direction to an organization's employees about the basic operation, OI is interpreted or even accepted in a peculiar way by each individual in a unique way (Harrison, 2000). Harrison concluded from his study of an organization named Hanson:

The complexity of the social imagination at the Hanson functioned to allow for a sense of an institutional identity, and it fueled loosely configured images of professional, occupational, or departmental identities. But individual employee imaginings were not fully circumscribed by these two parameters. Multiple imaginings of the Hanson generated in the locus of the individual employee fractured the coherence of both of these other imaginings. (p. 452)

Harrison observed that each individual differently perceived the hospital's identity: "We all work for the Hanson; we just all work for a different one" (p. 425). This study assisted by exemplifying the difficulty in defining OI. If each member of the organization passes OI through their filter to assimilate the institutional OI, then how can one OI be imagined or discoverable. As each person in the organization varies the interactions of OI, getting a clear picture or frame of OI is difficult, but not impossible. At the personal level OI is seen as the organizational identification (OID), which impacts 
specific employees according to their personality type. For example, when considering the big assessment, Harrison observes:

Employees with higher agreeableness may be more likely to have higher OID because they are more likely to agree with the practices, procedures, and policies of the organization and the behaviors of their leaders. Neurotic employees may be less likely to identify with their organizations because they are more likely to experience negative emotions in their workplaces. (p. 19)

Hence from this perspective, OI is a dynamic identity similar to the identity of a person, that can vary across time but retains some enduring qualities.

The third and last perspective is called the institutional perspective. In this perspective, OI "is still internally determined, but because organizations are embedded in broader social contexts, identity is highly influenced by strong external forces" (p. 25). Hence in this perspective, two concepts are observed: "distinctiveness" and "sameness." Institutionalist believe that an organization finds its identity while comparing to other organizations.

Understanding the various perspectives within OI, and leaving aside the diverse perspectives, OI in general terms, is summarized by answering two questions: "Who we are?" and, "What do we want to become" (He \& Brown, 2013; Whetten, 2006). One simple way a person could identify those questions is by reading the mission, and the vision of an institution since most institutions have these statements as written to clarify the organization identity.

Even though identity may be seen as the organization's core characteristic but fairly intangible, identity manifests itself in other aspects of the organization "from dress code to processes" to "nostalgia and media attention" (He \& Brown, 2013, p. 8). In that regard, Worley and Lawler (2010) mentioned that OI "is an integration of the organization's internal culture and external brand, image, and reputation, and represents a 
long-term value proposition for the organization" (p. 9). Therefore, identity is a core aspect of the organization that can be seen externally in a wide array of aspects, from the operations of the institutions to their public persona. However, the external aspects are not their core but only a manifestation of that core: Publicity is not identity, as in the same way the operations are not identity, but identity can permeate all aspects of the organization.

In the same manner, buildings are not the identity but are representations of it (Gioia \& Hamilton, 2016). Harquail and King expand the horizon of OI implications to "bodily-kinesthetic, visual-spatial, temporal- aural, and emotional experiences of their organizations" (p. 1620). He, while analyzing Harquail, determined that:

In order to figure out "what is central, distinctive, and enduring about an organization," resulting in putatively more productive analyses involving more different types of information such as temporality, spatiality, rhythms, audio cues, and odors, visual, and emotional displays. (p. 8)

Hence Harquail broadened OI's areas of repercussion to include characteristics in which the experience of whosoever is in contact with the organizations (either patient, employee, or visitor) could interpret $\mathrm{OI}$ in an individual manner. The sense that a person has while, for example, entering to a company, including its surroundings and other physical aspects feed the emotions of a person and are considered being part of an OI (Harquail \& Wilcox King, 2010); however as stated before these are not OI in itself but a representation of it.

Regardless of how OI's is represented or the approach to OI one takes, it appears that OI provides strong direction to an organization's operation. Cummings and Worley (2008), explain that OI "provides guidelines for the strategic choices that will work and can be implemented versus those that will not work because they contradict the true 
nature of the organization" (p. 171). Therefore, OI works to guide operation, set the course of an organization, and can function as a compass and an anchor at the same time. He and Brown (2013) say OI "regulates employee behavior" (p. 20). Therefore, OI provides both direction to the organization and regulation of employee's behavior.

Managing, Leading and Changing an Organization's Identity

Given the importance of OI, how can it be led and managed? And, how does it get changed, for better or worse? First, OI need not be viewed as a static force that stifles the institution and forces it to remain in the past. Cummings and Worley (2008) use Lawler and Worley's to explain:

The real power of an organization's identity was its ability to consistently support and encourage change even though identity itself remained fairly stable. An envisioned future can be compelling and emotionally persuasive to members only if it aligns with and supports the organization's core values, purpose, and identity. (p. 171)

Cummings and Worley refer to previous research in which identity was not a fixed structure but more of a guide or reference point to understand and plan an organization's evolution. Organization Identity could keep the organization faithful to its core as well as help it adapt to new trends and technologies (Worley \& Lawler, 2010). Worley and Lawler (2010) expanded, stating: “Like an individual's personality, an organization's identity is a defining characteristic that changes very slowly if at all” (p. 9). Hence, OI can be modified through the years; however, in a gradual manner if ever happens.

Organizations sometimes face an existential questioning and have to confront their identity. Leadership can play a crucial role in that process; it can come from the board, from the CEO or others in the organization (Stiffney, 2013). Researchers have studied the impact of leaders in the organization's performance (Stahl, Covrig, \& 
Newman, 2014). Ravasi \& Phillips (2011) argue that organizational leaders indeed assist on "shaping organizational identity" (p. 104), however "exist a 'gap between current performance and the ambitions of organizational leaders' that may well induce leaders to engage in strategic change that is not congruent with the identity of the organization" (p. 106). Hence, leaders could deviate OI by promoting a change that is against the institution's core values. Therefore, leaders are key players on the continuation of the organization's identity, either continuing to strengthen its core identity or working to abandon or dilute that core identity.

In addition to leaders, members and managers also play a crucial role in preserving and promoting an OI. Ravasi and Phillips (2011) stated that the way the organization could face the interactions and modifications of its identity is by a "process of 'claim-making' in which influential members and groups try to persuade other internal and/or external actors to accept their conceptualizations of the central, enduring and distinctive features of the organization" (p. 106), since the leaders "are expected to represent and to speak 'on behalf' of the organization" (p. 106) and being the leaders in key position, take advantage their access to key communication channels. Leaders should defend OI and be congruent. Hence, the organization needs to state, "official claims," in which the organization officially dictate its identity. However, it is not only a responsibility of the $\mathrm{CEO}$ of the organization, since all positions of power have an impact. The higher the level of authority, the higher the repercussion, such as the case of board's chairs (Stahl et al., 2014).

He and Brown (2013) also point out another challenge regarding OI: some organizations may have multiple identities, making OI complex to deal with. These 
researchers even explain that among the multiple identities, some could even be contradicting identities within the same organization. The multiple OI, in some cases, is merely "political acts" (p.5) and not really a conviction. Therefore, the board, leadership, management, and each of its members are vital parts of prevention of such conflicting statements.

The literature related to OI provided me with a framework for studying Adventist health care "institutional/organizational" identity over time. Having in mind that OI evolves, due to diverse factors, I felt I could try to trace that identify across multiple periods, organizations, and countries. One of the first tasks was to see if I could discover the original core of Adventist healthcare. Over time an organization may or may not continue with its founding ideology. Hence, I needed to separate OI from such founding institutional core. An institutional core is within OI, but OI does not necessarily refer exclusively to the institutional core. Facing such a conundrum, I searched for another field of OT: Institutionalism.

OI and Selznick's institutional character and old institutionalism

Long before Albert \& Whetten coined the OI term, Selznick already was using a slightly similar concept with a different name: organizational character (Selznick, 1948). This term was used as part of Selznick's institutionalism which, even though within social sciences by the 1950 s and 1960s, became one of the organizational theories studied in management. Institutional theory scholars argue that "organizational structure and processes tend to acquire meaning and achieve stability in their own right, rather than on the bases of their effectiveness and efficiency in achieving desired ends, such as the mission and goals of the organizations" (Miles, 2012, p. 145). In other words, 
organizations that become structured and matured in their processes get meaning of their own, instead of necessarily connecting to efficiency or even the fulfillment of the organization's mission.

Organization as a concept, according to Selznick, is defined as a group of organized people with a common aim (1948). This definition is similar to other OT scholars. However, compared to OT, Selznick adds to the definition that the organization's members have a particular assignment or roles to reach the organization's goal. As I have discussed earlier, organizations are a theme of study within different fields. Some of them have similarities such as OI and Institutionalism. However, these two fields' commonality varies depending on the type of institutionalism.

After Selznick's Institutional theory, several researchers have amended or modified the original premises in order to fit particular organizational types. Currently, scholars classify institutionalism in three types: Old institutionalism, new institutionalism, and agentic institutionalism (Phillips, Tracey, \& Kraatz, 2016). From the three types of institutionalism mentioned, old institutionalism is of particular interest to this study. Its core concepts are "institutions" and "values," as presented in Table 1 below. OI is the ultimate goal of an institution. An organization that becomes an institution is that which establishes identity as if the organization "takes on a life of its own" (2016, p. 355). 
Table 1

Summary of Organizational Identity in Institutional Theory

\begin{tabular}{|c|c|c|c|}
\hline & Old Institutionalism & New Institutionalism & Agentic Institutionalism \\
\hline Core Idea & $\begin{array}{l}\text { "Organizations" (i.e., } \\
\text { formally structure } \\
\text { entities with fixed } \\
\text { and limited goals) } \\
\text { gradually take on } \\
\text { lives of their own and } \\
\text { become "institutions" } \\
\text { (social collectivities } \\
\text { with complex social } \\
\text { structures and } \\
\text { broader, self-defined } \\
\text { purposes). }\end{array}$ & $\begin{array}{l}\text { Organizations seek } \\
\text { legitimacy by } \\
\text { conforming to } \\
\text { institutional demands } \\
\text { for isomorphism. } \\
\text { Institutions are field- } \\
\text { level phenomena. }\end{array}$ & $\begin{array}{l}\text { Organizations become } \\
\text { legitimate by strategically } \\
\text { altering their institutional } \\
\text { context or by drawing on } \\
\text { aspects of their } \\
\text { institutional context to } \\
\text { position themselves in } \\
\text { particular ways to different } \\
\text { audiences. }\end{array}$ \\
\hline Core Concepts & $\begin{array}{l}\text { Institution } \\
\text { Values }\end{array}$ & $\begin{array}{l}\text { Institutional Field } \\
\text { Institutional Logic } \\
\text { Isomorphism }\end{array}$ & $\begin{array}{l}\text { Institutional Entrepreneur } \\
\text { Institutional Work } \\
\text { Institutional Complexity }\end{array}$ \\
\hline Key Works & (Selznick, 1949) & $\begin{array}{l}\text { (Dimaggio and } \\
\text { Powell, 1983; Meyyr } \\
\text { and Rowan, 1977) }\end{array}$ & $\begin{array}{l}\text { (Maguire et al., 2004; } \\
\text { Lawrence and Suddaby, } \\
\text { 2006; Greenwood et al., } \\
\text { 2011) }\end{array}$ \\
\hline $\begin{array}{l}\text { Conceptualization } \\
\text { of Org. Identity }\end{array}$ & $\begin{array}{l}\text { Organizational } \\
\text { identity formation is } \\
\text { the end product of } \\
\text { institutionalization. } \\
\text { As an organization } \\
\text { becomes an } \\
\text { institution, it acquires } \\
\text { an identity and } \\
\text { becomes something } \\
\text { more than a socially } \\
\text { engineered tool. }\end{array}$ & $\begin{array}{l}\text { Organizations adopt } \\
\text { organizational } \\
\text { identities that are } \\
\text { available in the field } \\
\text { (or are associated with } \\
\text { the logic of their field) } \\
\text { to increase legitimacy } \\
\text { through a process of } \\
\text { isomorphism. }\end{array}$ & $\begin{array}{l}\text { Organizations shape the } \\
\text { identities of particular } \\
\text { organizational forms in a } \\
\text { field or build their own } \\
\text { distinctive identity by } \\
\text { drawing on or managing } \\
\text { aspects of their } \\
\text { institutional environment. }\end{array}$ \\
\hline $\begin{array}{l}\text { Primary Level } \\
\text { of Analysis }\end{array}$ & The Organization & The Field & $\begin{array}{l}\text { Individual/Organization/ } \\
\text { Field }\end{array}$ \\
\hline
\end{tabular}

Note. (Phillips et al., 2016)

Philips et al. (2016) did not consider that Selznick believed that institutions

should be fixed and unchanging since Selznick mentions the ability of organizations to expand and evolve in diverse ways. Organizations have a myriad of situations, including 
their formation, and crises and critical decisions that push the organizations to evolve ( $\mathrm{p}$. 363).

Selznick stated that for an organization to continue, or to have "maintenance of the system" as he named it, it required five imperatives:

1. The security of the organization as a whole in relation to social forces in its environment;

2. The stability of the lines of authority and communication;

3. The stability of informal relations within the organization.

4. The continuity of policy and the sources of its determination, and

5. Homogeneity of outlook concerning the meaning of the role of the organization (1948, p. 29).

Related to the imperative number five, Selznick expands on the concept of homogeneity by explaining the need that raises for a "unity derived from a common understanding of what the character of the organization is meant to be" (p. 30). He explains how organizations experience crises derived from organization-paradox, which is the tension an organization experiences between the formal and the informal realm derived from individual perspectives, primarily due to "divergent interest within the organization" (p. 28). This statement is similar to the OI perspectives previously explained.

Although this theory originated in 1948, current OI scholars praise Selznick's work and invite colleagues to consider his work. Among several things, they appreciate his work because of its focus on values and meaning. They also like his historical and diachronic orientation, wholistic approach, the embrace of dualities, and the view of 
organizations as self-acting subjects (Phillips et al., 2016). Many of these elements also were essential for this study, and we will return to them later to help us interpret our data on Adventist healthcare.

\section{Founding Governing Principles}

Since the start, I knew I wanted to look at the founding ideology of Adventist healthcare and understand its current role in current Adventist practices. However, it took a while to figure out what to call this "original intent." As explained previously, organizational identity is a broader concept than the original value that I was pursuing. Selznick's term, organizational character, was also useful but also could refer to the current organizational character. I was looking for the original ideology to help establish a beginning point, and later development could be compared.

In addition to reading OT and OI, I also reviewed popular work like Sinek (2009) who uses values, principles and guiding principles interchangeably, and Covey (2009) and others who explored these topics on YouTube and within the popular press market on leadership.

\section{"Principles" Terminology}

While searching for a term, many terms seem to relate well varying characterization of the core of Adventist healthcare. Table 1 lists these concepts: a) Principles (With a series of composed words: i-governing principles, ii-guiding principles, iii-founding principles), b) identity, c) constitution, d) values (With a series of compose words: i-Founding values, ii-core values), e) fundamental, f) integrity, g) purpose and h) mission. While pursuing to find the right term and revising the options (See Table 2) that fully define the idea needed, I realized that the concept of Principle is 
the most appropriate and wholesome since it is not defined by another term from the table and includes in the definition the "explanation" or "control" of actions. In addition, the term Governing provides the context of the organizational level. Hence, I selected the term Governing Principle for this study, having faith-based healthcare organizations in mind.

Table 2

Definition of Terms

\begin{tabular}{|c|c|}
\hline Term & Definition \\
\hline 1) Principle & $\begin{array}{l}\text { A basic idea or rule that explains or controls how something } \\
\text { happens or works. }\end{array}$ \\
\hline a- Governing* Principle & Having the power to govern a country or an organization. \\
\hline b- Guiding Principle & $\begin{array}{l}\text { An idea that influences you very much when making a } \\
\text { decision or considering a matter. }\end{array}$ \\
\hline c-Founding* Principle & $\begin{array}{l}\text { To bring something into existence. } \\
\text { To base a belief, claim, idea, etc. on something. }\end{array}$ \\
\hline 2) Identity & $\begin{array}{l}\text { Who a person is, or the qualities of a person or group that } \\
\text { make them different from others. }\end{array}$ \\
\hline 3) Constitution & $\begin{array}{l}\text { The set of political principles by which a state or organization } \\
\text { is governed, especially concerning the rights of the people it } \\
\text { governs. }\end{array}$ \\
\hline 4) Values & $\begin{array}{l}\text { The principles that help you to decide what is right and wrong } \\
\text { and how to act in various situations. }\end{array}$ \\
\hline a- Founding* values & $\begin{array}{l}\text { To bring something into existence. } \\
\text { To base a belief, claim, idea, etc. on something. }\end{array}$ \\
\hline b- Core Values & $\begin{array}{l}\text { A value, belief, etc. that is basic and more important than any } \\
\text { other. }\end{array}$ \\
\hline 5) Fundamental & $\begin{array}{l}\text { The most important facts, ideas, etc. from which something is } \\
\text { developed. }\end{array}$ \\
\hline
\end{tabular}


6) Integrity

7) Purpose

8) Mission

9) Commitment
The quality of being honest and having strong moral principles that you refuse to change.

The reason for doing something or the reason that something exists.

The result that a company or an organization is trying to achieve through its plans or actions.

A willingness to give your time and energy to something that you believe in, or a promise or firm decision to do something.

Note. Terms taken from Cambridge online dictionary on 23 May 2018 [Emphasis added] https://dictionary.cambridge.org/dictionary/english/values

* For the cases of composing words that were not appearing in the dictionary together, only the definition of the additional word was listed.

After using both the scholarly and popular resources, I also turned back to Ellen White, the place I was planning to start my analysis of Adventist healthcare principles. She used useful terms in several situations. One example is: "Our moral nature is to be revolutionized in its governing principles [emphasis added], love to God and love to man.” (White, 2018). For the specific case of healthcare, Ellen G. White Publications' trustees used the term at the beginning of Testimonies for the church volume 1:

Counsel was given that 'we should have a health home of our own,' which led to the establishment of the Health Reform Institute, to which and regarding much counsel was given. As the light was followed, this institution grew until it was one of the best of its kind in the world. During the period covered in this volume, the governing principles, which led to its success, were clearly laid down. (Ellen G. White, 1992b, p. xi) [Emphasis added]

As presented previously, the phrase governing principles could be separated to understand its full meaning. The word Principles is defined by dictionaries and encyclopedias in diverse ways ranging from "a basic idea or rule that explains or controls how something happens or works" (Cambridge) ; "a concept or value that is a guide for behavior or evaluation"( Everipedia); "to a comprehensive and fundamental law, doctrine, or assumption" (Merriam). Moreover, "an accepted or professed rule of action 
or conduct... a fundamental, primary, or general law or truth from which others are derived (Dictionary online).

Some popular authors defined the term as "fundamental truths that serve as the foundation for behavior that gets you what you want out of life" (Dalio, 2017, p. X); others even state that "they are natural laws that cannot be broken." (Covey, 2017, p. 17); "Correct principles are like compasses: they are always pointing the way" (Covey, 2009 p. 19); "Principles are guidelines for human conduct that are proven to have enduring, permanent value. They're fundamental. They're essentially unarguable because they are self-evident (Covey, 2017, p. 18). By these definitions, we can appreciate that Principles are applicable for both individuals and institutions context. However, this study is only to consider the institutional perspective.

On the other hand, Governing, once again, from the perspective of institutions, means: (a) "having the power to govern ... an organization" (Cambridge), or (b) "To rule over by right of authority, (c) to exercise a directing or restraining influence over; guide, (d) To hold in check; control, (e) to serve as or constitute a law for (Dictionary). (f) a: to control, direct, or strongly influence the actions and conduct of, $(\mathrm{g})$ to exert a determining or guiding influence in or over income must govern expenditure (h) to hold in check (i) to serve as a precedent or deciding principle for customs that govern human decisions (Merriam-Webster).

By putting the two terms together-governing and principle-I believed it would refer to "a fundamental moral rule that guides and influences how something is done" (Governing-principle, 2018). For this study, "governing principles" mean the foundational rules that guide the way an organization behaves. 
Once I settled on governing principles, I then added founding, to reflect the time of these governing principles. By using the word founding, I am demarcating the governing principles used originally from those currently being used. I use FGP and GP interchangeably to talk about the founding values and core identity of the original Adventist vision of healthcare.

\section{Understanding and Studying Founding Governing Principles}

Though principles are intangible, their influence, like identity discussed previously, can be felt in groups and organizations. One popular author Steven Covey has done much to promote the concept of principles as a "compass" given direction to persons and organizations (Covey, 2017). Principles can help frame the reason for existence (raison d'être). Principles are vital for our purpose in life both at a personal level and at organizational and institutional levels. The later especially since all decision making of an organization should be based on principles (Dalio, 2017). However, linking the concept with OI and Institutionalism previously discussed in which that foundational core (here referred to Governing Principles) shape the everyday operation (Selznick, 2011). Selznick linked governing principles with the institutional goals by stating that "goals cannot be divorced from the enunciation of governing principles" (2011, p. 144).

Once goals are "institutionally meaningful" they can direct the "what we should 'do' to become what we want to 'be."' In other words, adequate goal-setting establishes the character or identity.

\section{Dynamics of Governing Principles: Birth, Change, and Death}

Like identity, principles are born and can change and can die in the life of an organization. What Dalio states about personal principles can be said about an 
organization's interactions with principles: we "adopt holistic packages of principles, such as those of religions and legal frameworks" (Dalio, 2017, p. X). Hence, we both adapt and learn principles throughout the years. Some principles are timeless (Dalio, 2017). However, Selznick (2011) argues that institutional processes can reshape governing principles. Hence the character or GP can be modified if a given organization considers as necessary.

Institutional studies emphasize the adaptive change and evolution of organizational forms and practices. In these studies, the story is told of new patterns emerging and old ones declining, not as a result of conscious design but as natural and largely unplanned adaptations to new situations. The most exciting and perceptive analyses of this type show the organization responding to a problem posed by its history, an adaptation significantly changing the role and character of the organization. (Selznick, 2011, p. 12)

Undoubtedly, many companies have their mission statement hanging on their walls together with their vision and values. However, if these don't capture the principles of the organization and in turn guide practice, then their influence is weak. Selznick argued that the values should infuse everything:

Truly accepted values must infuse the organization at many levels, affecting the perspectives and attitudes of personnel, the relative importance of staff activities, the distribution of authority, relations with outside groups, and many other matters. (p. 26)

Therefore, the organizational values and principles should be accepted "truly," and their effectiveness would be shown by impacting all that the organizations do. Therefore, it is imperative to translate the Governing Principles to practical activities and to make "...them relevant to everyday life" (Selznick, 2011, p. vi).

If principles have an impact on everything an organization does, the contrary also applies. Everything we do, we have an impact on our governing principles. Every decision-making is related to the institutions' governing principle. Hence Selznick calls 
for "...an ability to sense when a course of action threatens institutional integrity." (Selznick, 2011, p. 150)

Hence to preserve the governing principles, these need to be well precise. Since they have opposite relation to the opportunity to affect "its development." According to Selznick, “The more precise an organization's goals, and the more specialized and technical its operations, the less opportunity will there be for social forces to affect its development." (Selznick, 2011, p. 150) That would mean that when the principles are more specific less space would be for personal interpretation.

This process of protecting the "organizational integrity" surely is not easy. Since "it takes nerve to hold a course; it takes understanding to recognize and deal with the basic sources of institutional vulnerability”. (Selznick, 2011, p. 150)

\section{Leaders Role in Governing Principles}

What is the role of leaders and their organizations' governing principles? Selznick (2011) argues that leaders should promote and protect institutional values since he or she is the one responsible for defining their mission (p. 26). Therefore, leaders are responsible in the organization that not only defined but also " promote and protect" ( $\mathrm{p}$. 28) the organizational values. To that protection of institutional values is what Selznick calls "institutional survival," which is really "maintaining values and distinctive identity." From all the leaders' responsibilities and functions, this is the "most important and least understood functions of leadership.” (Selznick, 2011, p. 63) 


\section{Relation Between Governing Principles and Organizational Identity}

As presented previously, GP and OI are not synonyms; however, they have a close interaction. By GP, I refer to the original why an organization is or behaves the way it is, the raison d'être. This reasoning is similar to the Why of Sinek's Golden Circle concept (2009); in which the leader and all members should answer three questions: Why (In the center), How (In the middle) and What (In the outer layer). Sinek argues that every leader and their members should find the organization's Why (Purpose, cause or belief) and work together to figure out how that why will be fulfilled and then manifest that in their products and services (see Figure 1). We could see Sinek's why as an invitation to understand the organization's governing principle and its original why as its founding governing principle.

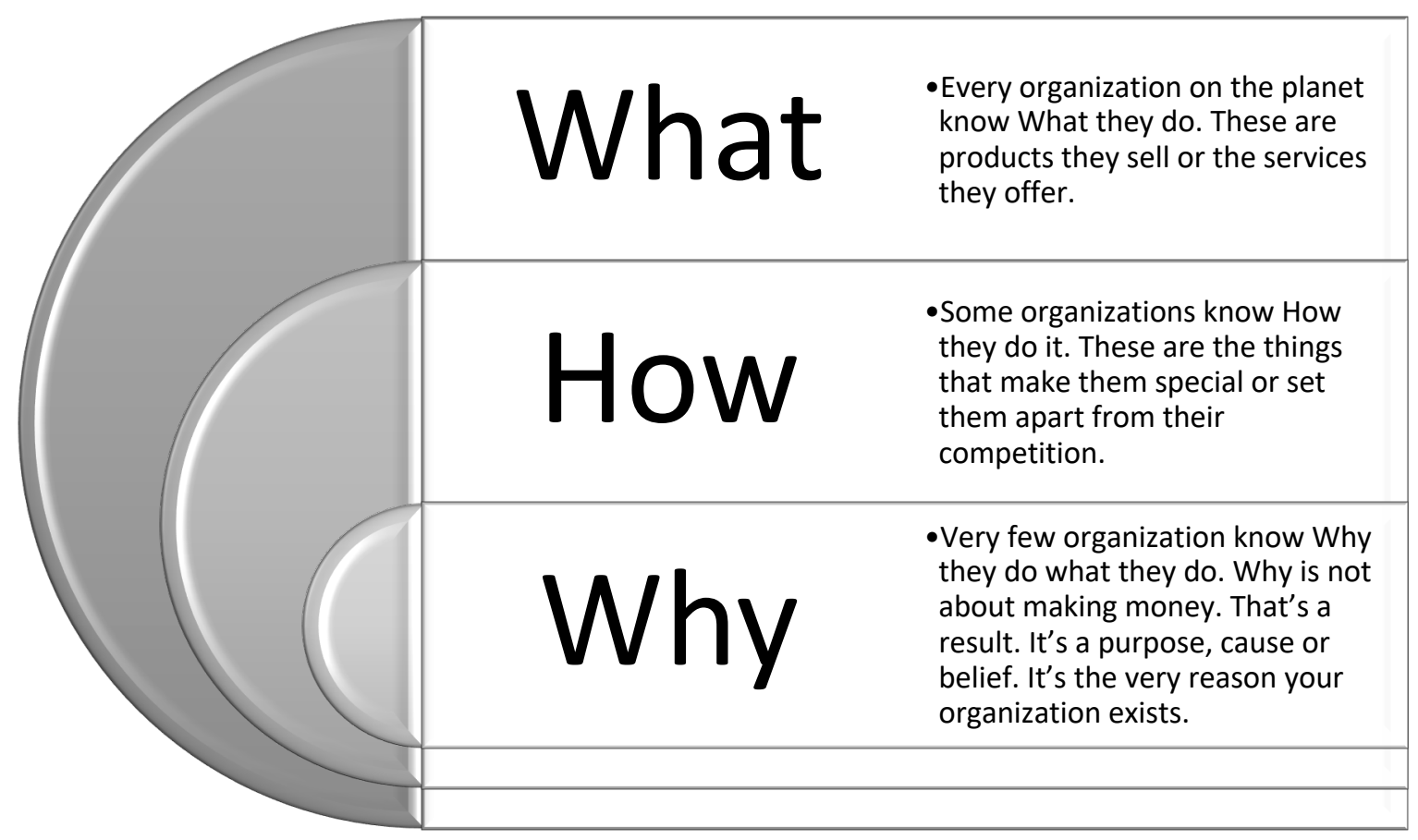

Figure 1. Sinek's golden circle (Sinek 2013) 
However, to compare to other institutions, Organizational Identity responds to the why, who we are and what we do. Using the metaphor of a tree: The Governing Principles are the seed used to originate the tree while the Organizational Identity refers the whole tree: roots, trunk, branches, and leaves; indeed, also intangible, but able to be identified. The tree is the OI, which others can witness in appearance. Therefore, through an Organizations Identity, we can detect glimpses of Governing Principles.

\section{Research on Governing Principles and OI in Specific Organizations}

We have discussed organizational theory, organizational identity, and made an argument for the concept of founding governing principles as the original intent of a group or institution. We will now turn attention to the study of these concepts with actual organizations, specifically faith-based healthcare.

From all organizations on earth, some are aiming at social assistance that has a distinctive mission and identity since they are in its majority derived from a religious concept. This concept is needed to begin understanding what constitutes a faith-based Organization (FBO). Olarinmoye (2012) in his research on the topic found that "a faithbased organization is 'any organization that derives inspiration and guidance for its activities from the teachings and principles of the faith or a particular interpretation or school of thought within the faith"' (p. 3). Therefore, the definition is straightforward since even in the name people can understand that FBO is fundamental on a particular faith and according to how they operate.

However, what is faith? Scholars consider the title of FBO limited (Jeavons, 2004) since it only presents a Judeo- Christian ideology leaving on the side other religions such as Islamic, Hindu, Buddhist, etc. since outside of the Christian sphere faith 
has no the same impact in meaning. Nevertheless, faith refers to religion. Religion is known for being a worldview force that impacts one's beliefs, attitudes, etc. According to Jeavons, even thought something does not seem religious, in an FBO, it will have a religious impact one way or another.

Some authors classified religious institutions as a faith-based organization (Bielefeld \& Cleveland, 2013; Chenhall, Hall, \& Smith, 2016). However, authors such as Sider and Unruh (2004) have expanded the concept by categorizing FBOs into six levels: Faith-Permeated, Faith-Centered, Faith-Affiliated, Faith-Background, Faith-Secular Partnership, and Secular. Such categories have been already opposed as not properly classified (Jeavons, 2004). However, we are not dwelling on the discussion of the categories of FBO since we need to move forward on the characteristics of FBO. In any case, all the authors reviewed on the topic agree that faith-based institutions that provide activities for social service are influenced by their religious values and try keeping that concept while including employees, volunteers, and other participants sharing the same faith (Bielefeld \& Cleveland, 2013). According to Bielefeld, this type of organizations keeps their identity from outside secularization pressures by promoting the individual religious call that each collaborator (either an employee or a volunteer) should have.

An important discussion regarding faith-based organizations unleashed a temporary research wave of federal funding during United States President Bush's administration since it was approved and regulated that federal funding could support faith-based organizations (Bielefeld \& Cleveland, 2013). However, the research peak has declined notably since 2011. Both positions, pro, and con- can be identified since the 
controversial procedure questioned the role of government on religious organizations and even some thought that the faith-based organization's identity could be in danger while receiving federal funding (Sinha, 2013; Wittberg, 2000, 2013). However, we once again would move on from this controversy to continue on our journey for faith-based healthcare identity.

\section{Healthcare identity}

Zooming deeper, we enter the world of FBO, especially as found in healthcare institutions. In healthcare, religion in itself has a wide array of implications. One is at the patient level who does not adhere to treatment on the grounds of breaking a religious belief or tenet (even with the promise that the medication could heal them) (Sattar, Ahmed, Majeed, \& Petty, 2004). Another implication is how FBO provide spiritual explanation to disease (Chu \& Sung, 2014). In all, healthcare without a religious worldview remains in a different setting - scientific only setting, both in the part of the institution and patients.

Within faith-based organizations, which include a variety of institutions, all in social services, the healthcare industry is a crucial aspect. Religious healthcare institutions have been for decades striving to continue with their mission. People look for institutions that are "more congruent with their sense of self" (p. 64) and their sense of identity (Rooney et al., 2010). Therefore, patients look for a place where they can be treated in line with their worldview. And this is not only for patients but also for employees since health professionals tend to look for places to work that share their worldview. 
Therefore, having patients and health professionals sharing worldview it seems that the religious identity is strong. And indeed researchers, as Kelly (2014) agree that “the stronger one's religious identity, the more one is motivated in ways that reflect this identity. The more one acts in the name of religion, the stronger one's religious identity becomes" (p. 449). Therefore, health institutions sharing religious identity will be stronger, either by reinforcing with leadership, management, medical personnel, and even patients sharing their worldview.

Therefore, we now will continue on our journey, reviewing some literature regarding specific healthcare religious systems.

\section{Faith-Based Healthcare Research}

It is believed that there are approximately 20 main religious clusters, (B. A. Robinson, 2015) the main groups being: Christianity (including Catholicism), Islam, Hinduism, Buddhism, and Judaism. All religions share the battle of keeping their identity in a world of agnostic, scientific and modern healthcare environment (Stiffney, 2013).

Aiming to grasp the sense of other religions healthcare institution's situation concerning identity, a research case would be presented to explore the situation of other healthcare religious-based organizations. Research on specific healthcare religion identity found was scarce. It is relevant to notice that the religions chosen were not arbitrary, but they were "chosen" as per the research available regarding the research available of that particular religion. The religions to explore are Christians (Protestant, and Mennonite), Muslim and Jewish. 
Mennonite Institution

Identity in Mennonite institutions appears to have similar identity challenges. In the quest to identify factors to preserve the identity, Stiffney (2013) conducted qualitative research on ten hospitals belonging to the Mennonite healthcare system in the United States. He faced himself with the critical situation on finding that key hospital positions (such as CEO) were chosen based on their professional competencies leaving on the side the worldview of the individuals as a requisite for recruitment. This problem became to such level that Stiffney had an awkward situation on board meetings to consider even if prayer was allowed. After his research, he obtains six aspects to maintain the running of healthcare institutions true to its mission:

1. Resources for governing boards and CEOs that support discernment about the challenges and possibilities for developing a distinctive faith identity in the context of increasing pluralism.

2. Resources for governing boards that are dealing with transitions of their CEOs would help to (a) clarify expectations concerning the relative priority of candidates' understanding and prizing of the religious frame of reference of the related community of faith and (b) communicate expectations concerning the CEO's work with organizational identity.

3. Resources to help CEOs to explain and interpret the unique perspectives of the related faith tradition.

4. Leadership formation activities for executives and other senior leaders that focus on practical issues of how a particular religious frame of reference (e.g., Mennonite/Anabaptist, Catholic, Quaker, United Methodist, etc.) can shape organizational policies and practices.

5. Resources to help CEOs to do more value-focused senior staff recruitment and screening. Included in this is a request for a thorough review of the legal parameters in which organizations can appropriately discriminate in hiring senior leaders.

6. Tools to assist CEOs and boards in reaching out to engage the local community of faith in greater degrees of ownership and exchanges that are mutually beneficial (p. 10). 
A critical recommendation derived from this study determined that from the CEO and chair of the board, alignment to organizational identity depends on the way the organization will continue with the mission.

\section{Christian Identity}

On the other side, there is research available in which the evaluation of different religions (Within the Christian area) work together in Ecumenical efforts (Eccles, 2014). This area is prone in government institutions as in the case of the chaplaincy department of a public hospital where the government has included chaplaincy services as a general practice for hospitals.

The challenges that multi-faith areas such as the ones in England and the United States face in which the patients and visitors come from an array of different beliefs. The outcome of this qualitative research stated that chaplains focus more on spirituality than their religiosity, leaving aside their main religious beliefs as such, rather focusing on their patients, in other words, uniting the particular religious identification in order to attend to the patient.

\section{Muslim Institution}

Regarding Muslim healthcare institutions, research (Yaghi, 2009) measured the way religious institutions are influenced by religious ideology even though the institution is not religious itself. The data was used from the U.S. (southeastern). The research included the review of comparing the values of Islam (coming from the way institutions were run by their leaders). It is relevant to point out that the institutions evaluated were not only healthcare but included an array of non-medical institutions. Stating that even 
though the business is not religious, the leaders transpire religious values into the institutional culture.

\section{Jewish Institution}

For Jewish hospitals, it is interesting to note that the reason Jewish hospitals flourished was the way Jewish people historically were left aside from other businesses (Banks and other commercial industries) leaving them no option but to develop in the service sector such as Hospitals, nursing homes, etc. (Ellenson, 2005). However, the reason this type of institution was chosen based on the Jewish worldview that transpires key pillars such as helping fellow Jewish (as a priority) and their communities, as well as God made a covenant with them. The identity of Jewish institutions such as hospitals lay within the Jewish spirit and not on the outside (Ellenson, 2005).

\section{Adventist's Identity}

After considering some research regarding religions and their healthcare identity, finally, we will explore the Seventh day Adventist Church (SDA), which is our main interest. However, unlike the previous religious healthcare systems reviewed, we will explore first what comprises the SDA identity.

The SDA movement gained its momentum in 1847 (Polanco, 2012) and was founded in 1863. Ellen G. White, one of the key founders of SDA, explained that Christ was to be a central identity in their new denomination (Tutsch, 2009). She and other founders presented the Bible as the word of God and the foundation of the "new" movement (Polanco, 2012), as the Bible and its practical application in life were considered central to SDA identity. Polanco argues that SDAs strongly connect their 28 beliefs to the Bible and see these beliefs as the foundation of the SDA faith and identity. 


\section{Identity Crisis: Denominational Institution Existence}

However, there seems to be an identity crisis in the church. The General

Conference SDA president, Ted Wilson, has acknowledged this by stating that the first of the four challenges the church is facing is the loss of identity (Canale, 2015). Canale confirms that "since our identity is grounded in Scripture, a loss of identity may flow from an undetected disconnect between our theological thinking and Scripture" (p. 115).

He further adds:

Therefore, the only way to change the direction of the church and finish God's mission is through a personal and corporate return to Scripture, characterized by the humbleness of mind and heart. We must heed God's words and then, personally and corporately, live out the Adventist vision in everyday life. (p. 147)

Nonetheless, what relevance has the crisis of the church in this analysis? Existing identity crisis in the SDA church could impact all its institutions. And indeed, this sense of identity crisis has transpired even to healthcare institutions. Knight (2015), a relevant SDA scholar, has warned the church about the urgency to decide if its identity will continue based on its mission or its institutionalism; and he added his recommendation on the church's need to focus on the mission of the church (proclaiming the evangelic message) and not on feeding expensive structure such as healthcare institutions. He further suggests leaving them for the good of the mission.

On the other hand, Cortez (2015) acknowledges that several scholars realize the existence of a "dilemma" in the church: either we attend the gospel of preaching for the coming world or attend the current world by helping the people through institutions such as healthcare institutions. However, after reviewing the source of the identity of the church, the Bible, Cortez concludes: 
Jesus' ministry was also a perfect expression of this dilemma. He healed, taught, and did good, but also preached the kingdom of God. There was no compromise in His purposes. Every healing action of Jesus was both a full expression of His interest in this world and an uncompromised expression of the power and hope of the kingdom of heaven. (p. 172)

Cortez further adds

Thus, if we follow the example of Jesus and John the Baptist, an identity of tension means that everything we preach and proclaim about the coming world should have an impact on our audience in a better way of life, better education, better health, better family and human relations, and better quality of life here and now. In this sense, every disconnection between our theology and our care for the world around us should be considered a betrayal of the essence of the gospel. On the other hand, every act of relief of human need, of care for social suffering, of interest in enhancing the quality of life around us should be just as much a part of our interest in their ultimate well-being and in the restoration of their relationship with the creator of the universe. In this sense, any disconnection between our care for human need and an interest in restoring the ruptured relationships with the Creator of the world would be considered a betrayal. (p. 172)

Hence, even though the mission of the church is to follow the Bible and its call for the mission, it is accepted and even commanded to continue in Jesus' steps in healing and preaching.

\section{Identity Crisis: Mission Diluted}

The challenge that Adventist healthcare institutions are facing is to have no difference between corporate world managers and Adventist healthcare managers (Branson, 2015). The existence of SDA healthcare institutions make sense only when it is unique. Being one more of the rest makes the existence of SDA healthcare institution pointless. However, departing from the organizational identity might happen without realizing.

Most Adventist healthcare institutions, while pursuing their mission, interact with government, communities, and corporate world; often establishing certain agreements of 
collaboration. Making commitments with other organizations cannot spare a toll on identity (Covrig, 2003). Neither can an organization keep its identity in isolation, trying to hold to what was the original foundational philosophy without adapting to the changes in the organizational environment, people, times, etc. However, "figuring out which influences will help, and which will dilute the mission is the tough stuff of leadership" (p. 168).

\section{Current Adventist Healthcare Institutions}

As the number of healthcare Adventist organizations increases, it also rises the diverse ideas on identity and management. In the United States, for instance, there are several independent systems: such as AdventHealth (formerly Florida Hospital), Adventist Health, and Loma Linda Health. Some Adventist hospitals have the governing structure connected denominational entities. However, some others are legally independent of the church system. In spite of that, these organizations have Adventist church leaders as board members. In this section, we review research related to Adventist healthcare and institutional identity.

There were some studies conducted regarding the collaborative work of Adventist organizations. In Mexico, for instance, records exist of combined efforts between university, hospital, and community to continue the mission of the church (Gregorutti, Charles-Marcel, González, Avilés, \& Cea, 2015). On the other hand and in a similar case, there is another study in China (Wu, 2015), which presents the collaborative efforts of not just university but church administration, together with a hospital.

On the Mennonite health system study mentioned earlier, an emphasis is done on the CEO of the hospital. However, there is research conducted on an SDA hospital 
regarding the role of chair of the board of the institution (Stahl et al., 2014). Nevertheless, this qualitative study barely touches the identity and mission of the church since its emphasis is inclined to the role of the board's chair. However, two relevant research publications were the object of study under the scope of identity: Loma Linda and AdventHealth (formerly Florida Hospital).

\section{Loma Linda Hospital's Case}

A landmark institution in Adventist healthcare is Loma Linda University (LLU). Even though it was not the first Adventist healthcare institution, it is one of the first that still operates, and not just surviving but leading healthcare institutions in an iconic manner. The first institution was in Battle Creek called the Western Health Reform Institute (D. E. Robinson, 1965). However, it is not currently operating. Covrig (2003) analyzed how, over more than 100 years of existence, there was a struggle to maintain LLU's original identity. The institution, which originally had strong religious lines, made significant changes over the years, including relevant aspects such as changing from a religious linked institutional name. However, changes were made to have an organization more open to all types of backgrounds. In a way the organization diluted the identity, but still some core aspects of the organizational identity could be identified.

\section{Florida Hospital's Case}

Research in line with Adventist healthcare identity was done on Florida Hospital in the U.S. (Haffner, 2013). Haffner addresses the research question on the alignment's degree of Florida Hospital's employees to the Seventh-day Adventist core convictions in healthcare. Furthermore, the author states that by a combination of methods (Historical review, official church manuals, four original white papers and 11 interviews of 
healthcare administrators) that there are six core elements: Wholeness, The healing ministry of Christ, Health Principles, Seventh-day Adventist Beliefs, the Image of God and Community.

After such a definition, Haffner explains the quantitative study, in which a sample of 653 Florida Hospital's employees participated. Afterward, the researcher establishes the parameters for stating compliance of core values, which are divided into three aspects: cognitive, practical, and emotional. The author included several variables to gather relevant information such as religion and the number of years in the institution. Additionally, the author states four main questions to be answered: (a) Perception of alignment to core convictions, (b) Understanding, behavior and emotions of the Florida Hospital's employees, (c) The way in which the employees' religion impacted the outcome of the study, (d) The way in which the employees' religion "understand, behave and emotionally connect" with these core convictions.

The results were presented in the same order as the appearance of the questions. The result concluded that the highest core evaluated was the Healing Ministry of Christ, and the least was Wholeness. Another outcome of the study is that compliance and emotion vary according to the group in which the employee belongs since leadership, and management have higher compliance expectations than the associates. Also, it is relevant to see that in religion-wise, the groups behave fairly similar, except for those identified as having "None" religion. The author realized that within the "Christian faith group, there is a similarity in understanding, behavior and emotional connection across the six core convictions" (p. 32). The findings of the research present the seamless fulfillment of the purpose of the research design. 
During the discussion, Haffner explains a model in which a confessional identity can be maintained, and it is by using efforts to work through Head, Hand, and Heart that the confessional identity can have continuity. The author stated answers to questions on how an organization work on the behavioral aspect of a core conviction can respond with some ideas on how organizations can work on continuing these core convictions. Also, the researcher states the importance of the confessional identity and the determination to guard it.

\section{Summary and Conclusions}

Adventist healthcare identities and principles is a topic that requires further analysis. Little research is found on the subject regarding the evaluation of healthcare institutions in the light of the mission and identity at international levels as well as regionals and even local institutions. As presented in this document, the Organizational Identity has vast material either on how it can be measured and protected. There is a horizon of research opportunities for SDA healthcare identity and the preservation of founding governing principles being guided by FBO and religious research already done that could be replicate in the SDA system. 


\section{CHAPTER 3}

\section{METHODOLOGY}

\section{Introduction}

Three research questions drive this study:

1. What were the 19th-century governing principles of Adventist healthcare?

2. How do Adventist historians and experts understand and interpret these Adventist healthcare core commitments?

3. How do Adventist healthcare leaders and experts believe these governing principles work to define the unique Adventist identity in Adventist healthcare?

I chose two research methods to address the research questions described. In order to respond to research question 1 , I used a documental analysis, distilling from the historical data the essence of principles from phrases explaining the claimed God's given message. Once the principles were collected, I contacted a group of Adventist historians to obtain the confirmation the documental analysis. Further, I used focus groups with Adventist healthcare leaders where they voiced their perspective on the applicability of such governing principles.

Chapter 3 is divided into the following sections: Introduction, stages one and two in the subsections with general methodology and research design, research sample, data collection methods, data analysis; synthesis, ethical considerations, issues of trustworthiness, delimitations, and finally the chapter summary.

This qualitative study uses a combination of document analysis and focus groups. A study of $19^{\text {th }}$-century Adventist healthcare governing principles and their interpretation 
by contemporary Adventist historians and Adventist healthcare leaders involves both document research and interpretative social science. This mixed-method approach had originally three phases of data collection and analysis. However, due to several considerations posterior to the focus group, the study was reduced to two phases of data collection, with their respective validations, and the analysis.

By pursuing the answers to the research questions, a series of steps were covered as presented in Figure 2 .

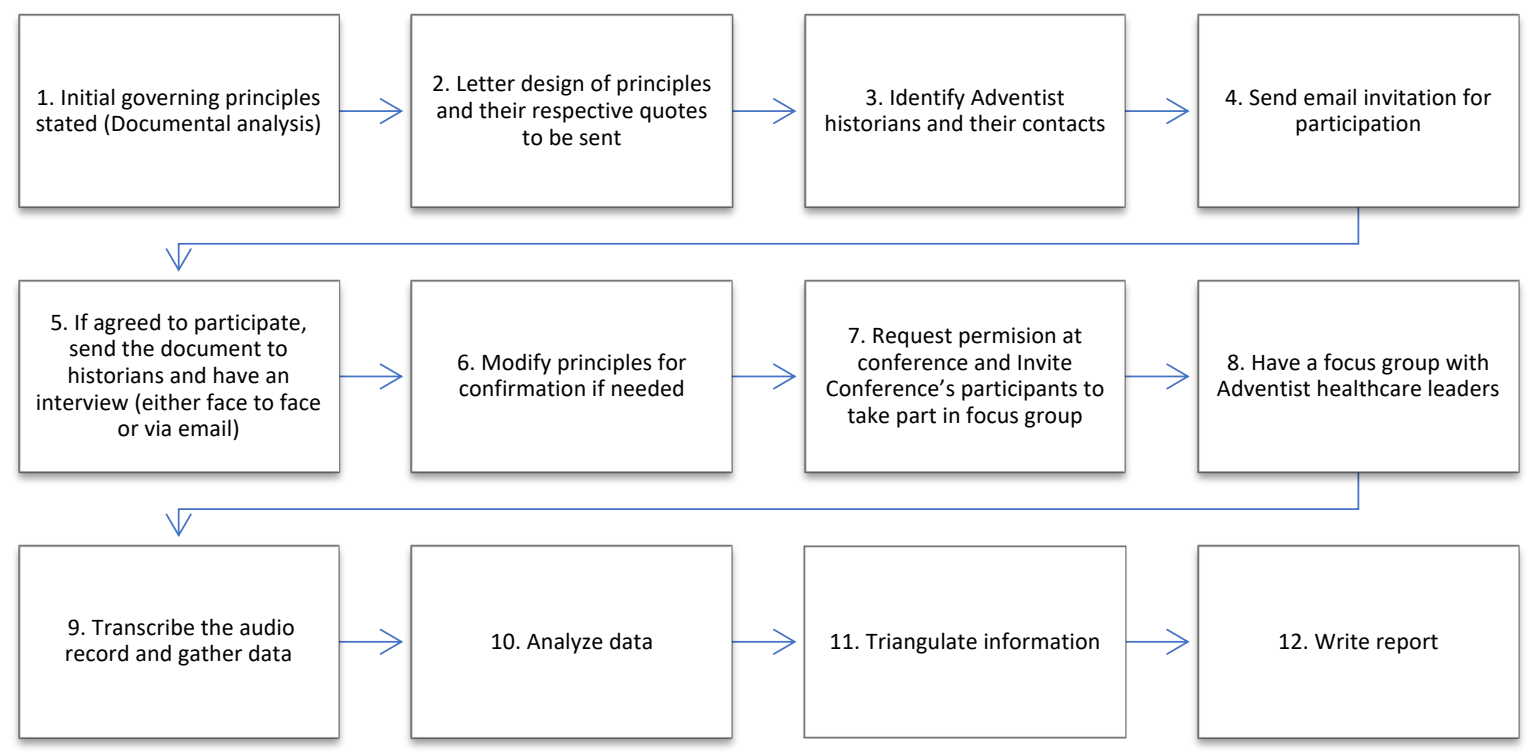

Figure 2. Flow chart of research design

\section{Document analysis}

\section{Methodology and Research Design}

Phase one required the $19^{\text {th }}$-century principles from the original record written by SDA co-founder, Ellen G. White, from the first time when the instructions to established Adventist healthcare institutions was given. Since the redaction is in narrative form, 
keywords were identified such as "I saw" or "It was shown to me," to identify those phrases referring to the claims of a divine message received versus the opinions of the receiver. This methodology was used to have an objective written reference to a message received from God.

The methodology, of identifying vision's references, was chosen regardless of receiving an observation by one of the Adventist historians explaining that any message given by Ellen G. White was a Divine message. In the historian's opinion, visions can be received in diverse ways, not only in supernatural manners such as in dreams or trance but also through the thoughts of a prophet. However, to highlight the message claimed to be received during a state of trance or vision, the methodology of direct quotes was used.

\section{Sample and Collection}

The source of data for White's vision document analysis comes from Ellen G. White's Testimonies for the Church in which she recorded her visions, included the healthcare-related ones (1992b). The "testimonies" were written as independent pamphlets that eventually were compiled and numbered. The first one dated from 1855 . Testimonies for the church were written in the first person and compiled in chronological order.

The documents used for this study were Testimonies for the church volumes 1 and 3. I chose these two volumes since in Volume 1 includes White's description of the first healthcare-related vision before the existence of any Adventist healthcare institution. In volume 3, I found a reinforcement of volume 1 with expanded clarification on the instructions provided in volume 1. Even though during that period the first Adventist healthcare institution already existed, no new instruction was given. Despite that my first 
language is Spanish, I was careful only to use document sources that were in the original English language used by the Adventist pioneers for this stage, to avoid translation errors.

\section{Document Data Analysis}

While revising the documents, I identified expressions such as "I saw" or " "It was shown to me" to identify textual declarations from the "visions" received. From the revision of these criteria, the purpose was to identify a list of topics that clearly states instructions or mandates. Then I highlighted the themes and instructions given. From the list of themes, I wrote twelve sentences that contained the details of the instruction. As explain further in chapter 4 , only two vision were use since the purpose is to grasp the principles of healthcare prior to any Adventist hospital being established.

\section{Document Analysis Validation}

Originally a phase two, and posteriorly a validation stage, I proceeded to the confirmation of the document analysis of $19^{\text {th }}$ century Adventist healthcare governing principles by experts on Adventist history. Experts were identified as Adventist historians within the Seventh-day Adventist denomination using the snowball technique.

I was introduced first via email to two Adventist historians at Andrews University, my host university, by my dissertation committee's chair. One of the candidates accepted to participate. The other referred me to another "better" participants. After my first face-to-face interview, I received other recommendations for possible participants. I also received recommendations by email from other acquittances and in one case from an Andrews University's Ph.D. alumni. I selected all those recommended that fitted the profile and contacted them via email. 
After the candidate agreed to participate, I sent a summary of my document analysis and a consent form for Adventist Historian (See Appendix A. Letter for Adventist historians and Appendix B. Consent form Adventist historian). Of the ten contacted from around the world that were conversant in English, four did not respond. Two of the ten people contacted explicitly declined to participate since they did not consider themselves to fit the profile of "Adventist Historian". In total, four agreed to participate but only three responded. All three participants belong to the North American division, and are doctoral holders, authors of books and academic articles related to Ellen G. White topics, have wide experience in teaching and research in Adventist studies, Adventist church history and Ellen G. White's studies. Two of them are currently working in an Adventist university and the third one is already retired from one.

Subsequently, I received the participants' feedback and gathered their opinions, and compared the participant's input to the proposed document sent. Then, I adjusted the original document analysis as the recommendations that I considered fit the purpose of the study.

\section{Focus Group}

Methodology

The last stage required focus group techniques to obtain Adventist Healthcare Leaders' input. Focus group is a technique within qualitative research, which is also called group interviews. Bloomberg \& Volpe explain how this technique facilitates "group discussions and possess elements of both participant observation and individual interviews, while also maintaining their own uniqueness as a distinctive research method" (2016, p. 156). 
The origin of this technique goes back to 1926 with Emory Bogardus being the first researcher that recorded it (Liamputtong, 2011). According to Liamputtong, the fields that use more focus group techniques are health and social sciences, due to the interactions of group interviews that facilitates social studies. A small group of participants is chosen due to their common experience, which is of interest of the particular study in question. The dynamic is quite simple, "natural and relaxed" in contrast with one to one interview (Bloomberg \& Volpe, 2016). Focus groups are well structured and follow a design; however, at the same time, they are flexible while attempting to know what people think and why they think that way (Liamputtong, 2011).

One of the advantages of a focus group technique is that the researcher can listen to the participants and learn from them; besides that time, the technique offers quick results (Liamputtong, 2011). Some disadvantages are known such as the power struggle among the participants in the exercise; therefore, the need for a "strong facilitator" to be able to obtain the data is needed (Bloomberg \& Volpe, 2016).

\section{Sample}

The focus group session were done with global Adventist healthcare leaders who were asked to interpret, clarify, elaborate, and confirm the nature of Adventist healthcare's governing principles and their modern application. To qualify as an Adventist healthcare expert participants needed to fit the following profile: (a) Adventist healthcare leaders; (b) Seventh-day Adventist professionals; (c) At least five years of experience in an Adventist denominational institution or Adventist based institution; (d) High-level hospital management experience either as CEO, High-level executive (e.g., Chief of Medical Officer, Chief Financial Officer, Chief Nursing Officer, Chief Quality 
Officer, etc.) President or Board member, either active or retired. The participants could be active or former hospital administrators, health university leaders with field experience in Adventist healthcare or church leaders officiating over Adventist health care processes or institutions.

Regarding the size of the group, five to ten members are the ideal (Curry, 2015), and I originally planned to have two or three focus groups. The purpose of the size is to have a balance of views in one group and thus avoid the threat in small focus groups of an extreme voice while keeping the group small enough so everyone can respond. Having more than one group allows me to ensure I get more diverse groups and to ensure that if one group gets too fixated on one area, that a second or third focus group would not have the same challenges.

Even though the SDA church is a worldwide church, Adventist Healthcare leadership is fairly connected. Many of these leaders get together at various conferences, especially those in the same division. The Adventist church Health Department holds one worldwide event specifically for Adventist hospitals and clinic's leaders: The Global Healthcare Conference. This event gathers a wide range of Adventist health experts from around the world, taking place every two years in Loma Linda, California. This conference is done in collaboration with Loma Linda University, Adventist Health International, General Conference Departments of Education and Health Ministries, and the Consortium of Adventist Medical Leaders.

In 2014 and 2016, I participated in this conference, representing the Adventist Hospital in Mexico: Hospital La Carlota. I was acquainted with the multicultural environment and the world-wide representation this event has. While facing the need of 
contacting Adventist healthcare leaders from around the world, this event came to my mind and together with my dissertation committee the plan of focus group substituted my original plan of sending emails to the Adventist hospital leaders from around the world since it seemed to have a higher response rate than email survey.

After getting approval from my dissertation committee, to do the study with participants of the Global Health Conference, I contacted the General Conference of the Seventh-Day Adventist church's Health Director via email in order to gain authorization to hold focus group sessions on the sidelines of the conference. Once I received a positive response, the Health Director redirected me to the person organizing the conference in Loma Linda, California, where the event was going to take place. She assisted me with the conference program and agenda and inquired for more details on the research's needs. She informed me that they were expecting about between 250 to 350 participants. Afterwards, I was given four times to hold focus groups sessions with their respective room number: the first session was schedule on Thursday during lunch time from 12:50 to 2:00 pm; the second one on Friday from 6:30 to 8:00 am; the third one the same Friday during lunch time from 12:30-2:00 pm and the last one on Sunday at 6:30 - 8:00 am. The time allocated was the actual time that no activity was held in the conference agenda. This time included the participants obtaining their meal and walking to the meeting room, have the focus group session and return to the conference afternoon's program. In other words, the one hour and a half given was not for only focus group session.

On Wednesday of the Global conference's week, I visited the venue to familiarized myself with the place and make sound check with the voice recorder trying to confirm that neither air-conditioning sounds or echo would interfere with the 
recording. The location assigned was one floor below the auditorium where the conference was taking place. I noticed the organizers had located signs with my name and the room number that was assigned to focus group sessions in several places: in the hall and in front of the elevator. Since several meetings were taking place during breakout sessions, my sign was not the only one. I had also prepared a sign to put outside the door where the focus group session would take place.

On Thursday morning while registering to the conference, I met several participants. I had with me a sign-up form with space for ten names and phone numbers for every one of the four focus group sessions. Some of the participants I had seen in previous conferences making it easier to approach; however, I also approached first time participants . When I spoke to any of them, I explained them that I was working on a research project about Adventist healthcare using focus group session, I told them the time and venue and ended with the question if they would like to participate. If they agreed I took their name and phone number. In few minutes, I had the list of ten participants full for the first session to take place in few hours from then.

In general terms, I noticed a positive willingness to participate. Since big proportion of the participants were coming from outside the country, and since internet was available on the building, I managed to communicate with most people sending them a remainder via smartphone app What's up, during the time of the conference about the time and room number; as well I reminded them that they needed to pick their lunch box and take it with them to the venue. Unfortunately, just when the main conference was breaking up for lunch and I was getting ready to go one floor below, the organizers announced that two divisions leaders were calling for a lunch meeting with all their 
respective delegates. To my dismay, most of the people that did sign up for the first session were coming from one of those two divisions. Having few minutes left to start the focus group session and only a couple of participants from the sign-up list available, I swiftly started recruiting new participants and filling a new list with the help of two individuals that were familiar with my research project and the sessions. Only one of the original participants showed up.

\section{Data Collection}

In preparation for the focus group to take place, I reviewed the Adventist governing principles. I also had a focus group session protocol to guide myself in which I would ask every participant to introduce themselves, then ask them about what they believe made an Adventist Hospital Adventist, and at the end I would hand over the 12 principles with a key quotation from the original Testimonies from the church and inquire their perception on the applicability and validity of the principles on nowadays setting.

I did take written notes during the sessions and voice recording in order to have transcripts as data collection. I used two methods of recording: a voice recorder and a smart phone as a backup. Additionally, my dissertation chair that was present in all the sessions, used his smart phone to record as a second backup. Once in the room, participants arrived with their lunch box and were eating while discussing the topic. In the two sessions that were held during lunch time I could hear the spontaneous sounds of the food packaging being open or moved; however, these sounds did not seriously interfere with the recording. That first session lasted 55 minutes and had seven participants. 
The next session was meant for key leaders in Adventist healthcare. Purposely, this session was small with the intention to avoid having leaders in the Adventist system and having them in one venue prevented them from potentially influencing other participants. I approached them personally and requested their participation. I knew all of them from other meetings. I texted them a What's up message in order to remind them on the meeting since the meeting was schedule at 7:00 am. When I arrived one of them was having a meeting which had overextended beyond schedule. Therefore, the other participants waited for some minutes until all participants were available. This meeting had no presentation section since all of the participants were acquainted each other. By the time we were about to start, the conference's program was about to start, hence this meeting only lasted 24 minutes. However, I believe that the quality of the contributions were valid and relevant to the study despite the time given.

The next session was held on the same Friday as session two and was the biggest with nine participants during lunch time (from 12:30-2:00 pm), lasting a total of 46 minutes. Once again people brought with them their lunch box. After we started, two participants arrived late due to the fact that they have mistaken the room, since several groups were holding meetings during lunch time.

The session that I was more concerned about was the last session on Sunday 6:30 am. I was worry that no participants would manage to be present, especially after the previous day the conference agenda had a free evening meant for social activities and shopping trips. Since most participants were staying in different hotels around the area and the majority had no control about their transport, I was doubting if any would show up. Indeed, some of the participants that were scheduled declined via what's up, while 
others simply did not arrive. Having no participants, I went to the conference's meeting hall and to my glad surprise several participants were already present waiting for the conference to start. When I invited them to join the focus group session, all agreed to participate. This last meeting lasted 30 minutes and had seven participants. In this last session I felt more confident and I managed to be more concise on introduction and dwelled more on the study in itself.

\section{Analysis}

Once the focus group was concluded, the analysis process started. The first step was to transcribe the recording of the meeting with the participants of the Adventist healthcare leaders. For this I used an online software called Transcribe in order to assist me in pausing and replaying small sections of the recording of the focus group sessions. Once the transcript was concluded, the analysis stage started. The analysis consisted of recording at least one participant expressing if the principle under discussion was still valid. The purpose was not to manage the analysis as a quantitative; meaning that the number of responses made a particular opinion of lower or higher relevance. Hence, when participants identified the principles, it still was considered valid.

\section{Selection of Analysis Method}

Traditionally, interview data from focus groups are analyzed manually, often by cutting words up and grouping them or by the use of color highlighting pens (Krueger, 1998). However, technology has evolved in a way that computers can assist in organizing, annotating, searching, and displaying the results with ideally large studies (Creswell, 2007). Both approaches work, but computer software like NVivo and Dedoose 
is typically used for larger data sets. I had less than 100 pages and opted for a manual system assisted by Microsoft Word and Excel.

I recorded the focus group sessions and transcribed them myself using the computer-based Transcribe software. Additionally, I used focus group notes from two researchers present during the focus group session (myself and my chair). Another aspect to consider was the focus group analysis methodology, either taking every particular response from each participant individually or analyzing throughout transcripts by themes. Richard A. Krueger (1997) recommends both methods, inclining for the first one mainly for beginner researchers. Since this research is guided by experienced advisors and due to the nature of the study and the aim of correlating the participants' responses with the summary principles from Stage 2 (See Chapter 5), the analysis by themes was chosen. Regardless, every participant's voice was identified by using Excel.

To help determine my method of analysis, I returned to my central research questions:

1. What was the 19th century governing principles of Adventist Healthcare? This question was addressed in Chapter 4, during Stage 1.

2. How do Adventist historians and experts understand and interpret these Adventist healthcare core commitments? This question is answered in Chapter 5 during Stage 3.

3. How do Adventist healthcare leaders and experts believe these governing principles work to define the unique Adventist identity in Adventist healthcare? The answer to this question is the Stage 2 and is answered in Chapter 6.

The objectives for Stage 2 derived from the third research question: 
Objective 1: Identify the perception that Adventist healthcare leaders have regarding what are the governing principles? (What makes Adventist Hospital Adventist?)

Objective 2: Identify if the participants perceive the governing principle list as absolute or if they provided additional EGW's principles not identified in Stage 1.

Objective 3: Explore the acceptance or rejection that Adventist healthcare leaders have of the 19-century governing principles identified as still valid in 21-century Adventist Healthcare institutions.

Objective 4: Evaluate if the Adventist healthcare leaders perceive principles that are already applied or able to be applied in 21st-century healthcare practice.

Objective 5: Evaluate if the Adventist healthcare leaders perceive principles that are challenging or complicated in its application in 21st century Adventist Hospitals.

To better understand the actions needed to address these five objectives, the following table is summarizing the information:

Table 3

Objectives and Their Actions

\section{Objective}

Action

Objective 1: Identify the perception that Adventist healthcare leaders have regarding what are the governing principles: (What makes Adventist Hospital Adventist?)

Objective 2: Identify if the participants perceive the governing principle list as absolute or if they provided additional EGW's principles not identified in Stage 1.
I have reviewed the transcript of each focus group. I have identified, from the first section of the focus group session, prior to the presentation of the principles I summarized, the principle that is related to the particular number from the participants' responses.

After reviewing the transcript of each focus group, I have identified any additional concepts, which were not listed in the summary list of principles from Ellen G. White original vision throughout the focus group session. 
Objective 3: Explore the acceptance or rejection that Adventist healthcare leaders have of the 19century governing principles identified as still valid in 21-century Adventist Healthcare institutions.

Objective 4: Evaluate if the Adventist healthcare leaders perceive principles that are already applied or able to be applied in 21 st-century healthcare practice.

Objective 5: Evaluate if the Adventist healthcare leaders perceive principles that are challenging or complicated in its application in 21 st century Adventist Hospitals.
I have reviewed the transcript of each group to identify the participants' perception regarding the acceptance or rejection of the principles shared with them, in their application on $21^{\text {st }}$-century hospital practice.

I have reviewed and coded on the transcript of each group to identify the participant's perception regarding the implementation of certain principles either in their institution or in another Adventist Institution of their knowledge.

I have reviewed the transcript of each group to identify the participants' perception regarding challenges on the application on specific principles in $21^{\text {st }}$ century Adventist Hospital.

\section{Ethical Considerations}

Indeed, the main purpose of this study embarks on answering the presented research question. However, this would not be at the expense of the participants, being human beings. Therefore, to have an objective manner of guarding the participants' wellbeing, the proposed study was presented for approval to the Andrews University's IRB to assure that the process of keeping confidentiality is trustful.

For the participants to be included, an informed consent form was presented prior to the interactions with both Adventist historians and focus group participants. The data collection was presented in a way that one could not track the identity of the participants.

\section{Validity and Reliability}

Validity and reliability are research terms that originated within quantitative research methodology. In such context, validation refers to the process of showing 
readers how "well-founded and sound" the process, data, and results of a study are and "whether or not the results generalized to a larger group" (Rudestam \& Newton, 2015, p. 131). However, several qualitative scholars consider that the term "validity" is conflicting to the qualitative research methodology and use other terms unique to the qualitative research such as trustworthiness, credibility, authenticity, transferability, dependability, confirmability, and so on to refer to validity and reliability. The understanding and practice related to "validity" in qualitative researchers (QLR) is fairly broad. Some authors do not even include a "validity" section (arguing that the role of understanding the object of study supersedes the validity on itself), to the other side of the spectrum were QLR accept and include validity similarly to quantitative research (Creswell, 2007).

Creswell, uses validation as a process more than a "verification" (p. 207). Furthermore, Creswell advises that each QLR, according to the subject of study and methodology, could choose which validation strategy and how to include it, if at all, in the respective qualitative study. Following, Creswell lists eight types of validation strategies that can be used in qualitative research, recommending the use of at least two strategies in a particular research study in order to reflect trustworthiness.

For this study, I used five of the eight strategies: prolonged engagement, peer review, clarifying researcher bias, rich, thick description and external audit. Regarding the prolonged engagement strategy, I consider my experience goes beyond what another researcher would achieve by getting acquainted with the system and process of Adventist healthcare. I have worked as a leaders in three Adventist hospitals in three different countries. Hence, I am very familiar with the challenges that Adventist healthcare leaders 
face. I actually fit in the profile of a participant to the focus group sessions. I consider my previous experience as fulfilling the objective of a prolonged engagement strategy.

Additionally, I used the peer review strategy while contacting two medical doctors with at least five years of administration experience in an Adventist Hospital. The two Adventist Hospital's leaders joined me on a group review of the focus group's data in which all the transcripts were physically highlighted. In addition, I clarified my bias as a researcher by explaining in chapter one my background and my previous experiences that lead have my criteria today. I paired this strategy with rich, thick description on the focus groups process or selecting candidates, data collection and analysis, as presented in this chapter.

Finally, I held an external audit assisted by an Andrews University alumni, $\mathrm{PhD}$ holder and researcher whom reviewed the transcripts and reached conclusions prior for him to subsecuentently revise my conclusions and provide feedback on my methodology and conclusions. This strategy assisted me in identifying key adjustments required to have, as far as possible, an unbiased process.

Similarly, to validity, Reliability has the same concerns in the qualitative sphere. Reliability refers to the "replicability of the study under similar circumstances" (Rudestam \& Newton, 2015, p. 132). The validation strategy described above, that addresses the possibility of replicating this study and reaching to similar results, is addressed by the rich and thick descriptions. In order to reproduce this same study and reach to the same conclusions, the criteria for selecting the principles by a documental analysis has been described in this chapter and in chapter 4: the keywords and White's publications used to conclude the principles presented. Regarding the results from the 
Adventist historians, overall the Adventist experts participating shared the main concern on a particular principle. Therefore, in general terms, the Adventist historians showed the similar pattern. The focus groups, their participants, data collection and analysis have been described in detail in order to have the possibility that the study is replicated. I am convinced that if this study is replicated as detailed in this study, similar conclusions would be reached. 


\section{CHAPTER 4}

\section{DOCUMENT ANALYSIS}

\section{Purpose of Adventist Healthcare Institutions}

\section{Historical Context}

Health has been a key aspect not just now but from the beginning of the Adventist movement in the $1860 \mathrm{~s}$. The early church faced setbacks because of the poor health of some of their hard-working and devoted leaders impending their evangelistic effectiveness (D. E. Robinson, 1965). Health concerns were of such dimensions for the Adventist group that a day of prayer and fasting was set aside. Leaders were forced to cancel appointments and preaching due to health challenges. James White was one such leader. His wife, Ellen G. White, took him to "Our Home” in Danville (Douglass, 1998; Numbers, 2008; D. E. Robinson, 1965), where he received natural remedies and hydrotherapy. After several months of treatment, James White did not fully recover as expected. Having disagreements with the way the hospital management restricted prayer to reduce all mental stress on the ailing man, among other topics, Ellen White took her husband back home.

\section{Ellen G. White's Visions Regarding Healthcare Institutions}

Once Ellen White returned from Dansville to Rochester, she received a healthcare institution related vision. This was not her first vision regarding health. Previously she had received three visions with the last one presenting health concepts in a 
comprehensive manner (See Table 1). In her $4^{\text {th }}$ vision on health, it was "shown to her" the need of an Adventist Institution, among other instructions.

Table 4

Ellen G. White's Visions on Health.

\begin{tabular}{lrlll}
\hline Number & Date & & \multicolumn{1}{c}{ Place } & Main message \\
\hline Vision 1 & 1848 & & & Against tobacco, tea and coffee \\
Vision 2 & 1854 & Feb 12 & & Hygiene and appetite control \\
Vision 3 & 1863 & June 5 & Otsego, MI & Health Reform and natural remedies \\
Vision 4 & 1865 & Dec 25 & Rochester, NY & $\begin{array}{l}\text { Instruction to establish health } \\
\text { Institutions }\end{array}$ \\
Vision 5 & 1871 & Dec 10 & Bordoville, VT & $\begin{array}{l}\text { Confirms principles of health } \\
\text { Institutions }\end{array}$
\end{tabular}

Note. (Los adventistas y el mensaje de salud. Historia, fundamento y desarrollo, n.d.; Ellen G. White, 1992b)

The vision presents the governing principles for an Adventist healthcare institution (Ellen G. White, 1992b), in which the mission is given to develop an Adventist “institution to introduce our faith" (Douglass, 1998, Loc. 10119 of 20425).

These principles, according to Douglass, were:

"Home for afflicted and those who wish to learn how to take care of the body to prevent sickness."

"Financially independent (Constant expenditures of means w/o realizing any returns)."

"The main object is perfection and spirit of holiness (Cannot with diseased bodies and minds)." 
"The sick are to be taught that it is wrong to suspend all physical labor in order to regain health."

"Greatest danger: Managers to depart from the spirit of the present truth and simplicity which should characterize the Disciples of Christ."

“The principles set forth are still valid" (Loc. 10132 of 20425).

In other words, these characteristics were requested: the education of healthcare principles, financially viable, wholeness of treatment, exercise, and manager's commitment. After the idea was maturing, and before opening the first Adventist healthcare institution, Ellen White articulated five purposes of healthcare institutions:

(1) The object is not primarily for "gain", although it must be financially independent, not drawing on other denominational funds; (2) Standards must not be lowered in order to "patronize unbelievers"; (3) The institution, though not to be a place for "diversion or amusement", will create an environment free from "diseased imaginations," "dissatisfied feelings," and discontent repining's", (4) The institution is established to "improve the health of the body that the afflicted may more highly appreciate eternal things"; (5) The institution should not expand any faster than adequate "skill, experience, and finance could be provided." (Loc. 10117 of 20425)

The lack of identity and loss of purpose was highly stressed since the reason for proposing a different healthcare institution was exactly that: being peculiar. After five years of operations, Douglass expands that there were several mistakes done by the administration. Then on December 10, 1871, she received another vision reinforcing the following key aspects:

Adventist health principles should "be agitated, and the public mind deeply stirred to investigate."

The Adventist institutions are "established upon different principles" from health centers that are "conservative, making it their object to meet the popular class half way... that they receive the greatest patronage and the most money."

Adventist healthcare institutions are to unite Biblical principles with the care of the sick. But Adventist distinctive "should not be discussed with patients," 
even in the weekly prayer meetings. "Silent witness will do more than open controversy... We must meet people where they are."

Wise health-care workers realize that many sufferers have more than physical pain. "Many carry a violated conscience and can be reached only by the principles of Bible religion."

The home church at Battle Creek must live up to its "greatest responsibility, and when church members do not live up to the light that health-care workers are giving to the patients, confusion and discouragement are the result (Douglass, 1998, Loc. 10162 of 20425).

The follow-up vision on healthcare institutions assisted in confirming the early principles presented prior to the opening of the Adventist Institution. The concession made to make the place financially stable were not a justification in eroding the original identity. In Ellen White's view, Adventist health institutions should not operate as the world conducts the hospitals (White, 2015). However, critics such as Knight are considering closing (or leaving) healthcare institutions on the grounds of leaving the church without funds. It is interesting to point out that even from the beginning, Ellen White explained that healthcare institutions should not be a burden to the church. Later, Ellen White expanded the description of the principles for Adventist Healthcare Institutions. Table 4 presents the five major visions or explanations of these ideas.

At the General Conference session on May 1866, Ellen White presented to the audience the message she received in which she explained the importance of the health reform and the relevance of physical health with the spiritual life. Furthermore, at this session she recommended to have healthcare institutions. "To climax the appeal, she said that Seventh-day Adventist "should have an institution of their own. ... for the benefit of the diseased and suffering among us" (p. 145). The purpose was to have a place in which the same Adventist members could be treated according to the light she received. 
Robinson continues the story stating that the response was outstanding, with people committed to action, not only in adopting the health message but promoting it by educating others. In 4 months, the pioneers had not only taken the decision of purchase, but they had purchased the land, organized it, and inaugurated the first institution: The Western Health Reform Institute located in Michigan, USA.

After reports of success, she warned: "I saw that in an institution established among us, the greatest danger would be of its managers departing from the spirit of the present truth, and from that simplicity which should ever characterize the Disciples of Christ" (p. 154). From the start, she raised concerns about SDA institutional leaders failing to align with Christian and Adventist identity. She continued: "God forbid, she added, that the patients "should ever be disappointed and grieved in finding the managers of the institute working only from a worldly standpoint, instead of adding to the hygienic practice the blessings" (p. 155). I understand that the "worldly" perspective is such that is not from the beginning even before the Adventist Healthcare Systems were in place a warning was presented to guard the "hygienic practice" or medical practice together with the "blessing" or mission of the Adventist healthcare.

\section{Governing Principles Analysis}

The theoretical framework grounding this research is the analysis of the first two instructions given by Ellen White regarding the purpose of Adventist Healthcare Institutions (Vision $4 \& 5$ ). The first instruction, regarding health institutions, given in December 1865 (Vision 4), presented the need of Adventist Healthcare institution and explained its purpose. The second instruction given in December of 1871 (Vision 5) reemphasizes and clarifies the original instruction. 
To confirm Douglas's principles listed, I analyzed the original source:

Testimonies I and III. Indeed several authors had written about the beginning of the SDA church including the "health message" (Douglass, 1998; Fortin \& Moon, 2013; Numbers, 2008; D. E. Robinson, 1965). Ellen White herself is well known, not just among Adventist, due to her prolific portfolio of publications on healthcare and health principles. However, the best source is from the reference where she published the two original visions, in which it makes references to the instructions for the Seventh Day Church to open healthcare institutions are Testimonies volumes 1 and 3. Indeed, Ellen G. White Publications' trustees confirm this at the beginning of Testimonies for the Church Volume 1:

Counsel was given that "we should have a health home of our own," which led to the establishment of the Health Reform Institute, to which and regarding which much counsel was given. As the light was followed, this institution grew until it was one of the best of its kind in the world. During the period covered in this volume, the governing principles [emphasis added], which led to its success, were clearly laid down. (Ellen G. White, 1992b, p. xi)

Therefore, the same trustees validate this source as the one that presents Ellen White two visions. The sources reviewed can be seen in Table 5:

To identify which principles stated by Ellen White proclaimed God-given testimonies, I identified phrases such as "I was shown and "I saw" to show that the statement is provided directly from the impression of the vision and not just comments that she is stating. In addition, the words institution and principles were identified as well. Some of the principles identified were presented negatively. Especially those that were presented once the healthcare institute was already operating, since they were admonitions of the manner the institution had departed from the guiding principle. For this research, all principles listed are presented in a positive manner. 
Table 5

Ellen G. White's Visions Document Analysis

\begin{tabular}{|c|c|c|c|c|c|c|}
\hline 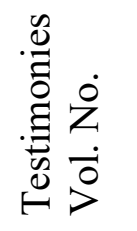 & 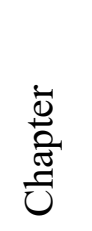 & 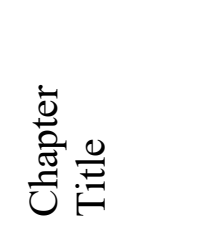 & 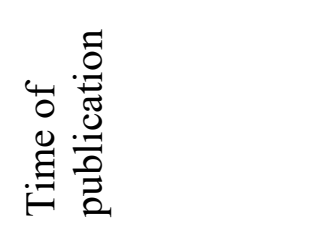 & 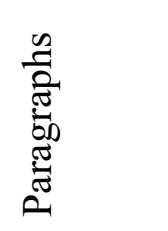 & 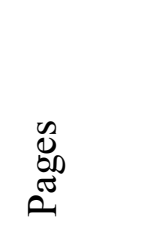 & 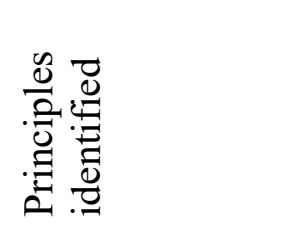 \\
\hline $\begin{array}{l}\text { T1 } \\
\text { No. } 11\end{array}$ & 85 & $\begin{array}{l}\text { The Health } \\
\text { Reform }\end{array}$ & $\begin{array}{l}\text { Prior to beginning } \\
\text { the Institute }\end{array}$ & $485-495$ & $451-458$ & $1,2,3,4$ \\
\hline $\begin{array}{l}\text { T1 } \\
\text { No. } 12\end{array}$ & 99 & $\begin{array}{l}\text { The Health } \\
\text { Institute }\end{array}$ & $\begin{array}{l}\text { After the opening } \\
\text { of the institute }\end{array}$ & $554-564$ & $512-520$ & $\begin{array}{l}5,6,7,8,9 \\
10,11,12\end{array}$ \\
\hline $\begin{array}{l}\text { T1 } \\
\text { No.12 }\end{array}$ & 100 & $\begin{array}{l}\text { Health and } \\
\text { Religion }\end{array}$ & $\begin{array}{l}\text { After the opening } \\
\text { of the institute }\end{array}$ & $565-567$ & $521-567$ & $\begin{array}{l}\text { Confirmation of } \\
\text { principles }\end{array}$ \\
\hline $\begin{array}{l}\text { T1 } \\
\text { No.13 }\end{array}$ & 106 & $\begin{array}{l}\text { Cutting and } \\
\text { slashing }\end{array}$ & $\begin{array}{l}\text { After the opening } \\
\text { of the institute }\end{array}$ & $612-620$ & $564-571$ & $\begin{array}{l}\text { Confirmation of } \\
\text { principles }\end{array}$ \\
\hline $\begin{array}{l}\text { T1 } \\
\text { No.14 }\end{array}$ & 110 & $\begin{array}{l}\text { The Health } \\
\text { Institute }\end{array}$ & $\begin{array}{l}\text { After the opening } \\
\text { of the institute }\end{array}$ & $633-643$ & $583-591$ & $\begin{array}{l}\text { Confirmation of } \\
\text { principles }\end{array}$ \\
\hline $\begin{array}{l}\text { T3 } \\
\text { No. } 22\end{array}$ & 15 & $\begin{array}{l}\text { The Health } \\
\text { Institute }\end{array}$ & $\begin{array}{l}\text { After the opening } \\
\text { of the institute }\end{array}$ & - & $165-185$ & $\begin{array}{l}\text { Confirmation of } \\
\text { principles }\end{array}$ \\
\hline
\end{tabular}

Note: Testimonies Vol. 1 and Testimonies Vol. 3 refer to the volume number of the Testimonies.

From the exercise mentioned above, the following 12 categories were determined:

1. Health education and preventive medicine.

2. Healthcare for SDA members

3. Silent witnessing to non-believer patients

4. Sustain financial and administration model despite attention to all social classes

5. Unwavering Biblical principles

6. Wholistic perspective 
7. Exercise as part of treatment

8. Preparing people to be perfect before God

9. Prayer combined with treatment and obedience to the laws of health

10. God-fearing personnel

11. Therapeutic nature interaction

12. An altruistic and trusting institutional model

The categories of governing principles are numbered only for convenience to identify them properly; however, the order does not represent that the first principles are of higher importance than the others, but they were listed following the order as they appear in the Testimony's volumes 1 and 3.

\section{Adventist Governing Principles Description}

Ellen White presented each principle with ample explanation for them to be clear. Therefore, each guiding principle is explained in light of her writings from Testimonies volumes 1 and 3 .

\section{Health Education and Preventive Medicine}

The 1863 vision did indeed provide the health reform concept. However, at the beginning of the testimonies of 1865, Ellen White writes that she "was shown" that the implementation of health practices was not followed as it should. In line with the health reform, she states clearly that Adventist Healthcare institutions should focus on teaching and prevention: "I was shown that we should provide a home for the afflicted and those who wish to learn how to take care of their bodies that they may prevent sickness (Ellen G. White, 1992b, p. 453). 
The principle of prevention of disease (besides the obvious principle to treat sickness) calls for institutions to teach patients how the body functions and how to prevent sickness; going beyond merely the treatment of disease. What type of teaching is expected? The information to be taught is the laws of health referred by White in several documents as the "laws of nature" (Ellen G. White, 1909, 1963, 1992b). As presented in Testimonies I, such laws are nothing else but how the body functions and implicitly the eight remedies presented widely in her writings. The main lesson to be taught; if a person does not obey the health laws, the body will present consequences: disease.

\section{Healthcare for SDA Members}

Any healthcare attention intrinsically carries a particular worldview. Ellen White knew this through as a personal experience with her husband's illness and treatment. In repeated occasions in her testimonies, she presents the need to have an institution "of our own" for believers, or also called Sabbath keepers, to be attended without having to be constantly on guard from ideologies contrary to the Adventist beliefs. She stated:

I was shown that Sabbathkeepers should open a way for those of like precious faith to be benefited without their being under the necessity of expending their means at institutions where their faith and religious principles are endangered, and where they can find no sympathy or union in religious matters. (Ellen G. White, 1992b, p. 454)

She highlighted that sick persons have weakened moral strength, and only people with extraordinary spiritual strength and constant vigilance could withstand temptations from dubious ideologies; hence the importance to be treated in a place where the faith and religious principles are aligned with those professed was needed. 


\section{Silent Witnessing to Non-Believing Patients}

The best way to know about principles is to see them in practice, and according to White, hospitals were an ideal setting for that. One of the advantages mentioned was that people tend to have prejudgments about the Adventist faith. However, if those that are unbelievers could see the principles in practice, they could get acquainted with them. Being in other circumstances, these patients and their relatives would reject the information even before learning about it. She explained:

Such an institution, rightly conducted, would be the means of bringing our views before many whom it would be impossible for us to reach by the common course of advocating the truth. As unbelievers shall resort to an institution devoted to the successful treatment of disease and conducted by Sabbathkeeping physicians, they will be brought directly under the influence of the truth. By becoming acquainted with our people and our real faith, their prejudice will be overcome, and they will be favorably impressed. By thus being placed under the influence of truth, some will not only obtain relief from bodily infirmities, but will find a healing balm for their sin-sick souls. (Ellen G. White, 1992b, p. 456)

After five years of the health institute's beginning, Ellen White proclaimed a follow-up vision of admonition regarding the first governing principles for healthcare institutions. Some observations regarding the Health Institute's attitude towards witnessing was regarding the erroneous manners of discussing faith aspects with nonbelieving patients. She declared: "But our peculiar faith should not be discussed with patients. Their minds should not be unnecessarily excited upon subjects wherein we differ, unless they themselves desire it" (Ellen G. White, 1992a, p. 166).

Indeed, the best way of witnessing in a healthcare institutional setting, White highlighted, is to present the Adventist faith as a "silent influence." A practical sermon should include not only the systems and protocols but also physicians and personnel at large that follow the professed faith. 


\section{Sustainable Financial and Administration Model Despite Attention to all Social Classes}

One may think that a faith-based institution's main objective is to attend to all people, regardless of the ability to pay. However, Ellen White promoted a sustainable organization. An institution that does not care for its expenses would only last but a short time. She reminded her readers that many healthcare institutions had closed due to financial challenges. She warned, "This enterprise should never be left to struggle in poverty." Nevertheless, the Adventist Healthcare institution should be for all sorts of patients, including those that do not have the means to cover their expenses. She directed that:

A fund should be raised to be used for the express purpose of treating such of the poor as the church where they reside shall decide are worthy to be benefited. Unless those who have an abundance give for this object, without calling for returns, the poor will be unable to avail themselves of the benefits derived from the treatment of disease at such an institution, where so much means is required for labor bestowed. Such an institution should not in its infancy, while struggling to live, become embarrassed by a constant expenditure of means without realizing any returns.(White, 1992, p. 458 (p. 458)

Therefore, institutions should organize for funds to be open so that outside money from donations can be directed to the expenses of people with greater needs. In that concept, the organization remains able to cover the cost of their operations.

Additionally, White provided several emphases that Adventist Institutions should grow proportionally to obtain the right committed personnel needed, as well as the development of its infrastructure. 


\section{Unwavering Biblical Principles}

Another key principle for healthcare institutions is to have a high religious standpoint, and to avoid imitating business models which are focused on money-making enterprises, as the world operates at all cost. White admonished:

... I saw that there would be danger of imitating them in many things and losing sight of the exalted character of this great work. And should those connected with this enterprise cease to look at their work from a high religious standpoint, and descend from the exalted principles of present truth to imitate in theory and practice those at the head of institutions where the sick are treated only for the recovery of health, the special blessing of God would not rest upon our institution more than upon those where corrupt theories are taught and practiced. (Ellen G. White, 1992b, p. 512)

In the same line, White warned against lowering standards to make the model more palatable for non-believers, in order to receive paying patients. The lowering of standards would have an important impact on the believers since it presents a fragile conviction producing a harming influence instead of a positive one. White related biblical principles to health recovery, while expressing that "the religion of the Bible is not detrimental to the health of body or mind. The exalting influence of the Spirit of God is the best restorative for the sick" (Ellen G. White, 1992b, p. 514).

\section{Wholistic Perspective}

A landmark principle from the Adventist healthcare system is the concept of wholistic attention. Mind, body, and spirit are so intertwined that if any of them are affected the rest are equally impacted. White declared: "It should ever be kept prominent that the great object to be attained through this channel is not only health, but perfection, and the spirit of holiness, which cannot be attained with diseased bodies and minds" (Ellen G. White, 1992b, p. 512). 
Therefore, an Adventist institution should promote and practice the wholistic concept of health for every patient.

\section{Exercise as Part of Treatment}

A common misconception expressed by White is that rest is not only ideal but also required to regain health. However, in line with the principle of wholistic perspective, absolute rest may have an important impact on the patient's mental health. White declared: "The sick should be taught that it is wrong to suspend all physical labor in order to regain health" (Ellen G. White, 1992b, p. 513). Indeed, patients need rest when the physical condition is exhausted by extreme physical activity. However, in very few cases this condition applies. Physical labor refers to physical exercise, which has a positive impact not just in physical health but on the mind. One aspect that physical labor positively impacts is the ability to "keep the power of the will awake" (p. 515), becoming physically activities, partly with activity in a mental exercise. Therefore, exercise and movement have important benefits to overcome disease both physically and mentally.

\section{Preparing People to be Perfect Before God}

Ellen White states, "All should be conducted in strict accordance with the principles and humble spirit of the third angel's message" (Ellen G. White, 1992b, p. 516). Indeed, the term is based on the biblical reference in Revelation 14:9 (NKJV) which says:

9 Then a third angel followed them, saying with a loud voice, "If anyone worships the beast and his image, and receives his mark on his forehead or on his hand, 10 he himself shall also drink of the wine of the wrath of God, which is poured out full strength into the cup of His indignation. He shall be tormented with fire and brimstone in the presence of the holy angels and in the presence of the Lamb. 11 And the smoke of their torment ascends forever and 
ever; and they have no rest day or night, who worship the beast and his image, and whoever receives the mark of his name."

But what does the Third Angel's message have to do with health? Based on Ellen White's writings, Fielder (2012) concludes that the third angel's message refers to the medical missionary work that prepares all people for the sealing time. White, in Testimonies Vol. 3, confirms this by stating that "the institution is designed of God to be one of the greatest aids in preparing a people to be perfect before God" (White, 1992b, p. 166) . The relation presented is that health has an impact on spirituality. She asserted: "It should ever be kept prominent that the great object to be attained through this channel is not only health, but perfection, and the spirit of holiness, which cannot be attained with diseased bodies and minds" (Ellen G. White, 1992b, p. 512).

\section{Prayer Combined with Treatment and Obedience to the Laws of Health}

One principle that is identified widely as a faith-related activity in healthcare is prayer. Indeed Ellen White, speaks about the power of prayer. However, she presents the conditional required it needs to be done together with treatment and obedience to laws of health. White declared:

And I also saw that He designed the health reform and Health Institute to prepare the way for the prayer of faith to be fully answered. Faith and good works should go hand in hand in relieving the afflicted among us, and in fitting them to glorify God here and to be saved at the coming of Christ. (Ellen G. White, 1992b, p. 518)

Ellen White promoted in her writings the manner that healthcare institutions should conduct prayer meetings, which should not be for discussion of religious dogmas, but to connect the patients to God. The prayer session should include hospital staff and employees. 


\section{God-Fearing Personnel}

A principle that is linked to other principles is the type of personnel an Adventist Healthcare institution should have since only through the right employees could the other principles be fulfilled. To begin with, how can a physician teach health principles if he or she does not believe them? How could a nurse witness about a faith that she does not profess? How can a counselor pray for a patient when he or she does not practice prayer? The lack of the right people will diminish the impact of important principles.

Ellen White emphasizes the characteristics of the collaborators in this type of institution: believers, Sabbath keepers (Adventist), kind, loving, that always acknowledge God's power in the process of healing and not in their own skill. She even considered that the opening of healthcare institutions should be delayed until the right staff is located:

I saw that a very extensive work could not be accomplished in a short time, as it would not be an easy matter to find physicians whom God could approve and who would work together harmoniously, disinterestedly, and zealously for the good of suffering humanity. (Ellen G. White, 1992b, p. 513)

An important hiring trait that is relevant is disinterest since White highlights the need for employees that are not motivated by money. Nevertheless, she clarifies that employees should be well remunerated.

\section{Therapeutic Interaction with Nature}

Closely related to physical exercise for patients is interactions with nature, which has a direct impact on patient mental health. When people are under the damaging effects of a disease, the negative thoughts and feelings focus on the patient's problems. Having a wholistic approach mental health would affect both the spiritual and physical side. White described: 
I saw there should be connected with the Institute ample grounds, beautified with flowers and planted with vegetables and fruits. Here the feeble could find work, appropriate to their sex and condition, at suitable hours. These grounds should be under the care of an experienced gardener to direct all in a tasteful, orderly manner. (Ellen G. White, 1992b, p. 519)

Nature interaction, considered the second inspired book (Ellen G. White, 1909), could provide mental relief.

\section{Altruistic and Trusting Institutional Model}

Finally, Ellen White widely speaks regarding institutional motivation. "Money is not the great object with its friends and conductors. They conduct it from a conscientious, religious standpoint, aiming to carry out the principles of Bible hygiene" (Ellen G. White, 1992a, p. 165). The institution should not be like the other "worldly" institutions in which the motivation relies on profit.

White declares "that which had been shown me as a place where the suffering sick among us could be helped was one where sacrifice, hospitality, faith, and piety should be the ruling principles"(Ellen G. White, 1992b). The moneymaking drive, in an Adventist institution, should be substituted by altruism and a trusting environment.

\section{Why are the Adventist Governing Principles Relevant Today?}

Are these principles still valid in the $21^{\text {st }}$ century? Could it be that the principles were only applicable to the original Western Health Reform Institute or Battle Creek Institute? Years later when diverse Adventist healthcare institutions were opened, White confirmed repeatedly the principles originally stated in Testimonies 1 and 3: "As our work has extended and institutions have multiplied, God's purpose in their establishment remains the same. The conditions of prosperity are unchanged" (Ellen G. White, 1992c, p. 200). She insisted that the purpose of the institutions continues as presented in 1866 to 
the General Conference. Even though Ellen White passed away in 1915, the continuance resounds. Recently, authors such as Douglass believe that the principles still applied. "The implications of this Rochester vision were broad; the principles set forth are still valid." (1998, p. 10129)

\section{Participants}

My first phase analyzed two early visions of Ellen White to enumerate 12 principles of Adventist healthcare. Phase two was designed to get feedback through faceto-face interview or correspondence from Adventist historians or Adventist scholars in health care to better explain these principles. Their recommendations and observations are reviewed below. The responses from Participant 1 can be seen in Table 6, followed by a narrative explanation of how I used their responses.

\section{Table 6}

\section{Participant 1 Comments and My Responses}

\begin{tabular}{|c|c|}
\hline Observations from Participant & Response \\
\hline $\begin{array}{l}\text { 1. Modify the word "silent" from } \\
\text { principle three since it gives the wrong } \\
\text { connotation. }\end{array}$ & a. Implemented \\
\hline $\begin{array}{l}\text { 2. Operating Institutions of healing are } \\
\text { more than only hospital also } \\
\text { restaurants and food companies. }\end{array}$ & $\begin{array}{l}\text { b. While this statement is true, this study } \\
\text { was delimited to hospitals. I explain } \\
\text { this below. }\end{array}$ \\
\hline $\begin{array}{l}\text { 3. Battle Creek institution was the } \\
\text { original place where the visions were } \\
\text { applied, but more institutions, like } \\
\text { Loma Linda, came later. You should } \\
\text { expand to include advice to these other } \\
\text { institutions. }\end{array}$ & $\begin{array}{l}\text { c. The study was delimited to the original } \\
\text { visions which occurred in } 1863,1865 \text {, } \\
\text { before any established health } \\
\text { institutions. We will refer to later } \\
\text { additions and changes, but they are not } \\
\text { the focus of this study. I discuss this } \\
\text { more below. }\end{array}$ \\
\hline
\end{tabular}


4. Give more emphasis to include natural remedies not only the exercise: Expand on Hydropathical healing, Wholistic healing, Hygienic (More than a bath), Add some subcategories to this principle.

5. Open the scope: Not only using Testimonies for the Church as a reference but the Ministry of Healing since they do connect.

6. The criteria of using "I saw" is limited since inspiration also occurs outside of a vision. d. A revision of the principle is going to be done to present a clearer picture of these related therapeutic elements. e. As stated above, this study was delimited to the original principles. Other additional material after 1865 can be used in a future study, but I am focused here on original visions.

f. EGW comments outside of vision are also taken into consideration. The criteria for identifying "I saw" is separated for classification purposes.

I incorporated many of the observations provided by participant number one. Several suggestions I could not apply because they would take this study beyond the scope of its investigation. My goal was to look at the original principals of Ellen White's vision in 1963 and 1865. While I believe later revelations, writings, and Adventist experiences are crucial to understanding Adventist maturation in health care work, my focus here is to try to stay focused on the original strands of her vision and thinking. For example, health food companies or restaurants could be included in this study as she hints at them in her visions. However, I wanted to trace her original vision primarily to modern Adventist hospital processes and practices and will continue to delimit my interest in hospitals and recommend further studies for the other institutions.

In the same manner, opening the scope of data collection to determine original Adventist health principles to post- 1865 institutions and EGW counsel to these would also go beyond the purpose of this study. I desired to isolate original values and then jump to modern Adventist practices to see the connection. The purpose was not to do a 
long historical study of the development of these principles over time, but to focus on the original vision that EGW received even before the beginning of the Western Health Reform Institute as presented in the discussion section in Chapter 3.

There are many natural remedies included in the original visions, and I have referred to these. Ellen White also emphasizes exercise in a special way in this original vision, which is why I gave more emphasis to it. However, I will follow Participant 1's concern to keep these multiple natural remedies evident in my review process. I will, however, stay delimited to the original list despite the addition to later material because my study is delimited to the application of these original vision components to later Adventist health care practices. In the discussion chapter, a reference will be included to Ministry of Healing and the comparison with Testimonies for the Church Vol $1 \& 3$ to identify discrepancies related to these principles.

Participant 1 raised concerns about not using other aspects of Ellen White's inspiration other than those connected to "vision" wording ("I was shown" and "I saw" etc.). Once again, I am delimiting my focus on comparing original vision statements to current Adventist practices without focusing on the intervening statements. In my discussion chapter, I will discuss this and make it a recommendation for further studies.

The responses from Participant 2 can be seen in Table 7, followed by a narrative explanation of the comments and responses. Thanks to the feedback of participant 2, I realized how the wrong impression was given in the selection of words used. The proposed Principle 8 implied that only the medical ministry prepares people for the sealing time, which was not the intention. The observation definitely is being 
implemented in its totality, representing that the medical ministry is only an "arm" or aid to the whole body of ministries and mission.

The responses from Participant 3 can be seen in Table 8, again followed by a narrative explanation of the comments and responses. 
Table 7

Participant 2 Comments and My Responses

Observations from Participant

a. "In general, I think you have done very well in identifying essential principles for Adventist health care.

b. I was glad to see that \#1 includes the eight remedies of MH 127 and elsewhere. That is the core, and if Adventists, in general, were careful to follow them and would study to be true to their deeper implications, that alone would greatly improve our health. The concept that disease is the result of broken health laws is crucial.

c. The only place I would disagree with your conclusions (if I understand what you are saying) is in \#8, in the paragraph at the top of page 6 . Here is the crucial part:

"Based on Ellen White writings, Fielder (2012) concludes that the third angel's message refers to the medical missionary work that prepares all people for the sealing time." This is not exactly right. I would say that White, in Testimonies, vol. 3, does not "confirm this" but corrects it by stating that "the [medical] institution is designed of God to be one of the greatest aids in preparing a people to be perfect before God" (White, 2010c, p. 166). [Notice that the health message is an "aid" to the message; it may even be considered an essential part of the message, but the health message is not in itself the whole message].

To make Fielder's statement true, you should change it to read: "the third angel's message refers to and includes the medical missionary work that prepares all people for the sealing time."

\section{Response}

a. I accepted this as confirmation.

b. Participant 2, opposite to Participant 1, noticed the eight remedies were included This confirmed my need to include them in the focus group and this study.

c. This was a very helpful nuance of this point, and I will be careful to make these distinctions as I go into phase 3 of the study. 
Table 7-Continued

Observations from Participant

Response

Ellen White rebuked Dr. John Harvey Kellogg for precisely this error. Kellogg viewed health reform, not as the "right arm" of the Adventist message, but as the very essence of that message, hence his term, "the Gospel of Health." In contrast, Ellen White viewed health reform as an important aid to worshipping God with all the mind, body and strength, while, with Paul (Rom 14:17; 1 Cor 8:8), she denied that health reform constituted the essence of the gospel. Thus, Kellogg and White had fundamentally different conceptions of the relation of health to the gospel.

In this context, Ellen White wrote:

"The work for the poorer classes has no limit. It can never be gotten through with, and it must be treated as a part of the great whole. To give our first attention to this work, while there are vast portions of the Lord's vineyard open to [cultivation] and yet untouched, is, to begin with, the wrong place. As the right arm is to the body, so is the medical missionary work to the third angel's message. But the right arm is not to become the whole body. The work of seeking the outcasts is important, but it is not to become the great burden of our mission" (White, 1899).

d. I believe you are absolutely right that "health has an impact on spirituality," and as you quoted from Ellen White, "It should ever be kept prominent that the great object to be attained through this channel [the health message and medical missionary work] is not only health, but perfection, and the spirit of holiness, which cannot be attained with diseased bodies and minds. (White, 2011, p. 512). But we must be clear that the "right arm" is not the whole body. The salvation message and the health message must be combined [participant emphasis] to achieve the needed result of holiness and sanctification.

e. As I stated at the outset, I think you have done very well in identifying the most prominent principles of Ellen White's health message."

d. I accepted this as confirmation.

e. I accepted this as confirmation. 
Table 8

Participant 3 Comments and My Responses

Observations from Participant

a. "I have read through your twelve principles and think you have correctly and concisely summarized Ellen White's counsel for health care institutions of her day which apply to the Adventist health care industry today. I have two suggestions.

b. First, when you send this to the health care leaders show the biblical basis for Ellen White's counsel. She always had scriptural principles in mind as she wrote. I'm sure you will cover this in the dissertation, but it would be insightful and helpful for these leaders to see the biblical basis for Ellen White's counsel on the health care industry.

c. Second, the only principle I questioned was the wording of number 8: "Preparing people to be perfect before God." Without the context of what White meant, one could read different ideas into this statement; therefore, it needs explanation. My view is that she did not mean sinless perfection but perfection in the Wesleyan sense - complete surrender and perfect love to God, which is the "spirit of holiness." The Adventist health care leaders will most likely not notice this theological nuance. This discussion, of course, is best unfolded in the dissertation. For this point I would suggest wording it perhaps. "Preparing people to be holy before God" or "Preparing people to be whole [or complete] before God." These possible wordings will avoid controversy and still get to the point I believe Ellen White had in mind regarding the intimate connection between good health and spirituality. If you use the phrase in her statement "perfect before God" then you should explain her meaning."
Response

a. I accepted this as confirmation.

b. I will revise the Testimonies for the church to revise the biblical references.

c. Seconding participant 2, Participant 3 , also observed areas to be addressed in Principle number 8. Both observations will be followed as described. 
Regarding the observation done by participant 3 refers to the concept of perfection. The proposed title for principle 8 was "preparing people to be perfect." This section was observed to be bias and objective since only historians would understand the Wesleyan concept of perfection. Using the original phrase used by EGW would require further explanation. Therefore, the wording is being changed to be used as "Preparing people to be whole [or complete] before God," as the participant suggested. Following the modified principles after the expert's opinion are the following:

\section{Principles Adjustment After Historian's Input}

After concluding analyzing the feedback from the Adventist historians, I revised the 12 principles presented in pages 67 to 75 , the revision led to having two principles, 3 and 8 , adjusted from the documental analysis, for better understanding. On table 9, I listed how the principles were adjusted to better wording in order to improve understanding.

\section{Table 8}

Principles adjusted after Adventist Historian's input

\section{Document derived Principles} (Page number)

1. Health education and preventive medicine. (p. 67)

2. Healthcare for SDA members (p. 68)

3. Silent witnessing to non-believer patients (p. 69)

4. Sustain financial and administration model despite attention to all social classes (p. 70)

5. Unwavering Biblical principles (p. 71)
Principle Adjustment after Adventist Historian's feedback

No adjustment required

No adjustment required

Discreet witnessing to non-believing patients

No adjustment required No adjustment required 
6. Wholistic perspective (p. 71)

7. Exercise as part of treatment (p. 72)

8. Preparing people to be perfect before God (p. 72)

9. Prayer combined with treatment and obedience to the laws of health (p. 73)

10. God-fearing personnel (p. 74)

11. Therapeutic nature interaction (p. 74)

12. An altruistic and trusting institutional model (p. 75)
No adjustment required

No adjustment required

Preparing people to be holy before God

No adjustment required

No adjustment required

No adjustment required

No adjustment required 


\section{CHAPTER 5}

\section{RESULTS FROM FOCUS GROUPS}

\section{Introduction}

In my first phase, I analyzed early visions of Ellen White to enumerate twelve principles of Adventist healthcare. Additionally, I got feedback from face-to-face interview and electronic mail from Adventist historians to confirm the integral recollection of these principles. In the second phase, I requested $21^{\text {st }}$ century's leaders of Adventist hospitals to evaluate and share their perspective on the applicability of the principles derived in phase one, in a $21^{\text {st }}$ century's hospital practice. The method I used was focus group with Adventist participants from around the world. As explained in chapter one, the focus group took place at an international conference where leaders of several Adventist hospitals were present. I conducted the four focus groups.

\section{Qualitative Results}

The focus group session was divided into two parts. The first part, besides the introduction and presentation of each participant, was an open question of "What makes an Adventist hospital Adventist? The second section the participants received the title and one quote of the twelve principles for them to give an opinion if this particular case was still applicable. 


\section{What Makes Adventist Hospitals Adventist?}

As presented in Table 4 and following the "Objective 1: Identify the perception that Adventist healthcare leaders have regarding what are the governing principles: (What makes Adventist Hospital Adventist?)" described in chapter 3, the participants provided spontaneous responses. Once a response was given, I noticed that the other participants would avoid repeating the same answer. In some cases, the participants expanded or became more specific on previous answers but not repeat the answer exactly as per se.

After listing the diverse responses, I grouped the answers into themes. Then it was evident that the answers that were mentioned the most were three:

1. Wholistic (Body, mind, and soul) perspective.

2. Health Education and preventive medicine.

3. Spiritual \& religious integration with medical practice.

Other responses, that were less frequently mentioned and that I linked to a particular principle of the twelve principles mentioned in Chapter 4, were:

1. Prayer combined with treatment and obedience to laws of health (Mostly mentioned as only prayer or morning devotional)

2. Altruistic and trusting institutional model

3. God-fearing personnel

4. Prepare people to be holy before God (The actual phrases were: Medical Evangelism and Salvation of patients as an aim)

\section{Perceptions That Were Indirectly Linked to $19^{\text {th }}$ - Century Ellen White's Principles}

Other responses that were less commented and that I could indirectly link to EGW $19^{\text {th }}$ century's principles were: 
Table 9

Participant's Responses and Their Link to Principles

\begin{tabular}{ll}
\multicolumn{1}{c}{ Participant Responses } & \multicolumn{1}{c}{ Principle indirectly linked } \\
\hline Emphasis on community impact & Health education and preventive medicine \\
Personnel with empathy and compassion & God-fearing personnel \\
Sabbath-keeping & Unwavering biblical principles \\
$\begin{array}{l}\text { Avoids non-biblical procedures such as } \\
\text { abortion }\end{array}$ & Unwavering biblical principles \\
$\begin{array}{ll}\text { Conducts Worship or devotionals with } \\
\text { patients or/and staff }\end{array}$ & $\begin{array}{l}\text { Prayer combined with treatment and } \\
\text { obedience to the laws of health }\end{array}$ \\
Offers chaplaincy services & $\begin{array}{l}\text { Wholistic (body, mind, and soul) } \\
\text { perspective }\end{array}$ \\
SDA mission & Unwavering biblical principles
\end{tabular}

\section{Perceptions Not Linked to a $19^{\text {th }}$-Century Ellen White Principle}

The Objective 2 aimed to "Identify if the participants perceive the governing principle list as absolute or if they provided additional EGW's principles not identified in Stage 1". Two responses, that were not directly or indirectly linked to any of Ellen White's $19^{\text {th }}$-century principles, were, “Ownership and control by SDA church” and "Experience."

\section{Do the Principles Presented Still Apply in a $21^{\text {st }}$ - Century SDA Hospital?}

After the first question, I passed around the room a document to each participant (Appendix D: Principles distributed to focus group participant). At that moment of the 
session, I explained the stages of this research study. Since I did not want to influence the participants, I had not mentioned details about the twelve principles before this time.

In line with the objectives three, four, and five and explained in chapter 3 , the principles were discussed to identify if they were accepted or rejected as being applicable in current hospital practice. If any of the principles were considered as applicable, the participants had to mention if they had seen it implemented or if they perceived any challenge or complication that leaders might face in applying such principles in $21^{\text {st }}$ century Adventist Hospitals. The analysis of applicability was done following the list of principles presented. If any of the responses in the first question, what makes Adventist hospitals Adventist? was linked to a principle, I considered that particular principle was already applicable since at least one participant had already identified the particular characteristic as already in use for a $21^{\text {st }}$-century hospital. My intention was not to statistically tally a particular principle but assess if any of the participants around the world believed that a particular principle still applied.

Table 10 presents a summary of the responses from all four focus groups. In the first column, I listed the twelve principles described in detail in chapter 4. On the vertical side, column two refers to those principles that directly or indirectly referred to the answer to question one: What makes Adventist hospitals Adventist? The third column shows those principles that were mentioned by at least a participant as still applicable. The fourth column identifies the principles that were labeled as challenging in the application. Column five marks those that were not considered applicable. The following column marks those principles that were considered as not applicable by at least one 
participant. And finally, column seven comments on proposed modifications to the term or the grouping of the principle.

I am presenting each of these principles and discussing in detail what I perceived from the group interactions (refer to Table 10.) They are not presented in order of importance but simply in the order that appeared on the document distributed to the focus group participants.

1. Health education and preventive medicine

Health education and preventive medicine were easily agreed upon as still applying. From the previous focus group section, "What makes Adventist Hospitals Adventist?", I concluded that health education and preventive medicine is considered by several people as a basic principle for Adventist Healthcare, and it was very well recognized among the participants. However, this concept is not unique to Adventist Healthcare. This can be seen by responses such as "It does [apply] but is not only for our hospital; there are other hospitals that are doing the same. Even the government is doing something with preventive medicine". [Explanation and emphasis added].

\section{Healthcare for SDA members}

Healthcare for SDA members was widely discussed in the focus groups. While the participants mentioned that the principle still applies and that currently is applied in some Adventist hospitals, it was labeled as one principle that is complicated to implement. I perceived this with responses such as: “We don't really know how to identify them [SDAs]," "It's difficult to have financial sustainability when you lower your prices so that every Adventist member can have access"; “... we fail to realize that when they [SDA members] get sick and they come back [to] the very same hospital 
Table 10

Summary of Focus Groups Responses

\begin{tabular}{|c|c|c|c|c|c|c|}
\hline Principles & $\begin{array}{c}\text { SDA } \\
\text { hospital } \\
\text { is: }\end{array}$ & Apply & $\begin{array}{l}\text { Challenges } \\
\text { in applying }\end{array}$ & $\begin{array}{l}\text { Applies } \\
\text { in some } \\
\text { places }\end{array}$ & $\begin{array}{c}\text { Do } \\
\text { not } \\
\text { apply }\end{array}$ & $\begin{array}{c}\text { Propose } \\
\text { Modification } \\
\text { of principle }\end{array}$ \\
\hline $\begin{array}{l}\text { 1. Health education } \\
\text { and preventive } \\
\text { medicine }\end{array}$ & $\mathbf{X}$ & $\mathbf{X}$ & & & & \\
\hline $\begin{array}{l}\text { 2. Healthcare for } \\
\text { SDA members }\end{array}$ & & $\mathbf{X}$ & $\mathbf{X}$ & & & \\
\hline $\begin{array}{l}\text { 3. Indirect witnessing } \\
\text { to non-believer } \\
\text { patients }\end{array}$ & $\mathbf{X}$ & $\mathbf{X}$ & & & & $\begin{array}{l}\text { Revise with } \\
\quad \# 5,9\end{array}$ \\
\hline $\begin{array}{l}\text { 4. Sustain financial } \\
\text { and administration } \\
\text { model despite } \\
\text { attention to all social } \\
\text { classes }\end{array}$ & & $\mathbf{X}$ & $\mathbf{X}$ & & & $\begin{array}{l}\text { Revise with } \\
\quad \# 12\end{array}$ \\
\hline $\begin{array}{l}\text { 5. Unwavering } \\
\text { biblical principles }\end{array}$ & & $\mathbf{X}$ & & & & Revise with \# \\
\hline $\begin{array}{l}\text { 6. Wholistic (body, } \\
\text { mind, and soul) } \\
\text { perspective }\end{array}$ & $\mathbf{X}$ & $\mathbf{X}$ & & & & \\
\hline $\begin{array}{l}\text { 7. Exercise as part of } \\
\text { treatment }\end{array}$ & & $\mathbf{X}$ & $\mathbf{X}$ & & $\mathbf{X}$ & $\begin{array}{l}\text { Use term } \\
\text { Physical } \\
\text { activity }\end{array}$ \\
\hline $\begin{array}{l}\text { 8. Preparing people } \\
\text { to be holy before } \\
\text { God }\end{array}$ & & $\mathbf{X}$ & & & $\mathbf{X}$ & \\
\hline $\begin{array}{l}\text { 9. Prayer combined } \\
\text { with treatment and } \\
\text { obedience to the laws } \\
\text { of health }\end{array}$ & $\mathbf{X}$ & $\mathbf{X}$ & $\mathbf{X}$ & & & \\
\hline $\begin{array}{l}\text { 10. God-fearing } \\
\text { personnel }\end{array}$ & $\mathbf{X}$ & $\mathbf{X}$ & $\mathbf{X}$ & $\mathbf{X}$ & & \\
\hline $\begin{array}{l}\text { 11. Therapeutic } \\
\text { Nature interaction }\end{array}$ & & $\mathbf{X}$ & $\mathbf{X}$ & & & \\
\hline $\begin{array}{l}\text { 12. Altruistic and } \\
\text { trusting institutional } \\
\text { model }\end{array}$ & $\mathbf{X}$ & $\mathbf{X}$ & $\mathbf{X}$ & & & \\
\hline 13. All of the above & & $\mathbf{X}$ & $\mathbf{X}$ & & & \\
\hline
\end{tabular}


and the comment is "I can't afford it." Hence difficulties of identification of members, sustainability challenges if prices are lowered and that some church members cannot afford to cover the fees of a private Adventist hospital.

The definition of "healthcare for SDA members" was also discussed regarding what is the real meaning of it. Some participants provided examples of how their institutions used to offer discounts for SDA members, insurance programs for SDA's members, or even preference membership cards, but these examples were criticized by other participants since EGW was not talking about discounts but for Adventist to have access to Adventist Hospitals. A participant explained:

It is not about discounts for Adventist or preferential treatment for Adventist, but she $[E G W]$ is saying that we should have facilities that instead of going, to, I use the term Babylon, Babylonian institutions to spend the money they can get the help from our institutions. In other words, SDA healthcare is available for our church member.

Another participant, in a different group, expressed how the original intent of Ellen White was due to the way healthcare was handled in her time, but that currently may be different since in general, healthcare is now respectful of the patient's religious beliefs. His response was "I think Adventist in --- [name of country] would be pretty comfortable about every mission hospital because they going to respect their beliefs. They aren't gonna make fun of them." The name of the country was removed to protect privacy.

Other participant perceived that the same church, through its unions and conferences, could do more, to the extent to even "budget to support our members who are unable to go to our institutions. Just subsidize it!". Other person believed that unions should make compulsory that all employees from Adventist institutions be attended in Adventist hospitals, if available since in some countries, not even Adventist denominational employees get attended in Adventist hospitals because of choice not due to finances. 
Some participants from diverse countries expressed their frustration on how SDA members behave as being entitled to special privileges since they belong to the same religious organization as the hospital. Some examples were given on how Adventist patients tend to request a financial discount or even expect not to pay at all. This comment was given by a couple of participants from countries identified as low-income countries by the World Bank (https://blogs.worldbank.org/opendata/new-countryclassifications-income-level-2018-2019). In the same line, some participants expressed their perception of how some Adventist patients are more demanding of an Adventist hospital than other non-Adventist healthcare systems. Overall, the discussion included how in most institutions represented by the participants, Adventist patients were a minority with the main cause being financial accessibility.

\section{Indirect witnessing to non-believer patients}

Similarly, to principle number one, Health Education and Preventive Medicine, Indirect Witnessing to Non-Believes Patients was easily agreed as Still Applies. In the same way as principle 1 was included in the responses of first section of the focus group with the open question: "What makes Adventist Hospitals, Adventist?".

However, it was unclear what includes in "witnessing." I noticed this when a participant expressed that prayer (Which is included in principle nine) was part of witnessing. He said: "So, how do you define prayer and witnessing, especially in this context. Because to me it could be the same thing".

For other participants, indirect witness constituted Sabbath-keeping. Indeed, a hospital would not stop its operations on Sabbath, but non-essential services such as administration and outpatient department as well as elective procedures would close in 
several of the hospitals that were represented in the focus groups. With this action, patients would learn indirectly about the Sabbath and its practical applications. However, for some high-income countries, where insurance companies are a key player in the healthcare system, performing non-essential work on Sabbath was something done even against their wishes since for some it is impossible to operate without following the insurance companies demands.

4. Sustainable financial and administration model despite attention to all social classes

As in the previous principles, principle four was considered as Still Applies. Interestingly, participants were clearly influenced by the country and financial setting of their institution. Those participants that come from low-income countries expressed how their hospital, which they often referred to as "mission hospital" attends to all, especially people with little or no resources. Some medical doctors' participants from such institutions expressed how they don't mind the finances, since their main focus is on the patients' wellbeing, and even proceed with the needed urgent treatment regardless of payment confirmation.

However, most participants expressed how financial sustainability is needed. Many participants commented on the challenges of applying this principle. I noticed this in comments such as: "Still applying this principle, but it continues to be a challenge. Because we do not continue receiving any support." This participant was not alone since even other participant mentioned:

"But we want, at the same time, to reach the poor. And we need to face the competition, and that makes a great challenge. And we really need the presence of God in our institution. Because that is a challenge right now." 
A participant expressed how they expect financial support from the Adventist church system for operation: "Because we do not continue receiving any support. For example, in our medical system, we do not receive any financial support from the organization, the union, or division." Another participant mentioned:

"It's difficult to have financial sustainability when you lower your prices so that every Adventist member can have access. Currently, we have this dilemma even how can you solve this because most of our people are going to government hospitals because they are free and yet our institutions we have to support ourselves even if you say you are a non-profit organization you still have to make enough to have your operations go on."

Few mentioned how, in their setting, they have managed to attend the poor and make a profit. Some participants said: "Charging very least but pricing at par for anybody who was above multi-bed criteria...You are mission hospital still.” Another participant mentioned how the same personnel is the one supporting those that cannot afford care:

"In our hospital, we have a donation box. Where doctors and nurses and workers and even people who come in there donate towards assistance for those who. . . because sometimes when they are discharged, they cannot pay to stay there. So, money is taken from that donation box to pay for some of those.

5. Unwavering biblical principles

Regarding principle five, there was not much discussion since it is one principle that is considered straight forward and applicable. This can be seen in comments such as

"I like five and six. I mean five and six, we use more than we apply four. Because in a lot of cases, we try to stick to the Principles of the bible, and we try to do wholistic. . . So, I think as in [Chapter] 5 and 6, we apply and its quite... it's still applicable today."

However, I perceived an oversimplification of this principle, since it appears so obvious and straight forward, but it is deep in content. Practically all what Adventist believed is linked to this principle since Adventist claim to have all fundamental beliefs 
derived from the Bible. No participant linked this principle to any of the comments referred to bible beliefs such as Sabbath-keeping, prayer, etc.

6. Wholistic (body, mind, and soul) perspective

Similarly, to principle one and three, Wholistic perspective was not discussed much since it was mentioned in the first section of "What makes Adventist Hospitals, Adventist?", hence it definitely was considered by participants as Still Applying to these principles

1. Exercise as part of treatment

In respect to principle seven, exercise as part of treatment, participants expressed how this principle is Still Applicable. Throughout the conversation, it was evident the perception that some participants got that "exercise also (is a) form of prevention." Several participants shared how they implement this principle with comments such as "in the rehab, we do explain to them [patients] about the importance of exercise." Or even "We teach that as lifestyle medicine to our patients."

However, this was not exactly the original intent of the principles expressed in EGW's writings described in chapter IV. The list of principles distributed to the participants included an EGW's quote explaining that "the sick should be taught that it is wrong to suspend all physical labor to regain health" (White, 201, p. 513). Hence, exercise was meant to be part of treatment during the stay in the health institution, and as far as the condition of the patient makes it possible. When this was explained to the participants in group four, still one of them reacted by saying that it "is difficult to implement exercise in a hospital setting based on their condition. Some may get out of bed, and you could have the nurse go around a little bit." 
One participant suggested for the need of a better word instead of "exercise" while expressing: "But I don't think exercise is the right word." And then the participant expanded on the observation by adding:

Because when people... when they [patients] hear exercise in today's world, they'll think of a gym. And about weights, I'll better do that. I don't use the word exercise to patients. I don't say exercise. I just say walk. You can walk half as many blocks as you want. And then afterward, you step it up. After six weeks, you increase it walking to increase your heartbeat to half an hour. They say, "Oh I can do that." But for them exercise means come and join a gym.

Then another participant in the focus group assisted by providing an option "Maybe physical activity." Several participants were positive of such suggestion by nodding their head and expressing accepting expressions such as "right!".

Hence, while all participants commented on these principles agreed that these principles still apply. Some perceived challenges in today's hospital settings, while others suggested a better word for exercise could be used in today's world.

8. Preparing people to be holy before God

Principle eight, preparing people to be holy before God, was one (if not the most) controversial principle. The reactions varied and were identified in three groups. First, those that perceived that the principle was not applicable since they had a hard time grasping the concept being implemented in a $21^{\text {st }}$ century hospital. This can be seen in comments such as: "is not ethical to do it with a captive audience," or even "is the wrong time." One participant bluntly said that principle eight "is not applicable" in the $21^{\text {st }}$ century.

The second group was not sure about the principle but were skeptical or having a difficult time conceptualizing the implementation. This can be seen in comments such as: 
"That is a hard one for me," "Preparing people to be holy before God" not sure how much we really believe that...", "But you have to be aware of how you perform the statement. I can't take you by the collar and tell you to love Christ."

However, the third group of participants perceived it fundamental or even obvious for an Adventist institution, in comments such as "...that is the role of the healthcare system." The same participant expanded on the point raised:

This is not only health but perfection. This is deep. We also need to deal with [church] members. But basically, here is more of educating the members knowing that disease bodies and minds would not attain perfection. So, people need to know the same natural remedies, understand them, and live them. But you need to understand them properly and scientifically. And somebody needs to teach this properly. Because again if they are not taught properly, they are extremes [cases] that we treat people. Like I treat a lot of Adventist's who become vegetarian, not understanding clearly why. They do have B-12 deficiencies and nerves problems. And so, you need to understand this balance. And that is why a health professional needs to come in.

Another participant leaning positively and in a different focus group expressed, that Principle 8:

Still applies. It is one of the reasons why we would stand out as a Christian institution. But I think in some areas you have restrictions in government, policies, and laws that limit it...

And also, perhaps the number 8: "Preparing people to be holy before God". We were hearing the issue of conducting some worship and doing some devotions and praying for the patients. I do pray with my patients before the operation.

Preparing people to be holy before God was also linked to principle number nine, prayer by this participant. In summary, principle eight is controversial since every person draws their own conclusions on what it means in practice, making it harder to have consensus. The diverse opinions extend to both sides of the spectrum: Either totally agreeing or rejecting it. 
Given the wide-ranging responses, several possibilities emerge for this principles. First, the principle may need to be defined differently, either more generally or more tangibly. Better doctrinal wording could assist on defining the concept in clearer words. Ideally, Adventist leaders should read the original Ellen G. White's writings to get better understanding and background. However, the principle sentence should be clear in such a way that an unambiguous statement be produce. The original word used was "perfect before God", the Adventist historians recommended to modify to other wording such as "holy" or "complete". Following such recommendation, I used "holy" for the focus group, but I gathered after the focus groups that both words, "perfect" and "holy" were ambiguous since some perceived that sinners could not ever be "perfect" or "holy". I believe that words such as "complete" or "whole" could be more accepting.

9. Prayer combined with treatment and obedience to the laws of health

Principle 9, Prayer combined with treatment and obedience to the laws of health, did not have much discussion since was one of the principles mentioned by the participants even before the principles were presented. Therefore, prayer is taken for granted. This can be perceived in comments such as "Obviously, every Adventist surgeon does that" while referring to prayer. A more conscious explanation of this as a matter-offact principle

"Before I put my patients to sleep, I am sure, it is not because of habit. I feel in my heart I have to do it. I need my Lord to be with me. So, I pray. So, after the patient is already ok. Before going home, I pray with my patient..."

Hence this principle not only still applies but also is being implemented, in diverse ways in Adventist hospitals. However, none of the participants mentioned the 
second emphasis on the principle, which is the condition implied: "obedience to the laws of health" as a two-step treatment.

\section{God-fearing personnel}

The second most controversial principle and the number one most discussed, was principle number ten, God-fearing personnel. In almost all focus groups, this principle was labeled as Still Applicable. However, the challenge was the implementation part. In all groups, at the beginning of the discussion, God-fearing personnel was automatically linked to be a member of the Adventist church. However, in two focus groups, after advancing in the discussion, a participant brought up the concept that "God-fearing" does not equal a member of the Adventist church.

Even some participants followed up the comment sharing personal experiences in which non-Adventist personnel were apparently more attached to Adventist principles than some Adventist coworkers. This can be seen in comments such as: "Frankly some of them [non-Adventist personnel] take it more seriously than our Adventists do and other's very jealously but still different. There is no question is still different." or "Because sometimes you get better God-fearing workers that are non-Adventist."

However, in both instances, the discussion was led to how to identify a "Godfearing" person objectively. This can be seen in comments such as: "But how do you know someone is God-fearing? In the interview: 'Are you God-fearing?'. Of course, they'll say yes. Do you want the job? So how do you know it?" "Everybody, I suppose would say, oh yeah, I'm God-fearing, but how do you know that is what you expect?"

Some hospitals have a minimum percentage of Adventist even though some participants wished to have $100 \%$ Adventist personnel but, in some instances, it was not 
possible. One of the reasons given was the lack of Adventist specialist. This can be seen in a comment such as "That is the trick. Even in the workers, we find that some of the skills we are looking for we don't find them within our community. So, sometimes it is necessary to bring them from outside.” Another participant concours with the idea by expressing the lack of available human resources:

"We don't have enough depth of talented seat weed of material. So that isn't a rule anymore. Just the CEO. In where I am, most of our CFO, actually, all of our CFOs are Adventist in the Adventist hospitals. But the CNOs, CMOs are not. The $\mathrm{COO}$, if we have them.

Another reason expressed for not being able to have all Adventist personnel was the labor laws and legal regulations of specific countries. This can be seen in comments such as: "Once you go outside saying that you are not going to hire an Adventist, you don't ... legalities, so basically they have to align into our mission." Even during interviews, the legalities impact:

Because if you read the statement, it is almost as if you are making church membership criteria for employment. And I think in our last workshop on human resources we were taught things that you should never ask during an employment interview and one of them is What religion are you?

While discussing implementation, some of the participants shared what they do to address the challenge of the low percentage of Adventist staff: Providing training and committing the staff to observe Adventist principles. "We ask them to abide by the principles of Adventism even if they don't believe in that." Another participant shared that at least they look for personnel with minimum religious background:

It says, "God-fearing personnel.” Even when you are not an Adventist working in our hospital. We want just that he [the physician] does [fear God], orientate you so that you be acquainted with Adventist Principles. We want you to have at least respect for God, even if you are not an Adventist. You should have that respect for God [to work in an Adventist organization]. We let them know that working in [an SDA] environment you have to know [about Adventist principles]. 
However, in some hospitals, this is not done. A participant shared how they have no process to ensure that at least they hire Christian personnel since "They [the nonAdventist personnel] buy into the mission even though... whatever [religion] they are."

For some, this was ideal; however, one particular participant considered that was needed to have non-Adventist personnel from in an evangelistic point of view:

"We can't find all 100\% Adventist to work in an Adventist institution. If we did that, we would not be able to share the message, because I can't tell you about Adventist because you are Adventist, right? We all in the same faith and we don't do anything when we come to work then we're not sharing anything."

Some participants highlighted the concept that for God-fearing personnel to strive, the environment and the institution also played a role. This can be seen in comments such as: "We try to make sure we still maintain an ambiance that conforms with the spirit of our religion." Another participant expressed how the spiritual environment of the hospital promotes having God-fearing personnel:

"We have devotions in the morning. We remind people constantly that they should focus on the patient and show Christ to the patient and then we have during the year we have several weeks of prayer or where you concentrate on your personnel so that they keep focus, you know on God."

Therefore, even though most participants mentioned that this principle still applies it was concluded that "...it is difficult to apply." In the follow up, "Yes. Because how do you a) screen the people, and b) enforce it. If somebody develops unchristian-like habits after two years of employment." One concluded that "what we can say in number ten then applies to different situations". 
11. Therapeutic interaction with nature

Another principle that was widely discussed was principle eleven, therapeutic

nature interaction. While this principle was identified as Still Applies, with comments such as "I hold on to it," "It would be ideal," and "Still applies. It does."

However, several participants acknowledged that this interaction with nature as therapy is not widely practiced in Adventist hospitals. This can be seen in comments such as: "most hospitals don't have" it. Or "I'd like to mention that number eleven should still be applicable, but it does not happen in many places, and our hospital is surrounded with flowers, beautiful flowers, and good landscaping..."

Several participants considered a challenge to implement such a principle in a $21^{\text {st }}$ hospital setting with comments such as: "But this is a difficult thing to ask to some of the hospitals. Because you are in an environment where you want to compete, but you are forced to compete."; "So I'm looking at it beyond the hospital." "I think this one wouldn’t really apply specifically to a modern western in-patient hospital."

One particular participant expanded on the reasoning behind being reluctant with these principles:

And even number eleven. If you look at the statement here, mmm, it says: "Yet the feeble could find work appropriate to the sex and condition at suitable hours." In other words, the implication is that...We should make our patients garden. You see. In modern medicine now, at least in my experience, you admit a patient who is very sick. So, now if you are admitting a patient who is very sick, the exercise program that the patient undertakes usually is a controlled environment with a physical therapist. Now, I wonder how that would suit well in [Name of the hospital] if my inpatients are appointed to do gardening and say "go and work" ...

By this participant comment, I recognized how some participants identified principle eleven and seven (Exercise as part of treatment) as if they are closely intertwined. 
12. Altruistic and trusting institutional model

Concerning principle number twelve, Altruistic and trusting institutional model, several people responded as Still Applies. Even one participant referred to principle number twelve as "our obligation" as an Adventist institution. Another pointed out that the principle "should be real" not only an ideal.

However, another participant expressed the intertwining link with principle number four, (Sustain financial and administration model despite attention to all social classes), since the challenge of having an altruistic model, if not careful, the model can be taken advantage of:

So, you must be very careful because many of the members believe that the church has a hospital for free. But you can't run an institution without money. This is a difficult task. I mean if you come up with what is supposed to be altruistic, you know. Give it to us for free! We want a free appendectomy. That's what you want. But the whole system isn't going to work.

Even another participant also referred to principle four while expressing: "I know we have to maintain the model. Sustain model and sustain the financial part of it". Indeed, this participant believes that the altruistic model should go hand and hand with sustainability.

Further, another commented on the altruistic model and the link to financial sustainability:

So, this probably would be the acts' model, from the book of acts where we sell our riches and take care of the poor and the needed and the people coming to the hospital. But for us to be able to get the resources to sustain this is not the reality. The resources are costly, and we don't know where to find the money.

Indeed, most participants that expressed their opinion considered that this altruistic and trusting model is the system way of being, but some acknowledge the challenges of balancing institutional survival with organizational altruism. 


\section{Triangulation}

After completing a draft of my analysis of focus groups, I sent my transcribed data and my draft of this chapter to a Ph.D. researcher, asking him to review the transcripts first and after the researcher reached the conclusions, compared with my conclusions to provide feedback. While I had my dissertation committee to help with this process, additional triangulation was done to detect any bias I may have brought to the focus group analysis and to improve my presentation of the focus group data. The reviewer used a manual system in which the twelve principles were manually highlighted. The invited researcher responded to two questions:

1, Can you reach the same conclusion based on the transcripts?

2. Did I miss or overemphasize in any areas?

The reviewer sent the following feedback:

After reviewing the transcripts and comparing it with your notes, I agree with your conclusions as to which of the principles of Adventist Hospitals is being practiced. You have fairly and accurately captured the content in your summary.

Please review my highlighted marks to verify that you have those in your list.

As you have already seen in the transcript, it looks like those who you interviewed do not know how to define what is a Seventh-day Adventist hospital. There is also a huge lack of inconsistency in answering the question about how the EGW principles you presented to the groups are being applied in Adventist hospitals today. It seems that they feel the local church or conference should be doing most of them or that what Ellen White's counsel for our hospitals can't be accomplished today because of laws or finances.

Additionally, two experienced Adventist healthcare leaders participated in discussion with me. We sat and reviewed the focus group's transcripts and the handout provided to the focus group participants. The triangulation's participants answered the two questions given to the focus group participant: What makes an Adventist Hospital 
Adventist? And are the EGW's $19^{\text {th }}$-century principles still valid in $21^{\text {st }}$-century hospital's settings. This exercise allowed me to identify a few things that I had underemphasize. The feedback above assisted me in confirming the conclusions described in this chapter.

\section{Summary and Conclusion}

Responses from the focus groups show general and widespread support for these principles as applicable to current Adventist health care delivery. This was especially true for principles on Wholistic, Silent Witnessing or Prayer. However, several principles seemed to be recognized as not universal and not unique to Adventist health care. For example, God-fearing personnel, preparing people to be Holy before God. Finally, a few principles seemed to have less or different application to modern practices such as Therapeutic Nature interaction on having patients do physical work may have been appropriate when hospitals had less acute care requirements.

After having the experience of conducting these four focus groups, I noticed the diversity in opinions on something apparently so basic: a founding principle. However, I remember how, similarly as with DNA, principles are impacted by the interaction with the environment. Indeed, all the participants belonged to an Adventist institution connected to a worldwide system. However, every one of them is located in a geographically, socially, and economically different scenario which has influenced the participant's perceptions on principles (DNA). 


\section{CHAPTER 6}

\section{CONCLUSION}

\section{Introduction}

Change and healthcare are almost synonymous, with healthcare continually responding to new technologies, techniques, research, innovation, and political and governmental reform. Leaders in faith-based institutions face an additional challenge of keeping their core "moral and spiritual commitments" and "integrity" (Iltis, 2003) during these changes. Leadership faces an existential problem. How can they change but remain faithful to their core commitments?

More than 150 years of Seventh-day Adventist healthcare change, in which hospitals have had to undergo rapid adaptation to changing environments, Adventist health care looks a lot different from it did in the late 1800 s, as other organizations have (Cummings \& Worley, 2008). Are there any shared characteristics between its founding values and governing principles and its current practices? What is the core identity or strong anchoring beliefs, values, and practices that make Adventist health care what it is?

\section{Research Questions and Design}

The present study had the following research questions:

Question One: What were the $19^{\text {th }}$-century-governing principles of Adventist Healthcare?

Question Two: How do Adventist historians and experts understand and interpret these Adventist healthcare core commitments? 
Question Three: How do Adventist healthcare leaders and experts believe these governing principles work to define the unique Adventist healthcare's unique Adventist identity?

The methodology I used to address the research questions presented above was a qualitative study with a combination of document analysis and focus group techniques. This study initially had three phases (but the first two phases were merged into one for the final report). In stage 1 (chapter 4), I reviewed Ellen G. White (EGW)'s 1860s writings. EGW, the Seventh-day Adventist church's co-founder, claimed that she received God-given visions on several topics. These messages were recorded in a ninevolume series called Testimonies for the church as well as other books. As a result of her visions, the SDA church in the $19^{\text {th }}$ - century established the first Adventist healthcare facility. Even though EGW wrote extensively about healthcare and healthcare institutions in diverse books and manuscripts, I only focused on volumes one and three of Testimonies for the church, since I was only looking for EGW's first messages regarding the governing principles that the new institution should have.

Between volume 1 and 3, I found the first visions related to healthcare institutions before any Adventist healthcare institution's existence. Additionally, I identified in the same volumes, messages that dated after the first SDA healthcare institution came into existence, but that clarified previous messages EGW provided without adding new principles per se. These clarifications appear to be EGW's attempts to amend already implemented misinterpretations of her first messages. I then solicited expert feedback on my analysis of $19^{\text {th }}$ century Adventist healthcare governing principles. I identified experts using a snowballing technique known as "network or chain sampling" (Bloomberg \& 
Volpe, 2016), from Adventist historians within the Seventh-day Adventist denomination. Three participants agreed to provide feedback; all were university scholar and doctoral holders with several academic publications to EGW's studies or Adventist church history.

For the second stage, I invited Adventist healthcare leaders attending an Adventist healthcare international conference, the 2018's Global Healthcare Conference, to participate in focus groups. I selected English-speaking leaders of Adventist hospitals with at least five years of experience in a leadership position. I invited the participants individually and the participation had no incentive. I held four different focus group sessions, with a total of 26 participants from 13 countries, representing four of the seven continents: North America, South America, Africa, Asia. Five participants were international workers; however, I recorded their origin according to the country their current institution is based. Effort was made to have a representative and diverse group of participants from each Division. The worldwide Adventist Church is divided into thirteen regional offices called divisions and two annexed territories.

Before showing them my conclusions from stage one, I asked their opinion of what makes an Adventist hospital, Adventist. After that, I provided participants a document that contained the principles with brief EGW's quotes (See Appendix D). Then participants were asked to identify if any of the governing principles listed were still valid and useful. The purpose of the exercise was not to create consensus about the principles but to initiate discussion. Some principles were discussed as still applicable, while other participants disagreed that a specific principle was still relevant. I also recorded identified disagreements. 
Besides, I triangulated my analysis. Once I summarized the focus group responses, I sent the transcripts to a Ph.D. researcher to review my transcript, reach a conclusion and posteriorly compar my conclusions and provide feedback over possible omissions or overemphasized areas. Finally, I held a group discussion with two experienced Adventist medical doctors who held the highest leadership position in an Adventist hospital for more than five years. We read the transcripts together and discussed possible conclusions. This exercise assisted me in confirming and adjusting potential misses. While I had my dissertation committee to help with this process, I wanted additional confirmation on my conclusion to help me identify gaps in my analysis.

\section{Summary of Findings}

I distilled twelve governing principles from EGW's early writings. Adventist historians and experts confirmed and made slight changes to my analysis. These 12 principles, with the historian's input and an expanded statement of these can be seen in

Appendix A. A shorter version is located in Appendix D. In short, these 12 principles are:

1: Health Education and Preventive Medicine. Principle 1 calls for institutions to teach patients how the body functions and how to prevent sickness, going beyond only treating disease. The information to be taught is the laws of health referred by EGW in several documents as the "laws of nature." (Ellen G. White, 1909, p. 158)

2: Healthcare for SDA Members: An Adventist healthcare institution was created primarily to attend Adventist members in line with their Adventist beliefs. EGW highlighted that a sick person had weakened moral strength. Only people with extraordinary spiritual strength and constant vigilance could withstand temptations from 
dubious ideologies, hence the importance of being treated in a place where the faith and religious principles aligned with those professed.

3: Indirect Witnessing to Non-Believer Patients: Adventist healthcare institutions also attend non-Adventist patients. The best way to know about principles is to see them in practice, and according to EGW, hospitals were an ideal setting for that. People tend to have prejudgment about the Adventist faith. However, if those "unbelievers" could see the principles in practice, they could get acquainted with them, hence having experienced a "silent influence."

\section{Sustain financial and administration model despite attention to all social}

classes: Ellen White promoted sustainable organizations. She reminded her readers that many healthcare institutions had closed due to financial challenges. Nevertheless, the Adventist Healthcare institution should be for all sorts of patients, including those that do not have the means to cover their expenses. Therefore, institutions should organize funds to be open so that outside money from donations can cover the expenses of people with greater needs. Additionally, Ellen White provided several emphases that Adventist Institutions should grow proportionally to obtain the profile of the right committed personnel needed, and expand its infrastructure.

5. Unwavering biblical principles: At all costs, the aim was to avoid imitating business models focused on money-making enterprises, as non-faith-based hospitals operate. White warned against lowering standards to make the model more palatable for non-believers, to attract paying patients. This has an important impact on the believers, since it presents a fragile conviction that produces a harming influence instead of a positive one. White exalted biblical principles to obtain health recovery. 
6. Wholistic (body, mind, and soul) perspective: Mind, body, and spirit are so intertwined that if any of them are affected, the rest are equally impacted. Therefore, an Adventist institution should promote and practice the wholistic concept of health in every patient.

7. Physical activity as part of treatment: According to White, rest is ideal and required to regain health. However, in line with the principle of wholistic perspective, absolute rest have an significant detrimental effect on the patient's mental health, since there are particular cases in which complete rest applies. Physical labor refers to physical exercise, which has a positive impact not just on the mind and will, but also on physical health.

8. Preparing people to be holy before God: White explains that "the institution is designed of God to be one of the greatest aids in preparing a people to be perfect before God" (White, 2010c, p. 166). The relation presented is that health has a direct impact on spirituality since a person in good health should be able to distinguish God's voice easier.

\section{Prayer combined with treatment and obedience to the laws of health: One} principle that is identified widely as a faith-related activity in healthcare is prayer. Indeed, Ellen White speaks about the power of prayer. However, she presents the conditional requires: it needs to be done together with treatment and obedience to laws of health. In her writings, Ellen White promoted how healthcare institutions should have prayer meetings, which should not be for discussion of religious dogmas, but to connect the patients to God. The prayer session should include hospital staff and employees.

10. God-fearing personnel: Having the right people to promote the Adventist Healthcare model was crucial for White. The expectation is that all staff are spiritually 
mature and to have faith. Since the model is shown by example, using live modeling, the personnel become key to the success of other principles such as health education and preventive medicine.

11. Therapeutic Nature interaction: Treatment should include physical activity through interaction with nature, since it has a direct impact on the mental health of the patient. When people are under the damaging effects of a disease, the negative thoughts and feelings focus on the patient's problems. Mental health would affect both the spiritual and physical side. Nature interaction considered the second inspired book (White, 2010b), which could provide psychological relief.

\section{Altruistic and trusting institutional model: Regarding principle number} twelve, White widely speaks regarding institutional motivation. "Money is not the great object with its friends and conductors. They conduct it from a conscientious, religious standpoint, aiming to carry out the principles of Bible hygiene" (Ellen G. White, 1992a, p. 165). The institution should not be like the other "worldly" institutions in which the motivation relays on profit. White declares "that which had been shown me as a place where the suffering sick among us could be helped was one where sacrifice, hospitality, faith, and piety should be the ruling principles" (Ellen G. White, 1992b).

The focus groups resonated with all twelve principles, but principles were not equally emphasized, nor did all agree on their applicability. Table 11 shows various ways individuals interacted with these 12 principles. Three of the most affirmed principles and considered more applicable were wholistic perspective, health education, and preventive medicine and a generic reference to those principles related to spiritual \& religious integration with medical practice. Most felt these were applied well in their institutions. 
Table 11

Summary of Findings from Focus Group Discussions

\begin{tabular}{|c|c|}
\hline Principles & Application \\
\hline $\begin{array}{l}\text { 1. Health education and preventive } \\
\text { medicine }\end{array}$ & Still applies \\
\hline 2. Healthcare for SDA members & Applies with challenges \\
\hline $\begin{array}{l}\text { 3. Indirect witnessing to non-believer } \\
\text { patients }\end{array}$ & Still applies \\
\hline $\begin{array}{l}\text { 4. Sustain financial and administration } \\
\text { model despite attention to all social classes }\end{array}$ & Applies with challenges \\
\hline 5. Unwavering biblical principles & Still applies \\
\hline $\begin{array}{l}\text { 6. Wholistic (body, mind and soul) } \\
\text { perspective }\end{array}$ & Still applies \\
\hline 7. Exercise as part of treatment & $\begin{array}{l}\text { Divided opinion -Some see as not } \\
\text { applying in } 21^{\text {st }} \text { century's hospital }\end{array}$ \\
\hline 8. Preparing people to be holy before God & $\begin{array}{l}\text { Divided opinion -Some see as not } \\
\text { applying in } 21^{\text {st }} \text { century's hospital }\end{array}$ \\
\hline $\begin{array}{l}\text { 9. Prayer combined with treatment and } \\
\text { obedience to the laws of health }\end{array}$ & Applies with challenges \\
\hline 10. God-fearing personnel & Applies as far regulation allows \\
\hline 11. Therapeutic Nature interaction & Applies with challenges \\
\hline $\begin{array}{l}\text { 12. Altruistic and trusting institutional } \\
\text { model }\end{array}$ & Applies with challenges \\
\hline 13. All of the above & Applies with challenges \\
\hline
\end{tabular}

Two principles did not produce much discussion, indirect witnessing to nonbeliever patients, and unwavering biblical principles. Those principles were considered as still applicable. Seven governing principles were identified as valid and still applicable but led to widespread discussions about challenges in applying them to $21^{\text {st }}$-century healthcare. Those principles were: Healthcare for SDA members, sustain financial and 
administration model despite attention to all social classes, exercise (Physical activity) as part of treatment, prayer combined with treatment and obedience to the laws of health, God-fearing personnel, therapeutic nature interaction and altruistic and trusting institutional model. Some participants considered two principles as not applicable since

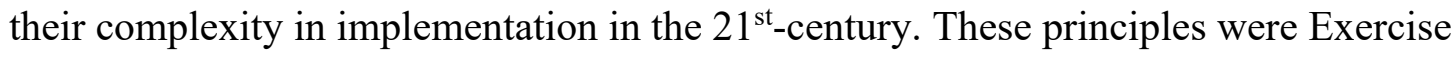
(Physical activity) as part of the treatment and Preparing people to be holy before God.

\section{Discussion}

I will now discuss seven themes that emerged while studying Adventist healthcare's founding governing principles. The first area focuses on the strong consensus related to the Adventist healthcare emphasis on the wholistic perspective, medical education and prevention, and those principles related to spiritual and religious integration in healthcare. Next, I discuss five areas that did not have a consensus and how this difference might be creating a dynamic diversity within Adventist healthcare. The last section deals with different responses grouped in themes ranging from universality, Adventist's uniqueness, diversity, and idealism.

\section{Strong Consensus}

This study helped confirm the strong cultural adherence to the wholistic perspective of body-mind-social-spirit, medical education \& prevention, and spiritual \& religious integration with Adventist practice. The three aspects raised in focus groups raised little discussion since they were considered as-a-matter of fact. Currently, those aspects are widely accepted in healthcare in general. For instance, researchers acknowledged the concept of a wholistic healthcare perspective and recommend consideration of this wholistic model to achieve a patient's wholesome wellbeing (Chan, 
Ying Ho, \& Chow, 2002; Clarke, 2010; Oakley, 2004). Adventist healthcare is wellidentified for lifestyle and longevity. Diverse research publications in this topic, such as Adventist Health Study version 1 and 2 ("Adventist Health Studies," 2019), as well as the Blue zones's study which includes Adventists communities (Buettner, 2016; Buettner \& Skemp, 2016) are a clear sample of the research related to Adventist lifestyle. In the same

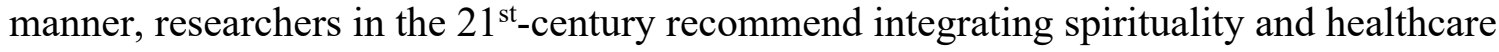
(Pesut, Fowler, Taylor, Reimer-Kirkham, \& Sawatzky, 2008; Zaidi, 2018).

\section{Exercise as Part of Treatment/ Therapeutic Nature}

\section{Although I listed Exercise as part of treatment and Therapeutic Nature} interaction as two separate principles, I am discussing them together due to their interconnection during the discussion. The focus group participants discussed them extensively. While some participants accepted them as a matter of fact, a couple of participants wondered about their applicability in a modern medical facility. White (2011), pointed out that "the sick should be taught that it is wrong to suspend all physical labor in order to regain health" (1992b, p. 513). This practice is currently implemented in several hospitals and recorded in diverse clinical settings in the research literature (Leggio et al., 2019; Zanini et al., 2019). However, Ellen White provided a specific purpose, besides the physical benefit, to "keep the power of the will awake" (1992b, p. 515). Once again, current research supports the information provided by E. G. White years ago. A study in the field of Leadership argues how will power is a mental capability that is affected by energy levels derived from "nutrition, rest, mental and physical practice" (Karp, 2014). However, the correlation of exercise and willpower strength is not restricted to leaders but the people in general. 
Related to exercise (or physical activity as EGW uses), White instructed for the interaction of patients with nature therapeutically. She explained:

I saw there should be connected with the Institute ample grounds, beautified with flowers and planted with vegetables and fruits. Here the feeble could find work, appropriate to their sex and condition, at suitable hours. These grounds should be under the care of an experienced gardener to direct all in a tasteful, orderly manner. (Ellen G. White, 1992b, p. 519)

White expanded in the manner that patients should perform physical activity, which was combined with nature therapeutic interactions. In the focus groups, a couple of participants considered assigning patients to "work" in a $21^{\text {st }}$-century healthcare facility, which is not only impractical but likely illegal. However, this principle has two key aspects: (a) the physical activity is not prescribed against the patient's will since is not a most but "could find work," and (b) the prescribed activity takes into account that work is "appropriate to their sex and condition, at suitable hours."

Indeed, patients in their particular conditions could work on numerous activities to redirect their mind and thoughts away from their problems. Interaction with nature assists in taking the patients' attention beyond their health problems and developing a sense of being useful (Huisman, Morales, van Hoof, \& Kort, 2012). Currently, global healthcare systems provide an array of activities, including art and music therapy, to assist inpatients (Art therapy and health care 2013; Arts, health, and well-being in America, 2017). However, EGW warned about the type of activity that people should use while sick; since not all the activities are constructive. Activities that were not recommended include:

Such mental exercises as playing cards, chess, and checkers excite and weary the brain and hinder recovery, while light and pleasant physical labor will occupy the time, improve the circulation, relieve and restore the brain and prove a decided benefit to the health. White, Test 1 p. 554 
Indeed, the ideal implementation: physical activity and nature therapeutic interaction in the traditional hospital setting may appear challenging. However, if the two principles are considered an integral part of the treatment, it can be implemented. The benefits of therapeutic nature interaction are already proven in various research journals. For example, researchers already identified the benefits of ornamental plants in a patient's room and recorded a quicker surgical recovery (Lipscomb \& Rollings, 2017; Park \& Mattson, 2009a, 2009b). How much more can be obtained if the principles are implemented in full.

\section{Preparing People to be Holy Before God}

The principle of Preparing people to be holy before God caused some of the most engaging discussions from participants. Some felt such a principle could be used to pressure individuals into a relationship with God, and that would be unethical. This principle generated the most diverse views. This principle was discussed in a variety of ways and with complicated explanations. Because of that, it is difficult to grasp its full content in one sentence. Even from the stage in which Adventist historians provided feedback, I realized the challenges of presenting this complex concept in a few words. I initially used the term "perfection", after the first stage, I changed the name to "holy", following one Adventist historian's suggestion. However, during the focus group's discussions, I realized those terms are linked to the deep theological discussion on the impossible, or even possible for some theologians, state for sinful human beings to reach perfection alone; hence their application requires further explanation. Intending to avoid such a polarized theological concept, I believe using the second word suggested, wholeness, from the same Adventist historian, would be more applicable. 
The concept intended behind Preparing people to be whole refers to a continual

process. In the Christian setting, holiness and perfection are terms that tend to seem unreachable for sinful humans. However, the statement is not saying "making" people perfect (holy), but "preparing." Going back to the EGW's statement, she highlighted that "the institution is designed of God to be one of the greatest aids in preparing a people to be perfect before God" [Emphasis added] (Ellen G. White, 1992a, p. 166). She further explains the importance of such an institution in preparing people for a unique encounter:

In former numbers of Testimonies for the Church I have spoken of the importance of Seventh-day Adventists' establishing an institution for the benefit of the sick, especially for the suffering and sick among us. I have spoken of the ability of our people, in point of means, to do this; and have urged that, in view of the importance of this branch of the great work of preparation to meet the Lord with gladness of heart, our people should feel themselves called upon, according to their ability, to put a portion of their means into such an institution. [Emphasis added] (Ellen G. White, 1992b, p. 633)

There are two critical concepts after the word preparation. The first concept is to meet the Lord, which implies an encounter with God either for reconciling or restoring the relationship between humankind and God individually. The second phrase gladness of heart is connected to Jude 1:24-25 (New American Standard Version):

Now to Him who is able to keep you from stumbling, and to make you stand in the presence of His glory blameless with great joy, to the only God our Savior, through Jesus Christ our Lord, be glory, majesty, dominion and authority, before all time and now and forever. Amen. [Emphasis added]

The gladness of heart is providing the context of a redemptive grace that is gifted to humankind. The reaction is of great joy as a sinner acknowledges the extraordinary privilege God has given humanity. Hence the Gladness of heart expression describes the extend of gratitude and appreciation since humankind can stand in God's presence not by own merit but by an undeserved gift. 
According to EGW's philosophy, it can be concluded that the institution

(Adventist Hospital) does not make anyone perfect in itself. Still, by teaching patients the importance of following God's laws, it assists in strengthening the moral powers of the patient. EGW's states: "Therefore it is of the greatest importance that he [the patient] knows how to live so that his powers of body and mind may be exercised to the glory of God" (Ellen G. White, 1992a). By taking the patient to the source of healing and knowledge, directing the patient to the teachings of the human body's Creator and the instruction for its well-being, the objective has been met according to EGW. At no point the records suggest that the aim is to convert people to a specific religion but to point them to God as the source. He will do the rest.

Once the person has acknowledged that God-given natural laws exist and understand its implications, the expectation is for that person to be connected to the Creator to strive obedience in body, spirit, and mind, so he or she can communicate better with God, and hence "prepare for the coming of the Lord"(Ellen G. White, 1992a, p. 162). EGW went further to explain that:

It should ever be kept prominent that the great object to be attained through this channel is not only health, but perfection, and the spirit of holiness, which cannot be attained with diseased bodies and minds. (Ellen G. White, 1992b, p. 512)

"It is impossible for man to present his body a living sacrifice, holy, and acceptable to God, while, because it is customary for the world to do so, he is indulging in habits that are lessening physical mental and moral vigor." (White p. 163)

Could the understanding be that only healthy people (balanced in spirit, body, and mind) could reach perfection and meet God? What about the fervent church member diagnosed with dementia or a faithful Christian involved in a car accident and remained paraplegic? Or what about someone that was depressed and indulged himself or herself in such bad eating habits that resulted in chronic diseases but repented and asked for God's 
intervention? If people with diseased bodies and minds cannot be saved, "Then who can be saved?" (Matthew 19:25) EGW comments on this:

"But [God] is all-pitiful, gracious, and tender, and when light comes to show who have injured their health by sinful indulgences and they are convinced of sin, and repent and seek pardon, He accepts the poor offering rendered to Him, and receives them." (p. 165)

Indeed, humankind can't save itself. But God does not ignore a sincere heart.

God's mercy does not cancel the ideal of having a mind, body, and spirit with full capacity to be presented as a living sacrifice, as the apostle Paul said. Therefore, according to EGW, the main aim of Adventist healthcare institutions is to prepare people for the second coming: that in this world of disease and weak minds and spirits, people can be strengthened to discern God's voice and be ready for His coming. This can be achieved through the actions of Adventist Hospitals in a conscious work on education on the obedience of natural laws for every individual to be pointed to the source of health and wisdom. The rest is beyond the Adventist Hospital's scope. Hence, I realized the best way to include all the concepts together is to redefine the wording of this principle to Preparing people to be whole to be reconciled with God.

\section{God-Fearing Personnel}

After considering the main aim of Adventist Hospitals, to prepare people for the second coming, it's almost automatic to think that for the model to work it is required that people convinced of God's role in health, Jesus' second coming, preparation needed and the Adventist Healthcare's mission, be involved with the institution. While some participants in the focus group immediately assumed that "God-fearing personnel" means 
a Seventh-day Adventist member, few participants reacted by providing examples of few Adventist members that won't live up to the Adventist standards.

Indeed, membership does not mean that the person lives up to the Adventist standards. However, it is easier to find an Adventist member who believes in fundamental Adventist beliefs impacting these principles such as the second coming of Christ, the preparation needed for Christ's coming and the role of Adventist Hospitals, non-Adventist. Hence, religion should not be the only criteria, since the evaluation should be on the individual. For this, Chapman (2006), advises having behavioral-based hiring, instead of regular office-based interviews, together with inspirational orientations and the periodic review of processes to have the best personnel aligned with the Hospital's mission.

One of the challenges that were discussed in the focus groups was the legislation in certain countries, such as:

"Employers may not discriminate against employees or applicants based on their religious beliefs. This means, for example, that employers may not refuse to hire anyone who does not share their faith, promote only Jews or Catholics, or require background checks only of Muslim employees" (Guerin, 2019).

Hence in some countries, the percentage of Adventist personnel is considerably low. In other cases, the need for specialized professionals that are not part of the Adventist system makes it a challenge. The disadvantage is when leaders downplay the role of the mission committed personnel, hence accepting any kind of worldview to be part of the workforce, even if such legal regulation is not in place. If the previous principle, with the Adventist Hospital's aim of preparing people for the second coming, is understood, this principle will become pivotal. No one can guide others without experience in where to guide them. 


\section{Prayer Combined with Treatment and Obedience to the Laws of Health.}

Prayer was widely mentioned in the discussions even before the principles were presented. Prayer is nowadays used as a research protocol by several authors such as Hendricks et al. (2019), Nimbalkar, Mungala, Khanna, Patil, and Nimbalkar (2019), Cain (2016) among many others, not only addressing patients but also as a coping strategy for healthcare personnel. However, none of the participants made comments related to obedience to the laws of health. EGW emphasized:

And I also saw that He [God] designed the health reform and Health Institute to prepare the way for the prayer of faith to be fully answered. Faith and good works should go hand in hand in relieving the afflicted among us, and in fitting them to glorify God here and to be saved at the coming of Christ. (Ellen G. White, 1992b, p. 518)

As she states it, the health reform is a modification on the habits that result in sickness, named non-communicative diseases. Prayer has its place and moment. However, institutions should not use or even promote prayer as a magical event in which everything goes back to normal, but a combination of our actions together with prayer. This does not apply to some healthcare areas that are not a cause of our behaviors, such as accidents.

\section{Sustain Financial Model with Attention to all / Service for SDA /Altruistic Model}

Sustain Financial Model with Attention to all, Service for SDA and Altruistic Model were three principles interconnected in the discussion. The reason why they often interacted is their understanding of financial implications. The sustainability of a financial model that can attend to all types of patients was widely discussed. This principle was discussed by the participants concerning the service of Seventh-day 
Adventist members and having an altruistic business model. Among the participants, several of them identified their institution as what themselves defined as a "Mission Hospital."

The Encyclopedia Britannica provides the following information about Mission Hospitals:

The spread of Western medicine (or conventional medicine) and the founding of hospitals in developing countries can be attributed in large part to the influence of the medical missionary. The establishment of mission hospitals gained momentum gradually in the second half of the 19th century. By the second half of the 20th century, however, this steady growth had already dwindled, since all but a few of the hospitals and dispensaries founded during that hundred years had been absorbed into the native health care system. The Christian missionaries had a great influence on the creation of centers [sic] of Western medicine in many developing countries and in promulgating the concept of a hospital in which health care would be centralized and organized for the benefit of the ill and injured, many of whom would not otherwise have survived....

Apart from its religious associations, a mission hospital functions as a general hospital in the sense that it admits all who need hospital care. (Percey, Scarborough, \& Fralick, n.d.)

Pradeep (2013) defines it as:

“A Mission Hospital must be Seeking God's Kingdom.

A Mission Hospital must seek specially [sic] to serve the poor and marginalized.

A Mission Hospital would seek to glorify His Name by running on the basis of principles put forward in His Word".

Regarding these principles, the nature of the hospital (Either not-for-profit or business-minded vs. mission hospital) provided a sharp difference in the principle of Sustain financial model with attention to all. From the participants' interactions, I perceived that most mission hospital leaders were coming from hospitals located in what is widely classified as low-income countries, while not-for-profit, business-minded 
hospital leaders were mostly located in high-income countries. The Adventist Mission Hospital participants expressed their commitment to attend to all patients and not turning away any needing patient. Not-for-profit, business-minded Adventist hospital leaders made clear comments on the need for revenue margins to be there for positive operation.

Participants connected the sustainability principle with the situation that many Adventist members (Specifically in Adventist Mission Hospitals) expect lower prices or special concessions, may be derived by the feeling that gives them to be a member of the institution that the church owns. Although the purpose of the study is not to define these two types of hospitals within the Adventist setting, I noted a pattern between the participants representing these two groups.

Besides, I realized that the principles in which the Altruistic Model was defined were losing the original sense of the "principles" characterized by E. G. White. The selection of words I used confused with the Sustain financial model. In chapter 4, I explained how Ellen G. White declares "that which had been shown me as a place where the suffering sick among us could be helped was one where sacrifice, hospitality, faith, and piety should be the ruling principles"(Ellen G. White, 1992b). Hence, the last principle is better rephrased to the Organizational character of sacrifice, hospitality, faith, and piety.

\section{Organizational Dimensions: Leadership, Drift and Institutionalizing Values}

Several organizational aspects emerged during the analysis of the study: Diversity, universality, and organizational drift. 


\section{Universality}

Following the analysis of the sustainability principle discussed in the section above, I realized that universality is not necessarily applicable to the implementation of the principles discussed. Although a principle is a core, specific situations such as national regulations and culture might interact with the principles. I perceived that even though all principles apply for the Adventist Health institutions in a $21^{\text {st }}$-century setting, their implementation would be impacted by the culture and regulations of where they serve. For example, it was noted by the participant's comments coming from westernstyle hospitals that due to their legal system, they were more open to having high percentages of non-Adventist members as personnel.

However, being a principle, the adaptability would have a limit, regardless of culture. Cases of polygamy (culturally accepted in some regions but goes against the Bible's principles) was an example presented in the God-fearing personnel principle. Selznick explains homogeneity with the need that raises for a "unity derived from a common understanding of what the character of the organization is meant to be" $(1948, \mathrm{p}$. 30). In a multinational faith-based institution, homogeneity and diversity should find a balance in which a breaking point is guarded concerning institutional integrity.

\section{Uniqueness of Adventist}

Another issue raised was the thrive for being "Unique." During the discussions, participants identified several principles that currently are both research supported and becoming the trend in healthcare practice. Are Adventist hospitals supposed to be different from others? What about if non-Adventist hospitals adopt Adventist uniqueness, 
are Adventist not themselves anymore? Do Adventist hospitals need to find more principles? Do Adventist hospitals need to look different to be different?

I believe all the principles combined make Adventist systems unique, regardless if non-Adventist hospitals do similar or identical activities. Adventist hospitals aim to prepare people for Jesus's second coming, and the combination of this objective with Adventist principles makes an Adventist institution. The key differentiator is not the "how" Adventist hospitals are perceived, but in the "why" Adventist hospitals do what they do (Sinek, 2009). Other institutions may focus on vegetarian diets or emphasize exercise and prevention, but the reasoning behind the why will impact the full range of the Adventist principles being implemented.

Diversity in Applicability of Governing Principles and Organizational Drift

Most participants saw these 12 principles as valuable or an ideal, and many were being applied. Most of the participants seemed eager to learn more about these principles and learn from others how to better make them part of their organizations. Several participants also hinted a gap between the ideal and real practice existed and often used the expression such as "that is the ideal." One of the participants that expressed opposition to the implementation of a couple of principles, before leaving the room said, “all these are utopia." This tension between ideal and reality is related to Selznick's organization-paradox of apparent incongruence between what people believe and what people do in an organization. This may be a universal tension between the desired and the real between the formal and informal realms for individuals and organizations. It may be the nature of "divergent interest within the organization" (1948, p. 28). 
Such tensions may be viewed in various ways, as a margin of growth motivating change or margin of unrealistic idealism by others where the ideal needs to be dropped. In the smallest focus group where well-known leaders of Adventist healthcare met, there was an exchange of opposite opinions by two particular leaders. The difference of opinion was relevant since the promotion, follow up, and implementation of founding principles appears to rest on personal inclinations. It was difficult to fully understand the subtle "emotions" or "feelings" about this gap, which was not assessed in this study.

As Harrison (2000) explains, organizational identity is interpreted or even accepted in a peculiar way by each individual in a unique way. Indeed, the world church is a global faith-based organization that welcomes diverse points of view, but the founding ideals of a particular ministry should be conciliated. This study did not dictate a given position but to point out the need for discussion, definition, promotion, and guidance on the relation between governing principles and the operation of modern Adventist hospitals.

Besides the role of leaders in guarding governing principles, Selznick points to a particular group of individuals in an organization: the elites (Selznick, 2011). If chosen correctly and nurtured in founding principles, this group of organizational members can also play a role in guarding organizational mission. Indeed, these elite groups may play a more substantial role since top executives often move around to other organizations more often than long-term elite members.

Another issue that is inseparable to faith-based organizations' governing principles is the organizational drift or unofficial behaviors that contradicts itself with its founding ideology or even revisited ideology. Indeed, Whetten stated that organizational 
identity should be "central, enduring, and distinctive" (Whetten, 2006). However, if an organization revises its governing principles and decides to modify its identity, it at least makes conscious decisions towards a new horizon. In such circumstances, change is not drifting, as Greer and Horst state (2014).

The challenge is the unofficial drift, not the official new direction. As Selznick pointed out, "when an enterprise is permitted to drift, making short-run, partial adaptations, the greatest danger lies in uncontrolled effects on organization character." (2011, p. 145). Linked to the Adventist healthcare system and speaking of "greatest dangers" EGW warned from the time of her first vision that the greatest danger is that managers "depart from the spirit of the present truth and simplicity which should characterize the Disciples of Christ" (Douglass, 1998, Loc. 10130 of 20425). Sometimes leaders follow operational opportunities to be aware of "institutional surrender made in the name of organizational survival.” (2011, p. 145)

Several questions emerge. First, how to preserve whatever an organization has proposed itself to be? How to face organizational drift if faith-based organizations are known for having a higher risk of drifting from its purpose? Researchers on this topic believe that for an organization to remain true to its mission it should: 1) Recognize that Christ is the difference, 2) affirm that faith sustains the organization, 3) understand that functional atheism is the path of least resistance (Greer \& Horst, 2014). This faithfulness, referred by Selznick as institutional integrity, can also be protected by “(1) selective recruiting, (2) specialized training, and (3) withdrawal from the everyday pursuits of mankind, especially from exposed competition in the marketplace" (2011, p. 122). 
Greer and Horst highlighted two main actions required for an organization to keep institutional integrity: have a clear Christian mission and intentionally protect it. From the focus group responses of what makes and Adventist hospital Adventist, I could perceive the need for a sharper definition of a $21^{\text {st }}$ century Adventist healthcare mission and governing principles. The first step would promote a clear mission and governing principles to ensure the second component takes place: guarding the mission.

\section{Limitations}

I encountered five limitations in this study. First, I would have liked to involve more experts and healthcare leaders in all 13 divisions, but time and resources were not available. Next, some of my data collection was not able to be done face-to-face and limited to email technology hence more depersonalized than I would have wanted. The third limitation was the limited number of research peer-review journals and articles on faith-based healthcare in general and Adventist hospitals in particular. Indeed, the one common element in the limited research available was the call for more research in these areas (Chenhall et al., 2016). The fourth limitation was the narrow timeframe to do my focus group participants (only during lunchtime or before the morning conference session). Lastly, this study had limited English proficiency by some participants, including myself. Many of us did not have English as our first language, and some nuanced understanding of some of my questions may not have been adequately understood or their ideas adequately communicated. These limitations notwithstanding, I remain convinced the findings will make a valuable contribution to this area of research. 


\section{A Revised Listing}

After the two stages of this research and the feedback received, the 12 principles identified in this study are as follows:

1. Health education and preventive medicine.

2. Healthcare for SDA members

3. Discreet witnessing to non-believer patients

4. Sustain financial and administration model despite attention to all social classes

5. Unwavering Biblical principles

6. Wholistic perspective

7. Physical activity as part of treatment

8. Preparing people to be whole to be reconciled with God

9. Prayer combined with treatment and obedience to the laws of health

10. God-fearing personnel

11. Therapeutic Nature interaction

12. Organizational character of sacrifice, hospitality, faith, and piety As earlier stated, the list does not follow a specific order of importance. However, Adventist hospital's main aim, according to EGW's statements is to prepare people for Christ second coming (Principle 8).

\section{Conclusions}

1. I found widespread support for many of these principles as foundational to the identity of Adventist healthcare. 
2. Many founding Adventist principles and innovative practices have become widespread to most hospitals in the world.

3. There was a broad interpretation for what constituted good Adventist healthcare, from the resource-challenged and culturally constrained mission hospital to their massive "industrial complex" non-for-profit counterparts.

4. There are were principles that Adventist healthcare leaders perceived as difficult to apply in modern settings, even if they were sympathetic to the value of the founding governing principle.

5. There are some differences and even resistance to a few of these principles being applied to modern Adventist healthcare.

\section{Recommendations}

This study's findings have implications for hospital leaders, healthcare researchers, Adventist healthcare, other faith-based hospitals and researchers.

\section{Recommendations for Adventist Hospital \\ Leaders}

Adventist hospital leaders concerned about maintaining a core Adventist identity around the founding governing principles might consider;

1. Promote attention and discussion of these 12 core Adventist healthcare principles in administrative and staff meetings by referencing founding governing principles in their decisions and justifications.

2. Identifying and celebrating programs or activities promoting these founding governing principles. 


\section{Recommendations for Regional and Global Adventist Healthcare Leaders:}

I recommend that regional and global Adventist healthcare leaders consider the following:

1. Establish a team with international and intercultural representation to further promote the study of founding governing principles and its reflection in current governing principles.

2. Include founding governing principles in the agenda of international forums to discuss and highlight their contribution to Adventist healthcare success.

3. Fund research and publications that guide Adventist hospital administrators and healthcare leaders in the ways these principles are practiced in their particular contexts.

4. Leverage these principles within the curriculum and experiences of regional and global healthcare training forums (universities, centers, churches, among others).

5. Record and promote principle implementation stories throughout the global Adventist healthcare system using other venues and online processes.

6. Communicate between Adventist Hospital leaders worldwide to create further networking such as a research congress, periodical publications, or online networking systems to promoting a network of dedicated personnel to develop and strengthen a sense of belonging, as well as opportunities for benchmarking and promotion of Adventist Founding principles in healthcare.

\section{Recommendations for Further Research}

This study provides initial data to address the problem of defining founding governing principles in Adventist healthcare. However, more research is needed. The document analysis was done based on the original Ellen G. White instructions before any 
Adventist healthcare facility began operating. Indeed, further study is required to include all the instructions given afterward, including the ones given to the only Adventist healthcare facility operating today that was also operating in Ellen G. White's time: Loma Linda Medical Center.

\section{Final Thoughts}

In the current Covid-19 pandemic that the world is desperately fighting, governments around the globe are classifying organizations as to whether they fall into essential or not-essential industries to operate amidst quarantine and lockdowns orders. The Seventh-day Adventist church has various types of organizations: Academies, universities, health stores, restaurants, food plants, press, and healthcare organizations. Healthcare organizations are by principles the most indispensable industry which continues operations during the contingency. Hence, the significance of the healthcare organizations, particularly hospitals, to faithfully fulfill its mission, while sister Adventist organizations are unable to operate.

This study has allowed me to appreciate the diverse opinions within the church. Indeed, Seventh-day Adventist church has assorted healthcare leaders worldwide that even though we all might share the zeal for the denominational mission, we all have myriad perceptions and strategies to define and implement the hospital's principles and work in different Adventist healthcare systems and settings. Understanding this, I want to express that my quest for principles was not aiming for a prescriptive or unchangeable set of "commandments" but a starting point to allude to. As Adventist healthcare leaders, we can refer to these principles as a compass or light house that guides us while we sail in our particular vessels, take our day-to-day decisions, and keep us true to our direction. As 
noted earlier, further study is required to provide a complete analysis of EGW's visions and messages in while new healthcare institutions were started. Also, it would be necessary to determine if thought the messages did ever change of direction as time passed compared to her original visions revised in this study.

Many, if not all, of the decisions that SDA healthcare leaders make have repercussions on the hospital's direction. Change of direction, change in itself, is not necessarily detrimental. As a larva experiences metamorphosis and becomes a beautiful butterfly without necessarily changing its DNA, I believe Adventist healthcare institutions can change without losing themselves in the process. Adventist Hospital's leaders can become more aware of these principles and distance themselves and their organizations from decisions that would undermine critical Adventist commitments and move forward by making decisions faithful to these principles. DNA should be consciously guarded against unofficial "mutations" that may arise from the pressures of operational activity, competition, and new technologies. This approach could be considered at least until an official revision of governing principles is deemed necessary.

The aim is to thrive on reducing the gap between the ideal and reality, between what we are supposed to be versus what we are as an organization. The aim is to be consistent, congruent, and true to whatever an organization consciously commits. This can only be obtained when we as leaders revise organizational principles by either making unofficial changes official or by strengthening the current founding ideology to avoid organizational amnesia. Part of identity is to have a good memory of where an organization is coming from and where it is going (Casey, 2019). Lest we forget (Deut. 
4:9, KJV) who we are as Adventist healthcare leaders or in which direction are we taking the Adventist healthcare institution we lead.

Dear Father in heaven I pray for the leaders of the Adventist Healthcare institutions around the globe. I plead that your Holy Spirit can guide us in our day-to-day decisions and help us identify those decisions that can take us away from our purpose and select those that can make your vision a reality. Help us to be true to our calling and to remember the way you have guided us in the past. Assist us, Lord, to fulfill the mission that you have appointed us of restoring people in a relationship with You. In the name of Jesus, I pray. Amen. 


\section{APPENDIX A}

\section{Letter for Adventist historians}

\section{Dear Adventist Historian:}

\section{RE: PARTICIPATION IN HEALTHCARE GOVERNING PRINCIPLES IDENTIFICATION STUDY}

Thank you for agreeing to review my analysis of the health principles of Ellen White's early visions on Adventist healthcare. This study examines the governing principles in Adventist healthcare through three phases of data collection. The first phase is my summary of the core principles I distilled from reading Ellen White's early health visions.

The second phase involves your feedback on my analysis. Your feedback will help me rewrite or reframe what the core governing principles of health care were in here early visions. I seek your help in making these as accurate, succinct and clear as possible for my third state, which is to ask Adventist health care leaders to comment on these guiding principles and their application and usefulness to modern Adventist health work.

I would like you to read the following document, which contains the 12 principles I summarized from her work. If you would like my literature review or full proposal to help in your feedback, please let me know.

You can send me your comments or suggestions by email, or we can set up a time for feedback by phone or Skype/Zoom.

\section{Health education and preventive medicine}

Indeed the 1963 vision provided the health reform concept. However, at the beginning of the testimonies of 1965, Ellen White writes that she "was shown" that the implementation of health practices was not followed as it should. In line with the health reform, she states clearly that Adventist Healthcare institutions should focus on teaching and prevention:

I was shown that we should provide a home for the afflicted and those who wish to learn how to take care of their bodies that they may prevent sickness. (White, 2011, p. 453) 
This principle, besides the obvious principle of any healthcare institution to treat sickness, calls for institutions to teach patients how the body functions and how to prevent sickness; going beyond only treating disease. What type of teaching is expected? The information to be taught is the laws of health referred by White in several documents as the laws of nature (White, 2010a, 2010b; White, 2011). As presented in Testimonies I, such laws are nothing else but how the body functions and implicitly the eight remedies presented widely in her writings. The main lesson to be taught, if a person does not obey the health laws, the body will present consequences: disease.

\section{Healthcare for SDA members}

Any healthcare attention intrinsically carries a particular worldview. Ellen White knew this as a personal experience with her husband sickness and treatment. In repeated occasions in her testimonies she presents the need to have an institution "of our own" for believers, or also called Sabbath-keepers, to be attended without having to be constantly in guard from ideologies contrary to the Adventist beliefs. She stated:

I was shown that Sabbath keepers should open a way for those of like precious faith to be benefited without their being under the necessity of expending their means at institutions where their faith and religious principles are endangered, and where they can find no sympathy or union in religious matters. (White, 2011, p. 454)

She highlighted that a sick person has weakened moral strength, and then only people with extraordinary spiritual strength and constant vigilance could withstand temptations from dubious ideologies; hence the importance to be treated in a place where the faith and religious principles are aligned with those professed.

\section{Silent witnessing to non-believer patients}

The best way to know about principles is to see them in practice, and according to White, hospitals were an ideal setting for that. One of the advantages mentioned was that 
people tend to have prejudgment about Adventist faith. However, if those that are

unbelievers could see the principles in practice, they could get acquainted with them.

Being in other circumstances, these patients and their relatives would reject the

information even prior to learning about it. She explained:

Such an institution, rightly conducted, would be the means of bringing our views before many whom it would be impossible for us to reach by the common course of advocating the truth. As unbelievers shall resort to an institution devoted to the successful treatment of disease and conducted by Sabbath keeping physicians, they will be brought directly under the influence of the truth. By becoming acquainted with our people and our real faith, their prejudice will be overcome, and they will be favorably impressed. By thus being placed under the influence of truth, some will not only obtain relief from bodily infirmities, but will find a healing balm for their sinsick souls. (White, 2011, p. 456)

After five years of the health institute's beginning, Ellen White proclaimed a follow-up vision of admonition regarding the first governing principles for healthcare institutions. Some observations regarding the Health Institute's attitude towards witnessing was regarding the erroneous manners of discussing faith aspects with nonbelievers' patients. She declared:

But our peculiar faith should not be discussed with patients. Their minds should not be unnecessarily excited upon subjects wherein we differ unless they themselves desire it. (White, 2010c, p. 166)

Indeed, the best way of witnessing in a healthcare institutional setting, White highlighted, is to present the Adventist faith as a "silent influence." A sermon presented in a practical way should include not only the systems and protocols but also physicians and personnel at large that follow the professed faith.

\section{Sustain financial and administration model despite attention to all social}

\section{classes}

One may think that as a faith-based institution, the main objective is to attend to all people, regardless the money. However, Ellen White promoted a sustain organization. 
An institution that does not care for the expenses would only last but a short period of time. She remained her readers that many healthcare institutions had closed due to financial challenges. She warned, "This enterprise should never be left to struggle in poverty." Nevertheless, the Adventist Healthcare institution should be for all sorts of patients, including those that do not have the means to cover their expenses. She directed that:

A fund should be raised to be used for the express purpose of treating such of the poor as the church where they reside shall decide are worthy to be benefited. Unless those who have an abundance give for this object, without calling for returns, the poor will be unable to avail themselves of the benefits derived from the treatment of disease at such an institution, where so much means is required for labor bestowed. Such an institution should not in its infancy, while struggling to live, become embarrassed by a constant expenditure of means without realizing any returns. isep: (White, 2011, p. 458)

Therefore, institutions should organize for funds to be open so that outside money from donations can be directed to the expenses of people with greater needs. In that concept the organization remains able to cover the cost of their operations.

Additional to this, White provided several emphases that Adventist Institutions should grow proportionally to obtain the profile of the right committed personnel needed, as well as the infrastructure.

\section{Unwavering biblical principles}

Another key principle for healthcare institutions is to have a high religious standpoint, and at all cost avoid imitating business models which are the focus on moneymaking enterprises, as the world operates. White admonished:

Yet I saw that there would be danger of imitating them in many things and losing sight of the exalted character of this great work. And should those connected with this enterprise cease to look at their work from a high religious standpoint, and descend from the exalted principles of present truth to imitate in theory and practice those at the head of institutions where the sick are treated only for the recovery of health, the 
special blessing of God would not rest upon our institution more than upon those where corrupt theories are taught and practiced. (White, 2011, p. 512)

In the same line, White warned against lowering standards to make the model more palatable for non-believers, to receive paying patients. This is having an important impact on the believers, since it presents a fragile conviction producing a harming influence instead of a positive one.

White exalted biblical principles to health recovery. "The religion of the Bible is not detrimental to the health of body or mind. The exalting influence of the Spirit of God is the best restorative for the sick" (White, 2011, p. 514).

\section{Holistic perspective}

A landmark principle from the Adventist healthcare system is the concept of holistic attention. Mind, body, and spirit are so intertwined that if any of them are affected the rest are equally impacted. White declared:

It should ever be kept prominent that the great object to be attained through this channel is not only health, but perfection, and the spirit of holiness, which cannot be attained with diseased bodies and minds. (White, 2011, p. 512)

Therefore, an Adventist institution should promote and practice the holistic concept of health in every patient.

\section{Exercise as part of treatment}

A common misconception expressed by White is that rest is not only ideal but also required to regain health. However, in line with the principle of holistic perspective, absolute rest have an important impact on the patient's mental health. White declares that: "The sick should be taught that it is wrong to suspend all physical labor in order to regain health" (White, 2011, p. 513), since there are very few cases in which this applies. Physical labor refers to physical exercise, which has a positive impact not just in the mind 
but also in physical health. One aspect that promotes is the "keep the power of the will awake" (p. 515). Therefore, exercise and movement have important benefits to overcome disease.

\section{Preparing people to be perfect before God}

Ellen White states, "All should be conducted in strict accordance with the principles and humble spirit of the third angel's message" (White, 2011, p. 516). Indeed, the term is based on the biblical reference in Revelation 14:9 (NKJV) which says:

9 Then a third angel followed them, saying with a loud voice, "If anyone worships the beast and his image, and receives his mark on his forehead or on his hand, 10 he himself shall also drink of the wine of the wrath of God, which is poured out full strength into the cup of His indignation. He shall be tormented with fire and brimstone in the presence of the holy angels and in the presence of the Lamb. 11 And the smoke of their torment ascends forever and ever; and they have no rest day or night, who worship the beast and his image, and whoever receives the mark of his name."

But what does the Third Angel message had to do with health? Based on Ellen G. White writings, Fielder (2012) concludes that the third angel's message refers to the medical missionary work that prepares all people for the sealing time. White in Testimonies Vol. 3, confirms this by stating that "the institution is designed of God to be one of the greatest aids in preparing a people to be perfect before God" (White, 2010c, p. 166). The relation presented is that health has an impact on spirituality. She asserts:

It should ever be kept prominent that the great object to be attained through this channel is not only health, but perfection, and the spirit of holiness, which cannot be attained with diseased bodies and minds. (White, 2011, p. 512)

\section{Prayer combined with treatment and obedience to the laws of health}

One principle that is identified widely as a faith-related activity in healthcare is prayer. Indeed, Ellen White speaks about the power of prayer. However, she presents the 
conditional requires: it needs to be done together with treatment and obedience to laws of health. White declared:

And I also saw that He designed the health reform and Health Institute to prepare the way for the prayer of faith to be fully answered. Faith and good works should go hand in hand in relieving the afflicted among us, and in fitting them to glorify God here and to be saved at the coming of Christ. (White, 2011, p. 518)

Ellen White promoted in her writings how healthcare institutions should conduct prayer meetings, which should not be for discussion of religious dogmas, but to connect the patients to God. The prayer session should include hospital staff and employees.

\section{God-fearing personnel}

A principle that is linked to other principles is the type of personnel an Adventist Healthcare institution should have since only through the right employees could the other principles be fulfilled. To begin with, how can a physician teach health principles if he or she does not believe them? How could a nurse witness about a faith that she does not profess? How can a counselor pray for a patient when does not practice own prayer? The lack of the right people will diminish the impact of important principles.

Ellen White emphasizes the characteristics of the collaborators in this type of institution: believers, Sabbath keepers (Adventist), kind, loving, that always acknowledge God's power in the process of healing and not in their own skill. She even considered that the opening of healthcare institutions should be delayed until the right staff is located:

I saw that a very extensive work could not be accomplished in a short time, as it would not be an easy matter to find physicians whom God could approve and who would work together harmoniously, disinterestedly, and zealously for the good of suffering humanity. (White, 2011, p. 513)

An important hiring trait that is relevant is disinterest since White highlights the need for employees that are not motivated by money. Nevertheless, she clarifies that employees should be well remunerated. 


\section{Therapeutic Nature interaction}

Ellen White advocated that treatment of patients should include more interaction with nature in promoting physical exercise. This has a direct impact on patient mental health. When people are under the damaging effects of disease the negative thoughts and feelings focus on the patient's problems. Having a holistic approach mental health would affect both the spiritual and physical side. White described:

I saw there should be connected with the Institute ample grounds, beautified with flowers and planted with vegetables and fruits. Here the feeble could find work, appropriate to their sex and condition, at suitable hours. These grounds should be under the care of an experienced gardener to direct all in a tasteful, orderly manner. (White, 2011, p. 519)

Nature interaction considered the second inspired book (White, 2010b), could provide mental relieve.

\section{Altruistic and trusting institutional model}

Finally, Ellen White widely speaks regarding institutional motivation. "Money is not the great object with its friends and conductors. They conduct it from a conscientious, religious standpoint, aiming to carry out the principles of Bible hygiene" White, 1992b, p. 165). The institution should not be like the other "worldly" institutions in which the motivation relays on profit.

White declares "that which had been shown me as a place where the suffering sick among us could be helped was one where sacrifice, hospitality, faith, and piety should be the ruling principles" (Ellen G. White, 1992b). 


\section{APPENDIX B}

\section{Consent Form Adventist Historians}

You are being asked to participate in a research study conducted by Doctoral Candidate, Cesiah Yareth Pimentel Melendez from the Department of Education at Andrews University. The results of the study will contribute to the completion of a dissertation. As an Adventist Historian, you match the initial criteria for participation in this study.

\section{Purpose of the Study}

The purpose of the study is to:

- define, contextualize, enumerate, and explain the governing principles distilled from the original guiding testimonies of Ellen G. White on health care ministry.

- clarify this interpretation of Adventist Healthcare governing principles among Adventist health experts.

- identify the core timeless beliefs, values, and practices that apply today that are believed to persist as a way to identify the "Adventist" nature of Adventist health.

1. I understand that to participate in this study; I must be an Adventist expert in Seventh-day Adventist Church history.

2. I understand that I will read the conclusions reached regarding governing principles derived by Testimonies to the Church volume 1 and 3 and provide my observations and make comments or observations. The reading has an expected time of 20-25 minutes.

\section{Risks:}

I have been informed that the study will bear no more than minimal risks.

\section{Voluntary Participation:}

I understand that participation is voluntary, that refusal to participate involves no penalty or loss of benefit to which the subjects are otherwise entitled, and that I may 
discontinue participation at any time without penalty or loss to which the subjects are otherwise entitled if I had completed participation in the research.

I have been informed that only researcher and dissertation committee members will have access to data collected for the study and that no other person will be able to see or use the data. In addition, that data will be under the custody of the researcher.

I have been informed and understand that should I have any questions or concerns about the research, I should feel free to contact Cesiah Pimentel (Principle Investigator) at $+(250)$ 78310063; email cesiah@andrews.edu or Dr. Duane Covrig (Dissertation Chairperson) at (269)471-3475; Email; covrig@andrews.edu

I have read and understand the information provided regarding the research, and by signing, I give my informed consent to participate in this study.

Printed Name

Participants Signature Date

Researcher Signature Date 


\section{APPENDIX C \\ Consent Form Focus Group Participants}

\section{Focus Group Consent Form}

Research project title:

Research investigator: Cesiah Yareth Pimentel Melendez

I agree to participate in the (name of focus group) carried out by (name of researcher) of the University of Edinburgh, to aid with the research of (name research project).

I have read the information sheet related to the (name the research project) and understand the aims of the project.

I am aware of the topics to be discussed in the focus group.

I am fully aware that I will remain anonymous throughout data reported and that I have the right to leave the focus group at any point.

I am fully aware that data collected will be stored securely, safely, and in accordance with Data Collection Act (1998).

I am fully aware that I am not obliged to answer any question, but that I do so, at my own free will.

I agree to have the focus group recorded (video or Dictaphone), so it can be transcribed after the focus group is held. I am aware that I have the right to edit the transcript of the Focus Group once it has been completed.

I am aware that I can make any reasonable changes to this consent form.

Printed Name

Participants Signature Date

Researchers Signature Date 


\section{Focus Group Consent Form}

School of Geosciences - Ethics Committee- 2013

2

Contact Information

This research has been reviewed and approved by the Edinburgh University Research Ethics Board. If you have any further questions or concerns about this study, please contact:

Name of researcher

Full address

Tel:

E-mail:

You can also contact (Researchers name) supervisor:

Name of researcher

Full address

Tel:

E-mail:

What if I have concerns about this research?

If you are worried about this research, or if you are concerned about how it is being conducted, you can contact the Chair of the Geoscience Ethics Committee, University of Edinburgh, Drummond St, Edinburgh, EH8 9XP (or email at ethics@geos.ed.ac.uk). 


\section{APPENDIX D}

\section{Principles Distributed to Focus Group Participants}

I. In your opinion, the following principles still apply in a $21^{\text {st }}$-century SDA hospital?

II. How have you seen them implemented, or how do you imagine these principles could be implemented in a $21^{\text {st }}$ century SDA hospital?

\section{Health Education and Preventive Medicine}

I was shown that we should provide a home for the afflicted and those who wish to learn how to take care of their bodies that they may prevent sickness. (White, 2011, p. 453)

\section{Healthcare for SDA Members}

I was shown that Sabbath keepers should open a way for those of like precious faith to be benefited without their being under the necessity of expending their means at institutions where their faith and religious principles are endangered, and where they can find no sympathy or union in religious matters. (White, 2011, p. 454)

\section{Indirect Witnessing to Non-Believing Patients}

Such an institution, rightly conducted, would be the means of bringing our views before many whom it would be impossible for us to reach by the common course of advocating the truth.... (White, 2011, p. 456).

But our peculiar faith should not be discussed with patients. Their minds should not be unnecessarily excited upon subjects wherein we differ, unless they themselves desire it. (Ellen G. White, 2010c, p. 166)

\section{Sustain Financial and Administration Model Despite Attention to all Social Classes}

A fund should be raised to be used for the express purpose of treating such of the poor as the church where they reside shall decide are worthy to be benefited ... Such an institution should not in its infancy, while struggling to live, become embarrassed by a constant expenditure of means without realizing any returns. isiep:i(White, 2011, p. 458)

\section{Unwavering Biblical Principles}


They conduct it from a conscientious, religious standpoint, aiming to carry out the principles of Bible hygiene" (Ellen G. White, 1992a, p. 165). And should those connected with this enterprise cease to look at their work from a high religious standpoint, and descend from the exalted principles of present truth to imitate in theory and practice those at the head of institutions where the sick are treated only for the recovery of health, the special blessing of God would not rest upon our institution more than upon those where corrupt theories are taught and practiced. (White, 2011, p. 512)

\section{Wholistic (Body, Mind and Soul) Perspective}

Those who have suffered greatly from bodily infirmities are week both mentally and morally. (White, 2006, p. 195). When serving them, we need to serve all aspects.

\section{Exercise as Part of Treatment}

"The sick should be taught that it is wrong to suspend all physical labor in order to regain health" (White, 2011, p. 513). Exercise helps "keep the power of the will awake" (p. 515).

\section{Preparing People to be Holy Before God}

It should ever be kept prominent that the great object to be attained through this channel is not only health, but perfection, and the spirit of holiness, which cannot be attained with diseased bodies and minds. (White, 2011, p. 512)

\section{Prayer combined With Treatment and Obedience to the Laws of Health}

And I also saw that He designed the health reform and Health Institute to prepare the way for the prayer of faith to be fully answered. (White, 2011, p. 518)

That is the place to find relief from disease by treatment and right habits of living, and to learn how to avoid sickness. (White, 2006, p. 223)

\section{God-Fearing Personnel}

Those who engage in this work should be consecrated to God and not make it their only object to treat the body merely to cure disease. . . but keep prominent the health reform from a religious standpoint. (White, 2006, p. 636)

\section{Therapeutic Interaction with Nature}

I saw there should be connected with the Institute ample grounds, beautified with flowers and planted with vegetables and fruits. Here the feeble could find work, appropriate to their sex and condition, at suitable hours. These grounds should be under the care of an experienced gardener to direct all in a tasteful, orderly manner. (White, 2011, p. 519) 


\section{Altruistic and Trusting Institutional Model}

"Money is not the great object ..." (Ellen G. White, 1992a, p. 165). The institution "that which had been shown me as a place where the suffering sick among us could be helped was one where sacrifice, hospitality, faith, and piety should be the ruling principles" (Ellen G. White, 1992b). 


\section{REFERENCE LIST}

Adventist Health Studies. (2019). Retrieved from https://publichealth.llu.edu/adventisthealth-studies/about

Adventists, G. C. o. S.-d. (2019). Adventist directory. Retrieved from http://www.adventistdirectory.org/. Retrieved 6 August 2019, from Office of archives, statistics and research http://www.adventistdirectory.org/

Art therapy and health care (2013). New York, NY: The Guilford Press.

Arts, health, and well-being in America. (2017). (H. M. Center for Performing Arts Medicine Ed.). San Diego, CA: National organization for arts in health.

Bielefeld, W., \& Cleveland, W. S. (2013). Defining faith-based organizations and understanding them through research. Nonprofit and voluntary sector quarterly, 42(3), 442-467. doi:10.1177/0899764013484090

Bloomberg, L. D., \& Volpe, M. (2016). Completing your qualitative dissertation: A road map from beginning to end (3rd ed.). Los Angeles, CA: Sage.

Branson, R. (2015). Health and the healing arts. In G. Chartier (Ed.), The future of Adventism: Theology, society, experience (pp. 223-244). Ann Arbor, MI: Griffin \& Lash.

Buettner, D. (2016). El secreto de las zonas azules: Comer y vivir como la gente más saludable del mundo (A. M. Tato, Trans.). Distrito Federal: Mexico: Penguin Random House

Buettner, D., \& Skemp, S. (2016). Blue zones: Lessons from the world's longest lived. American journal of lifestyle medicine, 10(5), 318-321. doi:10.1177/1559827616637066

Cain, C. D. (2016). The effects of prayer as a coping strategy for nurses. Journal of perianesthesia nursing, 31(4), e54. doi:10.1016/j.jopan.2019.03.013

Canale, F. (2015). Vision and mission-part 1: Historical and methodological background. Journal of the adventist theological society, 26(2), 111-148. Retrieved from https://digitalcommons.andrews.edu/cgi/viewcontent.cgi?article $=1044 \&$ context $=\mathrm{j}$ ats

Casey, A. (2019). Organizational identity and memory: A multidisciplinary approach. New York, NY: Routledge. 
Chan, C., Ying Ho, P. S., \& Chow, E. (2002). A body-mind-spirit model in health. Social work in health care, 34(3-4), 261-282. doi:10.1300/J010v34n03_02

Chenhall, R. H., Hall, M., \& Smith, D. (2016). Managing identity conflicts in organizations: A case study of one welfare nonprofit organization. Nonprofit and voluntary sector quarterly, 45(4), 669-687. doi:10.1177/0899764015597785

Chu, D. C., \& Sung, H.-E. (2014). Causation of drug abuse and treatment strategy: A comparison of counselors' perceptions of faith-based and secular drug treatment programs. Int $J$ offender ther comp criminol 58, 496-515. doi:10.1177/0306624X12462855

Clarke, J. (2010). Body and soul in mental health care. Mental, religion \& culture, 13(6), 649-657 doi:10.1080/13674676.2010.488416

Cortez, F. H. (2015). The mission-charity dilema: Fresh perspectives from Paul's practice. Journal of the adventist theological society, 26(1), 160-173. Retrieved from $\underline{\text { https://digitalcommons.andrews.edu/cgi/viewcontent.cgi? article }=1030 \& \text { context }=\mathrm{j}}$ $\underline{\text { ats }}$

Covrig, D. (2003). Institutional integrity through periods of significant change. In A. S. Iltis (Ed.), Institutional integrity in health care (pp. 139-174). Dordrecht, The Netherlands: Kluwer Academic

Creswell, J. W. (2007). Qualitative inquiry \& research design: Choosing among five approaches (2 ed.). Thousand Oak, CA: Sage.

Cummings, T. G., \& Worley, W. G. (2008). Organization Development and Change (9th ed.). Mason, $\mathrm{OH}$ : South Western Cengage Learning.

Dalio, R. (2017). Principles: Life and work. New York, NY: Simon \& Schuster.

Douglass, H. E. (1998). Messenger of the Lord: The prophetic ministry of Ellen G. White [Kindle].

Eccles, J. B. (2014). The chaplaincy experience: Negotiating (multi-faith) time and space in a northern english general hospital. Journal of pastoral care \& counseling, 68(3), 1-12. doi:10.1177/154230501406800305

Ellenson, R. D. (2005). What makes a Jewish organization "Jewish". Journal of Jewish communal service, 81(3/4), 129-132. Retrieved from http://research.policyarchive.org/9791.pdf

Fiedler, D. (2012). Dsozo: Reversing the worse evil. Coldwater, MI: Remnant

Fortin, D., \& Moon, J. (2013). The Ellen G. White Encyclopedia (2nd ed.). Hagerstown, MD: Review and Herald. 
Gioia, D. A., \& Hamilton, A. L. (2016). Great debates in organizational identity study. In M. G. Pratt, M. Schultz, \& B. E. Ashforth (Eds.), The Oxford handbook of organizational identity. New York, NY: Oxford University Press.

Governing-principle. (2018). In collins dictionary.com. Retrieved from https://www.collinsdictionary.com/es/diccionario/ingles/governing-principle. Retrieved May 23, 2018 https://www.collinsdictionary.com/es/diccionario/ingles/governing-principle

Greer, P., \& Horst, C. (2014). Mission dirft: The unspoken crisis facing leaders, charities and churches. Minneapolis, MN: Bethany house

Gregorutti, G., Charles-Marcel, Z. L., González, W., Avilés, G., \& Cea, R. (2015). Enhancing community-university engagement: The case of Montemorelos University. In W. J. Jacob, S. E. Sutin, J. C. Weidman, \& J. L. Yeager (Eds.), Community engagement in higher education (Vol. 3, pp. 287-302). Boston, MA: Brill Sense

Guerin, L. (2019). Reasonable accommodation for religious beliefs: An employer must accommodate employee religious beliefs, unless it would pose an undue hardship. Retrieved from https://www.nolo.com/legal-encyclopedia/reasonableaccommodation-religious-beliefs.html

Haffner, R. (2013). Holding on to what is sacred: Who to protect organizational values and enhance mission vitality. Journal of applied christian leadership, 7(2), 22-36. Retrieved from https://digitalcommons.andrews.edu/cgi/viewcontent.cgi?article $=1143 \&$ context $=\mathrm{j}$ $\underline{\mathrm{acl}}$

Harquail, C. V., \& Wilcox King, A. (2010). Construing organizational identity: The role of embodied cognition. Organization studies, 31(12), 1619-1648. doi:10.1177/0170840610376143

Harrison, J. D. (2000). Multiple imaginings of institutional identity: A case study of a large psychiatric research hospital. The journal of applied behavioral science, 36(4), 425-455. doi:10.1177/0021886300364003

He, H., \& Brown, A. D. (2013). Organizational identity and organizational identification: A review of the literature and suggestions for future research. Group \& organization management, 38(1), 3-35. doi:10.1177/1059601112473815

Hendricks, M., Steenveld, C. M., Thompson, V., Andrade, A., Kahl, G., Farlam, P., . . . Eyssen, A. v. (2019). Building a psychosocial and spiritual care service for children with cancer and their families - original research. SA journal of oncology, 3(1), 1-8. doi:10.4102/sajo.v3i0.52

Huisman, E. R. C. M., Morales, E., van Hoof, J., \& Kort, H. S. M. (2012). Healing environment: A review of the impact of physical environmental factors on users. 
Building and environment, 58(December), 70-80.

doi:10.1016/j.buildenv.2012.06.016

Jeavons, T. H. (2004). Religious and faith-based organizations: Do we know one when we see one? Nonprofit and voluntary sector quarterly, 33(1), 140-145. doi:10.1177/0899764003257499

Kacik, A. (2018, April 23, 2018). Adventist health and st. Joseph's merge operations. Modern Healthcare. Retrieved from http://www.modernhealthcare.com/article/20180423/NEWS/180429965

Karp, T. (2014). Leaders need to develop their willpower. Journal of management development, 33(3), 150-163. doi:10.1108/JMD-04-2012-0051

Kelly, K. (2014). Evangelical underdogs: Intrinsic success, organizational solidarity, and marginalized identities as religious movement resources. Journal of contemporary ethnography, 43(4), 419-455. doi:10.1177/0891241613516627

Knight, G. R. (2015). Si yo fuera el diablo. Cómo ver a través de la cortina de humo del enemigo: Los retos contemporáneos del adventismo (C. M. Aguilera, Trans.). Distrito Federal, Mexico: Gema Editores.

Krueger, R. A. (1998). Analyzing \& reporting focus group results (Vol. 6). Thousand Oaks, CA: Sage.

Leggio, M., Fusco, A., Loreti, C., Limongelli, G., Bendini, M. G., Mazza, A., . . Padua, L. (2019). Effects of exercise training in heart failure with preserved ejection fraction: An updated systematic literature review. Heart failure reviews, 24(4), 535-547. doi:10.1007/s10741-019-09841-x

Liamputtong, P. (2011). Focus group methodology: Principle and practice. London, England: Sage.

Lipscomb, M., \& Rollings, K. (2017). Outside in: Influences of indoor plants on psychological well-being and memory task performance in a workplace setting. Perkins \& Will research journal, 9(2), 373-381.

Los adventistas y el mensaje de salud. Historia, fundamento y desarrollo. (n.d.). Montemorelos, México: Centro White.

Mayer, H. (2018). Adventist health and St. Joseph's merge operations. Keep the faith. Retrieved from https://ktfnews.com/adventist-health-st-josephs-merge-operations/

Miles, J. A. (2012). Management and organizational theory: A Jossey-Bass reader. San Francisco, CA: Jossey-Bass.

Nimbalkar, A. S., Mungala, B. M., Khanna, A. K., Patil, K. H., \& Nimbalkar, S. M. (2019). Prayers and beliefs among relatives of children admitted in pediatrics 
wards. Journal of family medicine and primary care, 8(3), 1123-1128. doi: 10.4103/jfmpc.jfmpc_333_18

Numbers, R. L. (2008). Prophetess of health: a study of Ellen G. White (3rd ed.). Grand Rapids, MI: William B. Eerdmans

Oakley, R. (2004). How the mind hurts and heals the body. American psychologist, 59(1), 29-40. doi:10.1037/0003-066X.59.1.29

Olarinmoye, O. O. (2012). Faith-based organizations and development: prospects and constraints. Transformation: An international journal of holistic mission studies, 29(1), 1-14. doi:10.1177/0265378811427985

Park, S., \& Mattson, R. H. (2009a). Ornamental indoor plants in hospital rooms enhanced health outcomes of patients recovering from surgery. The journal of alternative and complementary medicine, 15(9), Advance online publication. doi:10.1089/acm.2009.0075

Park, S., \& Mattson, R. H. (2009b). Therapeutic influences of plants in hospital rooms on surgical recovery. American society for horticultural science, 44(1), 102-105. doi:10.21273/HORTSCI.44.1.102

Percey, W. D., Scarborough, H., \& Fralick, P. C. (n.d.). Hospital. Retrieved from https://www.britannica.com/science/hospital/The-modern-hospital. https://www.britannica.com/science/hospital/The-modern-hospital

Pesut, B., Fowler, M., Taylor, E. J., Reimer-Kirkham, S., \& Sawatzky, R. (2008). Conceptualising spirituality and religion for healthcare. Journal of clinical nursing, 17(21). doi:10.1111/j.1365-2702.2008.02344.x

Phillips, N., Tracey, P., \& Kraatz, M. (2016). Organizational identity in institutional theory. In M. G. Pratt, M. Schultz, B. E. Ashforth, \& D. Ravasi (Eds.), The Oxford handbook of organizational identity. New York, NY: Oxford University Press.

Polanco, V. (2012). En esto creemos: Para estar atentos a la palabra. Mexico, DF: Gema Editores.

Pradeep, N. (2013). What is a mission hospital? Retrieved from http://pradeepninan.blogspot.com/2013/01/what-is-mission-hospital.html

Pratt, M. G., Schultz, M., Ashforth, B. E., \& Ravasi, D. (2016). Organizational identity: mapping where we have been, where we are, and where we might go. In The Oxford handbook of organizational identity. New York, NY: Oxford University Press. 
Ravasi, D., \& Phillips, N. (2011). Strategies of alignment: Organizational identity management and strategic change at Bang \& Olufsen. Strategic organization, 9(2), 103-135. doi:10.1177/1476127011403453

Robinson, B. A. (2015). Religious Tolerance. Retrieved from http://www.religioustolerance.org/

Robinson, D. E. (1965). The story of our health message: The origin, character, and developmnet of health education in the Seventh-day Adventist Church (3rd ed.). Nashville, TN: Southern

Rooney, D., Paulsen, N., Callan, V. J., Brabant, M., Gallois, C., \& Jones, E. (2010). A new role for place identity in managing organizational change. Management communication quarterly, 24(1), 44-73. doi:10.1177/0893318909351434

Rudestam, K. E., \& Newton, R. R. (2015). Surviving your dissertation: A comprehensive guide to content and process (4th ed.). Los Angeles, CA: Sage

Sattar, S. P., Ahmed, M. S., Majeed, F., \& Petty, F. (2004). Inert medication ingredients causing nonadherence due to religious beliefs. Annals of pharmacotherapy, 38(4), 621-624. doi:10.1345/aph.1D324

Selznick, P. (1948). Foundations of the theory of organization. American sociological review, 13(1), 22-35. doi:10.2307/2086752

Selznick, P. (2011). Leadership in administration: A sociological interpretation(Kindle ed.).

Shafritz, J. M., Ott, J. S., \& Jang, Y. S. (2016). Classics of Organization Theory (8th ed.). Boston, MA: Cengage Learning.

Sider, R. J., \& Unruh, H. R. (2004). Typology of religious characteristics of social service and educational organizations and programs. Nonprofit and voluntary sector quarterly, 33(1), 109-134. doi:10.1177/0899764003257494

Sinek, S. (2009). Start with why: How great leaders inspire everyone to take action (Kindle ed.). New York, NY: Portfolio.

Sinha, J. W. (2013). Unintended consequence of the faith-based initiative: Organizational practices and religious identity within faith-based human service organizations. Nonprofit and voluntary sector quarterly, 42(3), 563-583. doi:10.1177/0899764012462457

Stahl, A., Covrig, D., \& Newman, I. (2014). Understanding board leadership: Adventist hospital board chair behaviours and effectiveness and organizational outcomes The journal of applied christian leadership, 8(2), 49-66. Retrieved from https://digitalcommons.andrews.edu/cgi/viewcontent.cgi?article $=1231 \&$ context $=\mathrm{j}$ $\underline{\mathrm{acl}}$ 
Starbuck, W. H. (2003). The origins of organization theory. In H. Tsoukas \& C. Knudsen (Eds.), Oxford Handbook of organizational theory: Meta-theoretical perspective (pp. 143-182). New York, NY: Oxford university press.

Stiffney, R. (2013). Leadership in tough times: How executives sustain organizational faithfulness. Journal of applied christian leadership, 7(2), 37-48. Retrieved from https://digitalcommons.andrews.edu/cgi/viewcontent.cgi?referer=https://scholar.g oogle.com/\&httpsredir $=1 \&$ article $=1144 \&$ context $=$ jacl

Tsoukas, H., \& Knudsen, C. (2003). Introduction: The need for meta-theoretical reflection in organizational theory. In H. Tsoukas \& C. Knudsen (Eds.), The Oxford handbook of organization theory: Meta-theoretical perspective. New York, NY: Oxford University Press.

Tutsch, C. (2009). El líder y el liderazgo según Elena G. de White (J. I. Pacheco, Trans. 1 ed.). Miami, FL: APIA.

Vision. (2018a). In Cambridge online dictionary

Vision. (Ed.) (2018b) Merriam Webster. https://www.merriam-webster.com/.

Whetten, D. A. (2006). Albert and Whetten revisited: Strengthening the concept of organizational identity. Journal of management inquiry, 15(3), 219-234. doi:10.1177/1056492606291200

White, E. G. (1909). The ministry of healing. Mountain View, CA: Pacific Press.

White, E. G. (1963). Medical ministry. Mountian View, CA: Pacific Press.

White, E. G. (1992a). Testimonies for the church (Vol. 3). Boise, ID: Pacific Press.

White, E. G. (1992b). Testimonies for the Church (Vol. 1). Boise, ID: Pacific Press.

White, E. G. (1992c). Testimonies for the church (Vol. 6). Boise, ID: Pacific Press.

White, E. G. (2015). Manuscritos inéditos (Vol. 1). Doral, FL: Inter-american Division.

White, E. G. (2018). Manuscript 37, 1886. Retrieved from https://egwwritings.org/?ref=en_Ms37-1886.42\&para=3975.48. EGW Writtings Retrieved May 23, 2018, from Ellen G. White Estate https://egwwritings.org/?ref=en_Ms37-1886.42\&para=3975.48

Wittberg, P. (2000). Called to service: The changing institutional identities of American denominations. Nonprofit and voluntary sector quarterly, 29(3), 357-376. doi:10.1177/0899764000293001 
Wittberg, P. (2013). Faith-based umbrella organizations: Implications for religious identity. Nonprofit and voluntary sector quarterly, 42(3), 540-562. doi:10.1177/0899764012461954

Worley, C. G., \& Lawler, E. E. (2010). Build to change organizations and responsible progress: Twin pillars of sustainable success. In E. Lawler Edward, A. P. William, B. S. Abraham, \& W. W. Richard (Eds.), Research in organizational change and development (Vol. 18, pp. 1-49). Bingley, England: Emerald Group Publishing Limited.

Wu, J. (2015). Collaboration in delivering the adventist health message in China: A single case study. Journal of applied christian leadership, 9(1), 30-40. Retrieved from

https://igitalcommons.andrews.edu/cgi/viewcontent.cgi?article=1262\&context $=\mathrm{j}$ acl

Yaghi, A. (2009). Is organizational behavior in U.S. Muslim nonprofit institutions religious? An examination of organizational values. Nonprofit management and leadership, 20(2), 235-249. doi:10.1002/nml.251

Zaidi, D. (2018). Influences of religion and spirituality in medicine. American medical association journal of ethics, 20(7), E609-612. doi:10.1001/amajethics.2018.609.

Zanini, M., Nery, R., Lima, J. d., Buhler, R., Silveira, A. d., \& Stein, R. (2019). Effects of different rehabilitation protocols in inpatient cardiac rehabilitation after coronary artery bypass graft surgery: A randomized clinical trial. Journal of cardiopulmonary rehabilitation and prevention, Advance online publication. doi:10.1097/HCR.0000000000000431 


\title{
CURRICULUM VITA
}

\section{Cesiah Yareth Pimentel Meléndez}

\author{
cesiah@andrews.edu
}

\section{Education}

2019

Doctor of Philosophy

Leadership (Projected completion: December 2019)

Andrews University, Berrien Springs, MI

Dissertation Title: Adventist healthcare: a qualitative study of 19th century founding governing principles in 21st century Adventist hospitals.

2004 Master's in Business Administration, Universidad de Montemorelos, Mexico

2001 Bachelor's in International Studies, Universidad de Monterrey, Mexico.

\section{Professional}

2018- to date Director for Quality and Mission Effectiveness- Faculty of Health Sciences. Adventist University of Central Africa, Rwanda.

2013-2017 Chief Quality Officer, Hospital La Carlota (Montemorelos University), Mexico.

2009-2013 Administrator, Maluti Vision Center, Maluti Adventist Hospital, Lesotho.

2004-2009 Business Manager, Lusaka Eye Hospital \& Lusaka Adventist Dental Clinic, Zambia.

2002-2004 Interim Institutional Planning Director, Montemorelos University, Mexico. 